\title{
A Manual for the Economic Evaluation of Energy Efficiency and Renewable Energy Technologies
}

Walter Short, Daniel J. Packey, and Thomas Holt

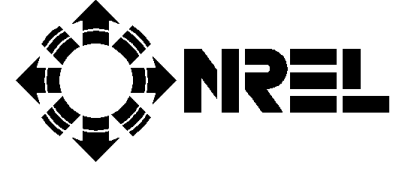

National Renewable Energy Laboratory 1617 Cole Boulevard Golden, Colorado 80401-3393

A national laboratory of the U.S. Department of Energy Managed by Midwest Research Institute for the U.S. Department of Energy under contract No. DE-AC36-83CH10093 


\section{A Manual for the Economic Evaluation of Energy Efficiency and Renewable Energy Technologies}

Walter Short, Daniel J. Packey, and Thomas Holt

National Renewable Energy Laboratory 1617 Cole Boulevard Golden, Colorado 80401-3393

A national laboratory of the U.S. Department of Energy Managed by Midwest Research Institute under contract No. DE-AC36-83CH10093

Prepared under Task No. AS026100

March 1995 


\section{NOTICE}

This report was prepared as an account of work sponsored by an agency of the United States government. Neither the United States government nor any agency thereof, nor any of their employees, makes any warranty, express or implied, or assumes any legal liability or responsibility for the accuracy, completeness, or usefulness of any information, apparatus, product, or process disclosed, or represents that its use would not infringe privately owned rights. Reference herein to any specific commercial product, process, or senvice by trade name, trademark, manufacturer, or otherwise does not necessarily constitute or imply its endorsement, recommendation, or favoring by the United States government or any agency thereof. The views and opinions of authors expressed herein do not necessarily state or reflect those of the United States government or any agency thereof.

Available to DOE and DOE contractors from:

Office of Scientific and Technical Information (OSTI)

P.O. Box 62

Oak Ridge, TN 37831

Prices available by calling (423) 576-8401

Available to the public from:

National Technical Information Service (NTIS)

U.S. Department of Commerce

5285 Port Royal Road

Springfield, VA 22161

(703) 487-4650 


\section{Preface}

A Manual for the Economic Evaluation of Energy Efficiency and Renewable Energy Technologies provides guidance on economic evaluation approaches, metrics, and levels of detail required, while offering a consistent basis on which analysts can perform analyses using standard assumptions and bases. It not only provides information on the primary economic measures used in economic analyses and the fundamentals of finance but also provides guidance focused on the special considerations required in the economic evaluation of energy efficiency and renewablc energy systems.

The Analytic Studies Division (ASD) of the National Renewable Energy Laboratory (NREL) developed this manual for the Office of Planning and Assessment (OPA) in the U.S. Department of Energy (DOE). It is envisioned that this manual will serve as a standard reference on cconomic evaluation within DOE's Office of Energy Efficiency and Renewable Energy.

Several NREL staff members contributed to this manual through valuable input and review. Outside of NREL, many people provided information for and reviewed drafts of the manual. Among the latter are Fred Abel of the Office of Planning and Assessment at DOE, Geopalachari Ramachandra of the Electric Power Research Institute, Jonathan Koomey of Lawrence Berkeley Laboratory, Lisa Chalstrom of the Iowa Utilities Board, Marshall Wise of Pacific Northwest Laboratory, Peter Bos of Polydyne, Inc., and Rosalie Ruegg of the National Institute of Standards. Their help, especially that of Rosalie Rucgg and Peter Bos, who provided many detailed comments, is very much appreciated.

Approved for the

National Rencwable Energy Laboratory

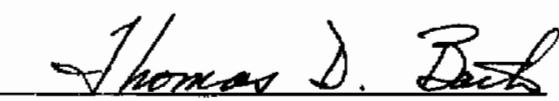

Thomas D. Bath, Director Analytic Studies Division

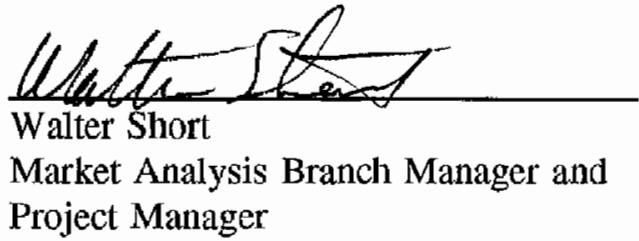

Project Manager 


\section{Table of Contents}

1 Introduction $\ldots \ldots \ldots \ldots \ldots \ldots \ldots \ldots \ldots \ldots \ldots \ldots \ldots \ldots \ldots \ldots \ldots$

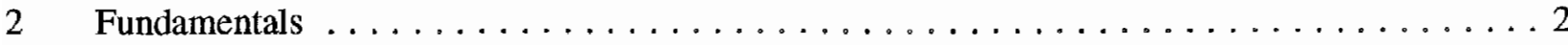

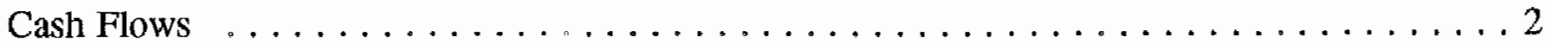

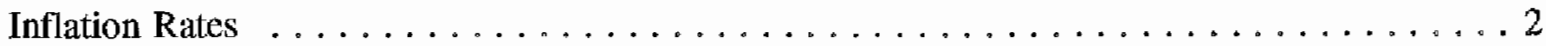

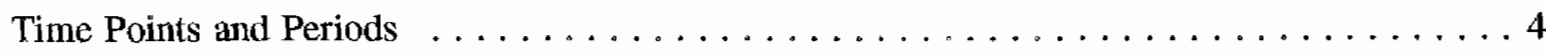

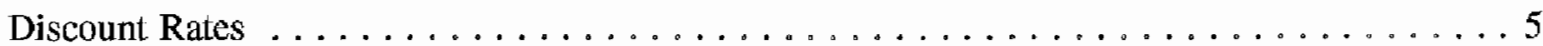

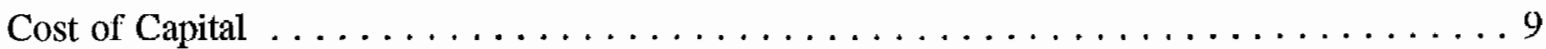

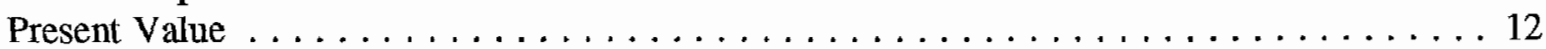

Taxes .................................. 14

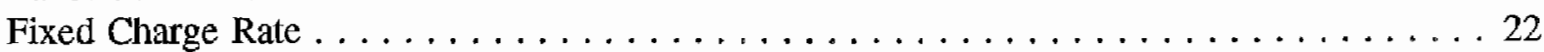

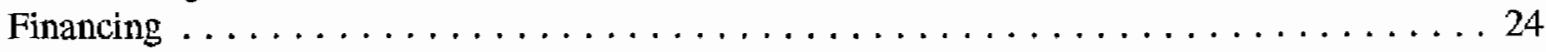

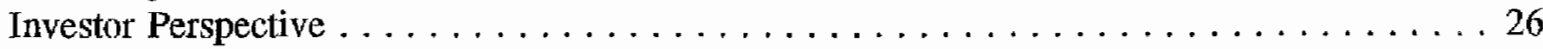

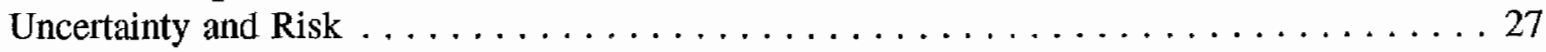

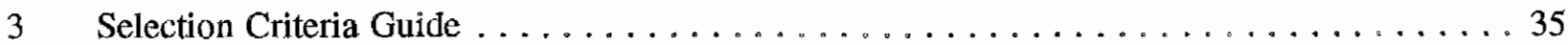

Explanations for the Economic Evaluation Measures Matrix $\ldots \ldots \ldots \ldots \ldots \ldots$

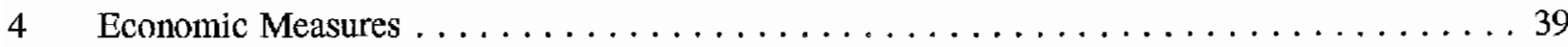

Net Present Value . . . . . . . . . . . . . . . . . . . . . . . . . . 39

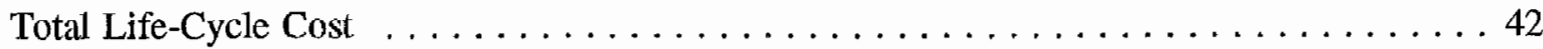

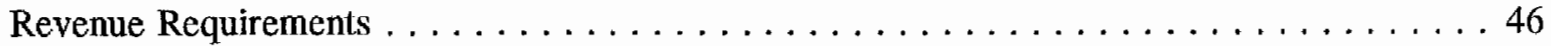

Levelized Cost of Encrgy $\ldots \ldots \ldots \ldots \ldots \ldots \ldots \ldots \ldots \ldots \ldots \ldots \ldots \ldots \ldots \ldots \ldots$

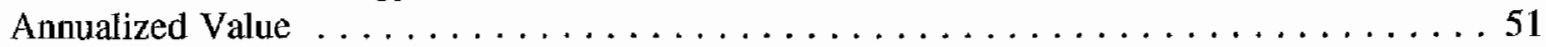

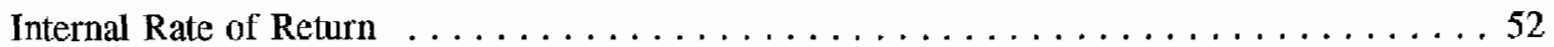

Modified Internal Rate of Return $\ldots \ldots \ldots \ldots \ldots \ldots \ldots \ldots \ldots \ldots \ldots \ldots$

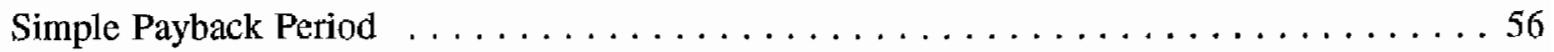

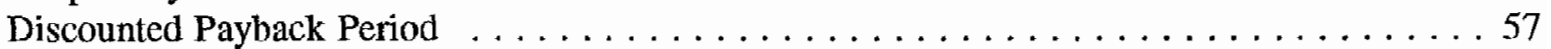

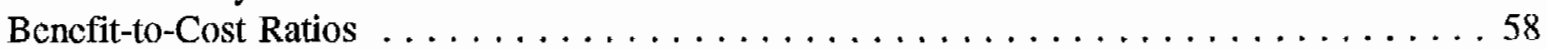

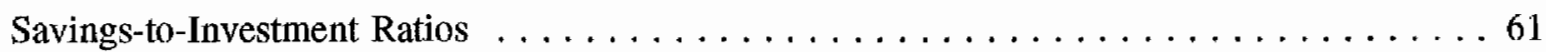

Integrated Resource Planning/Demand-Side-Management Ratio Tests . . . . . . . . 62

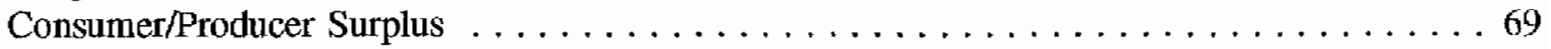

5 Special Consideralions for Energy Efliciency and Renewable

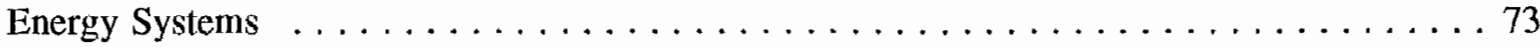

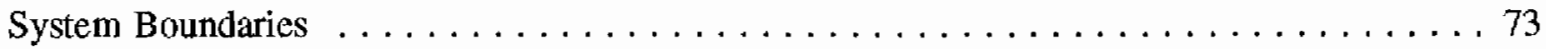

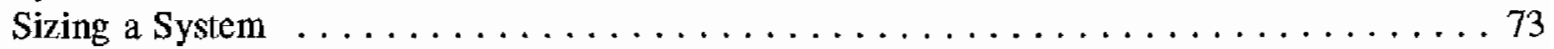

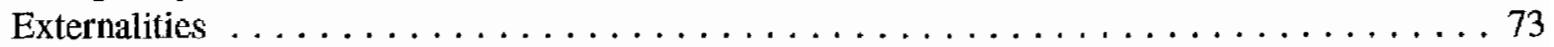

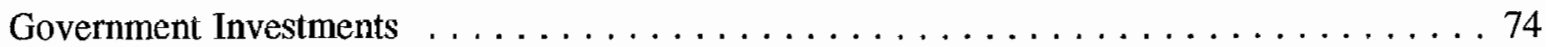

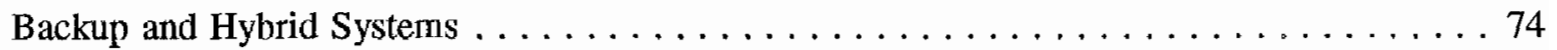

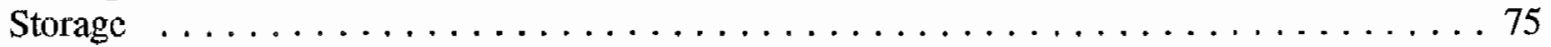

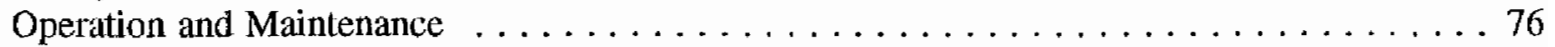

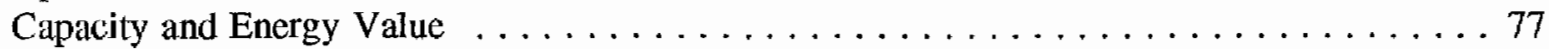




\section{Table of Contents (Concluded)}

Major Repairs and Replacements . . . . . . . . . . . . . . . . . 79

Salvage Value . . . . . . . . . . . . . . . . . . . . . . . . . . 79

Unequal Lifetimes . . . . . . . . . . . . . . . . . . . . . . . . . . 79

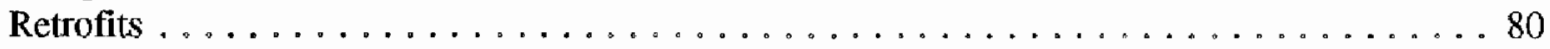

Incorporating Electric Utility Rates in an Analysis $\ldots \ldots \ldots \ldots \ldots \ldots \ldots \ldots$

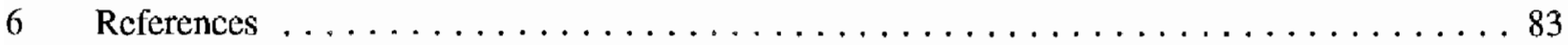

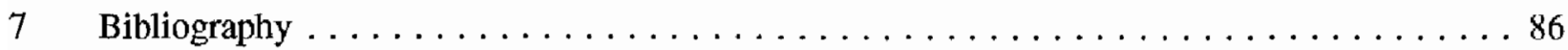

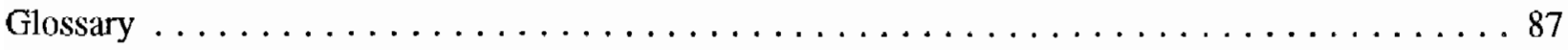

Appendices

Appendix A: Selected Inflation Indices $\ldots \ldots \ldots \ldots \ldots \ldots \ldots \ldots \ldots \ldots \ldots \ldots \ldots$. A-1

Appendix B: Escalation (De-escalation) Factors $\ldots \ldots \ldots \ldots \ldots \ldots \ldots \ldots \ldots \ldots \ldots$. . . . . .

Appendix C: Real Weighted Average Cost of New Capital 1976-1989 . . . . . . . . . . . C-1

Appendix D: Amortization Formulas . . . . . . . . . . . . . . . . . . .

Appendix E: Monthly and Continuous Discount Rates $\ldots \ldots \ldots \ldots \ldots \ldots \ldots \ldots \ldots$.1

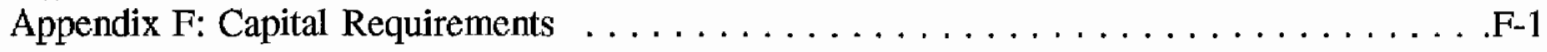

Appendix G: Retrofits . . . . . . . . . . . . . . . .

Appendix H: Documentation of Evaluation Software $\ldots \ldots \ldots \ldots \ldots \ldots \ldots \ldots$ 


\section{List of Figures}

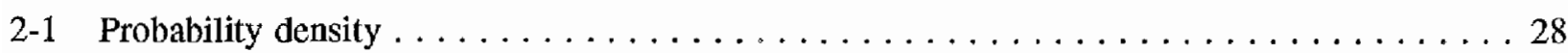

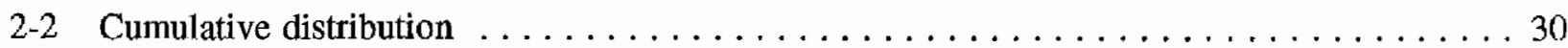

$2-3$ Probability distribution over quantity $\ldots \ldots \ldots \ldots \ldots \ldots \ldots \ldots \ldots \ldots \ldots \ldots \ldots \ldots \ldots$

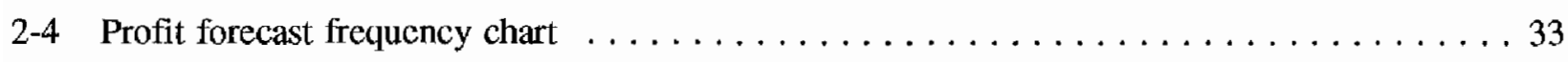

4-1 Levelized cost of encrgy cash flows $\ldots \ldots \ldots \ldots \ldots \ldots \ldots \ldots \ldots \ldots \ldots \ldots \ldots \ldots \ldots \ldots$

4-2 Consumer and producer surplus $\ldots \ldots \ldots \ldots \ldots \ldots \ldots \ldots \ldots \ldots \ldots$

4-3 Consumer and producer surplus with additional supply $\ldots \ldots \ldots \ldots \ldots \ldots \ldots \ldots$

4-4 Consumer and producer surplus wilh subsidy price changes $\ldots \ldots \ldots \ldots \ldots \ldots \ldots \ldots$

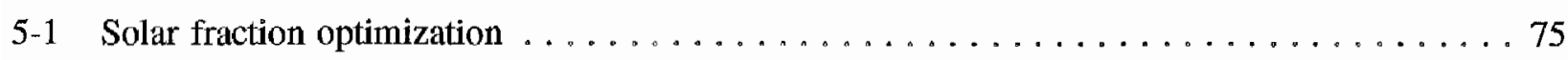

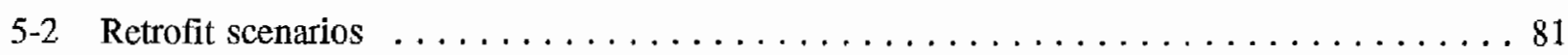




\section{List of Tables}

2-1 Office of Management and Budget Recommended Discount Rates $\ldots \ldots \ldots \ldots \ldots$

2-2 Recommended Discount Rates for Projects Lacking Investment-Specific Data $\ldots . . . . .9$

2-3 WACC Calculation Table $\ldots \ldots \ldots \ldots \ldots \ldots \ldots \ldots \ldots \ldots \ldots \ldots \ldots \ldots \ldots$

$2-4$ Present Value Calculation Table $\ldots \ldots \ldots \ldots \ldots \ldots \ldots \ldots \ldots \ldots \ldots \ldots \ldots$

2-5 Marginal State Income Tax Rates for Corporations as of December 31, $1993 \ldots \ldots \ldots \ldots 17$

$2-6$ State Incentives for Solar Technologies $\ldots \ldots \ldots \ldots \ldots \ldots \ldots \ldots \ldots$

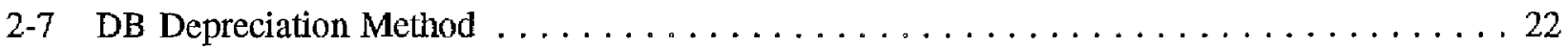

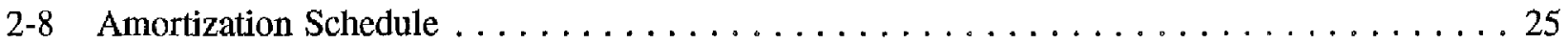

2-9 Variables for the Example of Deterministic Sensitivity Analysis . . . . . . . . . . 31

3-1 Overview of Economic Measures Applying to Specific Investment Features and Decisions . . 36

4-1 Calculation of Current Dollar After-Tax Cash Flow $\ldots \ldots \ldots \ldots \ldots \ldots \ldots \ldots \ldots$

4-2 Net Present Value of Current Dollar Cash Flows $\ldots \ldots \ldots \ldots \ldots \ldots \ldots \ldots \ldots \ldots$

4-3 Constant Dollar After-Tax Cash Flow $\ldots \ldots \ldots \ldots \ldots \ldots \ldots \ldots \ldots \ldots \ldots \ldots$

4-4 Net Present Value of Constant Dollar Cash Flows . . . . . . . . . . . . . . . . . 42

$4-5$ Current Dollar TLCC Evaluation $\ldots \ldots \ldots \ldots \ldots \ldots \ldots \ldots \ldots \ldots \ldots \ldots \ldots$

4-6 Constant Dollar TLCC Evaluation $\ldots \ldots \ldots \ldots \ldots \ldots \ldots \ldots \ldots \ldots \ldots \ldots \ldots$

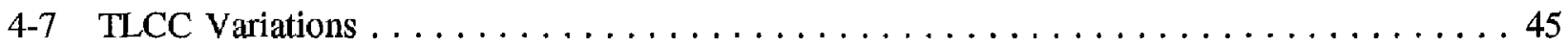

4-8 After-Tax TLCC Evaluation $\ldots \ldots \ldots \ldots \ldots \ldots \ldots \ldots \ldots \ldots \ldots \ldots \ldots \ldots \ldots$

$4-9$ Before-Tax TLCC Evaluation $\ldots \ldots \ldots \ldots \ldots \ldots \ldots \ldots \ldots \ldots \ldots \ldots \ldots \ldots$

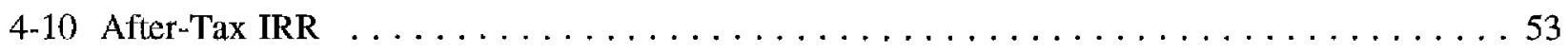

$4-11$ Results of Using IRR as a Sole Measure $\ldots \ldots \ldots \ldots \ldots \ldots \ldots \ldots \ldots$

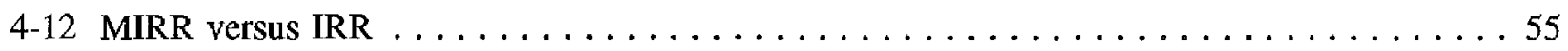

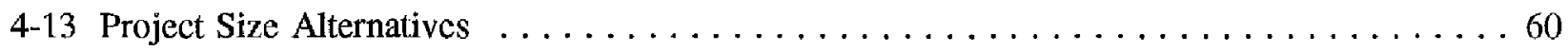

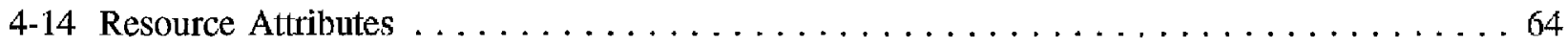




\section{Introduction}

This manual is a guide for analyzing the economics of energy efficiency and renewable energy (EE) technologies and projects. It is intended (1) to help analysts determine the appropriate approach or type of analysis and the appropriate level of detail and (2) to assist EE analysts in completing consistent analyses using standard assumptions and bases, when appropriate. Included are analytical techniques that are commonly required for the economic analysis of $\mathrm{EE}$ technologies and projects.

The manual consists of six sections: Introduction, Fundamentals, Selection Criteria Guide, Economic Measures, Special Considerations for Conservation and Renewable Energy Systems, and References. A glossary and eight appendices are also included. Each section has a brief introductory statement, a presentation of necessary formulac, a discussion, and when appropriate, examples and descriptions of data and data availability.

The objective of an economic analysis is to provide the information needed to make a judgment or a decision. The most complete analysis of an investment in a technology or a project requires the analysis of each year of the life of the investment, taking into account relevant direct costs, indirect and overhead costs, taxes, and returns on investment, plus any externalities, such as environmental impacts, that are relevant to the decision to be made. However, it is important to consider the purpose and scope of a particular analysis at the outset because this will prescribe the course to follow. The perspective of the analysis is important, often dictating the approach to be used. Also, the ultimate use of the results of an analysis will influence the level of detail undertaken. The decision-making criteria of the potential investor must also be considered.

In some cases, it is possible to use shortcuts that reduce the amount of detail needed and permit use of averages rather than detailed year-by-ycar calculations. Very gross analytical approaches may be suitable for instances in which the results are clear or the validity of detailed studies is questionable. For example, the cconomic value of an industrial conservation investment may be so clear that a complex analysis of annual savings, given the uncertainties of future production plans, is not warranted. This manual addresses these types of considerations.

This manual cannot provide an exhaustive and complete exposition of the theory and practical pitfalls of particular economic methods. For example, using this manual for developing a detailed economic analysis of a site-specific energy-related project would be difficult. In some cases, references to more cxtensive resources are provided, but even these may prove insufficient to answer certain detailed questions. This is particularly true when dealing with some of the special circumstances that relate to the application of energy efficiency and renewable energy technologies. A few of these special circumstances are addressed in Section 5 of the manual, Special Considerations for Encrgy Efficiency and Renewable Energy Systems. Although there may not be a specific right or wrong way or a specific formula for handling some of these cases, the issues are brought to the attention of the analyst.

No analysis will be valid if it is not bascd on sound and consistent data. If, for example, an EE technology is being evaluated in comparison with a conventional icchnology, analyses of both technologies must be based on comparable characterizations (the Energy Efficiency and Renewable Energy Technology Characterizations sets forth the basis for developing valid and consistent technology characterizations) (Carasso 1995). Similarly, the analysis should be conducted on relevant and consistent macroeconomic and microeconomic bases. This manual does not directly address these data input quality considerations. 


\section{Fundamentals}

This section includes an overview of the basic concepts and elements of economic and financial analysis. These fundamentals include cash flows, inflation rates, discount rates, cost of capital (including weighted average cost of capital and marginal cost of capital), present value, taxes and depreciation, fixed charge rates, financing, and risk and uncertainty.

\section{Cash Flows}

\section{Introduction}

Cash flows are an integral part of most analyses and are needed to compute the economic measures described later in the manual. It is difficult to explicitly define a cash flow because the type of cash flows used for an analyses will vary, depending on the type of analysis conducted (e.g., after-tax cash flows, before-tax cash flows, incremental cash flows, and so forth).

Cash flows can be thought of in terms of three different activities performed by a company: operating, investing, and financing. Cash flows from operating activities include all revenues captured, minus operating and maintenance expenses, interest paid, and income taxes paid. Investing aclivity cash flow includes capital expenditures, and financing activity cash flow includes repayment of debt principal and dividends.

Again, the specific type of analyses being performed will dictate the cash flow to be uscd. In the individual sections of this manual, detail is provided as to which cash flows are appropriate, given the analysis and investor perspective.

\section{Discussion}

Great efforts to be precise when describing the timing of costs and benefits in a cash flow series may not be worthwhile in analyses of developing technologies or of deployments projected far into the futurc. For example, an economic evaluation of an investment may cover a 30-year span, but even though costs and benefits will occur at different times throughout that time, representing complex cash flows in a more simple conforming pattern (i.e. annually) sacrifices little accuracy in most cases.

Commonly, cash flows occurring within a period are grouped as a lump sum at the beginning, middle, or end of the pcriod. This manual assumes the most common practice, which is end-of-the-period cash flows. Most capital investment analyses define a "period" as a year (Ruegg and Marshall 1990). As such, compounding or discounting the cash flows for the analyses can be performed using an annual discount rate (discussed in the Discount Rates subsection in Section 2).

\section{Inflation Rates}

\section{Introduction}

Costs and revenues can be expressed either in "current" dollars or "constant" dollars. Actual cash flows observed in the marketplacc are called current dollar cash flows. They represent the actual number of dollars required in the year the cost is incurred. Current dollar cash flows will change over time because of inflation (or deflation). Constant dollar cash flows $\left(\overline{\mathrm{F}}_{\mathrm{n}}\right)$ represent the number of dollars that would 
have been required if the cost was paid in the base year ( $n$ ). Cash flows expressed in current dollars in year $m\left(F_{m}\right)$ can be transformed into constant dollar cash flows in any year $n\left(\bar{F}_{n}\right)$ by removing the effect of inflation (e),

$$
\overline{\mathbf{F}}_{\mathrm{n}}=\mathrm{F}_{\mathrm{m}} /(1+\mathrm{e})^{\mathrm{m}-\mathrm{n}}
$$

This formula assumes a constant rate of inflation during the m-n years. ${ }^{1}$

The base year is defined as the year that the analysis is structured around (see the Time Points/Period subsection in Section 2). In the base year, constant and current dollar cash flows are the same,

$$
\vec{F}_{n}=F_{n}=F_{n} /(1+e)^{n-n}
$$

\section{Discussion}

It is important to be aware of inflation when conducting an analysis. It may be necessary to convert a stream of cash flows from current dollars to constant dollars, or vice versa, using an inflation rate index. There are a number of inflation rate indices (e.g., Gross National Product [GNP], Gross Domestic Product [GDP], Consumer Price Index [CPI], and Producer Price Index [PPI]). Appendix A presents tables of historical inflation indices, including GNP, GDP, CPI, and PPI deflators.

The CPI, which measures the average change in prices in a "basket" of goods and services and represents price trends at the retail level, is probably the most widely followed inflation measure. The national CPI is calculated by averaging the price changes of goods included in the basket for 85 separate locations in the nation every month. CPIs are also published on a regional, size-class, and cross-classification of region and size-class basis, and for 29 local areas.

GNP is the measure of output supplied by U.S. labor and property. As of December 1991, the federal government has switched from GNP to GDP as the primary indicator of national production, primarily because nearly all other countries use GDP instead of GNP. GDP is the measure of the national output of goods and services at market prices, or the measure of output attributable to national located factors of production. Both measures represent cconomywide price trends. The actual levels of GNP and GDP differ very little, but percentage changes sometimes vary. Given the fedcral change, the availability of GNP measures will become more difficult to obtain, and it is recommended that GDP implicit price deflators be used. The implicit price deflator is the measure of the difference between current dollar GDP (or GNP for GNP implicit price deflators) and constant dollar GDP. It is calculated by dividing the current dollar GDP for a period by the constant dollar GDP in the same period. The movements in the GNP and GDP implicit price deflators closely track those of the CPI (U.S. Dept. of Commerce 1992).

The PPI represents price trends at the wholesale level, based on nearly 3100 commodity price serics. Though more erratic, patterns in the PPI normally rack and foreshadow movements of the CPI, GNP, and GDP indices. Other inflation indices include the Industrial Matcrials Prices Index, the Dow Jones Commodity Spot Price Index, and the Futures Price Index.

${ }^{1}$ If inflation rates vary by year and it is important to account for this variation (i.e., an average annual rate will not suffice) the $(1+c)^{m-n}$ portion of the formula would have to be broken down into multiple periods with uniform inflation, i.e., $(1+\mathrm{e})^{\mathrm{m} \cdot \mathrm{n}}$ would be replaced by $\left(1+\mathrm{e}_{1}\right)^{\mathrm{m} 1-\mathrm{n}}\left(1+\mathrm{c}_{2}\right)^{\mathrm{m} 2-\mathrm{ml} 1} \ldots \ldots$ $\left(1+e_{\mathrm{y}}\right)^{\mathrm{mit}-(\mathrm{mr}-1)}$. 
There is neither a correct nor an incorrect inflation index to use for an analysis. However, it is recommended that the inflation indices used match as closely as possible the work at hand. For example, if the work is general and national in scope, then the GDP deflator is suitable. On the other hand, if the work is more narrowly defined, such as the regional price of electricity, a regional CPI is suitable. The analyst must use judgment when deciding which indices to apply.

Sometimes it is necessary to incorporate future estimates of inflation in an analysis. The analyst should bc aware of the high degree of uncertainty inherent in projected inflation rates and perform sensitivity analysis (discussed in the subsection Uncertainty and Risk in Section 2) using different inflation rates. Projected inflation rates can be obtained from many private sector sources; the federal government projects these rates twice a year in presidential administration economic forecasts (OMB 1992).

It is important to note that there may be price changes in particular goods and services that are larger or smaller than changes resulting from gencral price inflation. See Appendix B for a discussion on cscalation.

\section{Time Points and Periods}

\section{Introduction}

Time points and periods are crucial factors in an analysis. Time points considered critical to an analysis include the base year, dollar year, and investment year. These are important primarily from a reporting standpoint.

Base Year/Year Zero - Year to which all cash flows are converted.

Dollar Year

- Year to which base year results are converted and reported (possibly for comparison purposes with other years).

Investment Year - Year in which the actual investment occurs.

Important time periods for the analyst include the investment lifetime $(\mathrm{L})$, the analysis period $(\mathrm{N})$, the depreciation period $(M)$, the finance period $(Y)$, and the levelization period $(P)$.

Investment Useful - Estimate of a particular investment's useful life. (If not already available Lifetime through sources such as the EPRI TAG [EPRI December 1991], which provides values for generating technology book lives [investment life, 30 years in most cases], the equipment manufacturer should be contacted.)

Analysis Period - Period of time for which an evaluation is conducted.

Depreciation Period - Period of time over which an investment is amortized (usually for tax purposes).

Finance Period - Period of time for which an investment's financing is structured (e.g., a loan is amortized over 30 years).

Levelization Period - Period of time used when calculating a levelized cash flow stream. 


\section{Discussion}

In an analysis, the time points selected may all be equal (they generally are), different, or in combinations. For example, an independent power producer might wish to evaluate a central recciver plant that would require 2 years to build. The present year could be the base year, 1995 could be the investment year (point in time at which plant would go into service, or inservice date), and 1992 could be the dollar year (year for which material costs are available).

Understanding will improve by providing time point information in the reported results of an analysis. If nothing else, it is imperative that the dollar ycar be reported. Results are meaningless to the reader if values are reported and the dollar year of those results is missing.

Results reported in any detail should also include all information pertaining to time period assumptions. Investment lifetime, depreciation periods, and finance periods arc all values obtained outside of the analysis but represent factors to be included in the evaluation. For example, an investment might have an estimated useful life of 30 years, be financed over a 20 -year period, and be depreciated over 15 years.

The selection of an appropriate analysis period is essential. Many times the analysis period is equal to the investment's life span. However, other factors that should be considered include the investor's time horizon and perspective and the decision to be made (accept/reject or choice among alternatives). The investor's time horizon is often used as the analysis period. For example, the independent power producer evaluating a central receiver plant is planning to sell the plant after 10 years and the central receiver plant under evaluation has an investment life of 30 years. In this example, the analysis period should be 10 years. A longer study period, however, should be used for analyses conducted from society's perspective ( 30 years or more in most cases). Evaluations incorporating accept/reject decisions should use investment life as the analysis period, subject to the constraint of the investor's time horizon. When choosing among alternatives, it is generally agreed that the same study period should be used when evaluating each of the alternatives. Problems can arise if the investment lives of the alternatives differ. More detailed information on projects with unequal lives can be found in the Unequal Lifetimes subsection in Section 5, and in Ruegg \& Marshall (1990).

\section{Discount Rates}

\section{Introduction}

Time value is the price put on the time that an investor waits for a return on an investment. A dollar received today is worth more than a dollar received tomorrow because the dollar today can be invested to earn interest immediately. Conversely, a dollar received tomorrow is worth less than a dollar received today because the opportunity to earn interest on the dollar is lost. The discount rate acts as a measure of this time value and is central to the calculation of present value. Discount rates are often used to account for the risk inherent in an investment (risk-adjusted discount rates are discussed in the Uncertainty and Risk subsection in Section 2). As such, the choice of a discount rate is important to any economic analysis.

\section{Discussion}

Analyses can be performed using either current or constant dollar cash flows, but it is important to remain consistent throughout the study. For example, a discount rate is used to calculate the present value of a future payment (present value calculations are addressed in a later section), and a discount rate either includes the effects of inflation (nominal) or excludes inflation (real). The discount rate used in the 
analysis should be consistent with the form of all cash flows. To summarize, real discount rates and constant dollar cash flows exclude inflation, whereas nominal discount rates and current dollars include inflationary effects. A current dollar analysis requires the use of a nominal discount rate, and a constant dollar analysis requires the use of a real discount rate. . Discount rates can be converted from real to nominal, and vice versa, with the following formula:

$$
\begin{array}{ll}
\left(1+d_{n}\right) & =\left(1+d_{r}\right)(1+e) \\
d_{n} & =\left[\left(1+d_{r}\right)(1+e)\right]-1 \\
d_{r} & =\left[\left(1+d_{n}\right) /(1+e)\right]-1
\end{array}
$$

Where:

$\mathrm{d}_{\mathrm{n}}=$ nominal discount rate

$\mathrm{d}_{\mathrm{r}} \quad=$ discount rate in the absence of inflation (real)

$\mathrm{e} \quad=$ inflation rate.

For example, given an inflation rate of $6 \%$ and a nominal discount rate of $10 \%$, a real discount rate of $3.77 \%$ is calculated using the above formula. ${ }^{2}$

Recall that the discount rate is a measure of time value. This time value or cost of money is not necessarily the same for all investors. The discount rate will be influenced or determined by a wide variety of factors, such as the investor's rate of return, risk premium, planning horizon, interest rates, and income and property taxes. Discount rates will vary from state to statc, industry to industry, and company to company.

In Circular No. A-94 (OMB 1992 revised January 1995), the Office of Management and Budget (OMB) has established discount rate guidelines for use when evaluating the cost-effectiveness of internal government investments. Appendix $C$ of the circular lists recommended discount rates for short- and longterm projects. These rates, presented in Table 2-1, are based on U.S. Treasury botrowing rates and are updated annually. ${ }^{3}$ Analyses of programs with terms different from those presented below may use a linear intcrpolation. Also, projects with terms longer than 30 years may use the 30 -year discount rate.

Table 2-1. Office of Management and Budget Recommended Discount Rates (January 1995-February 1996)

\begin{tabular}{|lccccc|}
\hline & 3-Year & 5-Year & 7-Year & 10-Year & 30-Year \\
\hline Real & $4.2 \%$ & $4.5 \%$ & $4.6 \%$ & $4.8 \%$ & $4.9 \%$ \\
\hline Nominal & $7.3 \%$ & $7.6 \%$ & $7.7 \%$ & $7.9 \%$ & $8.1 \%$ \\
\hline
\end{tabular}

In addition, the federal government annually sets a discount rate for use when evaluating federal projects in which one of the primary purposes of the project includes conservation or renewables. The rate is

\footnotetext{
${ }^{2} \mathrm{~A}$ reasonable approximation is realized by assuming $\mathrm{d}_{\mathrm{n}}=\mathrm{d}_{\mathrm{x}}+\mathrm{e}$. For this example then, the approximate real discount rate is $d_{\mathrm{r}}=10 \%-6 \%=4 \%$.

${ }^{3}$ OMB Circular A-94 also dictates the use of a real discount rate of $7 \%$ (based on the average private sector return on investment before taxes) for the evaluation of regulatory programs and public investment; i.e., for investments that benefit the general public (such as a new highway).
} 
adjusted annually and is based on long-term Treasury Bond rates averaged over the previous 12 months. This designated discount rate is provided in the annual supplement to NIST Handbook 135, Energy Prices and Discount Factors for Life-Cycle Cost Analysis 1995. If one of the primary purposes of the federal project includes conservation or renewables, the handbook recommends use of a real discount rate of $3.0 \%$ and a nominal discount rate of 6.6\% (Petersen 1994).

In the private sector, there are no guidelines as to the appropriate discount rate to use for evaluation. As such, sensitivity analysis is recommended with respect to the discount rate. Sensitivity analysis shows the variation in the cost or benefit measure as the values of input variables, such as the discount rate change. The subject of sensitivity analysis is covered in the Uncertainty and Risk subsection in Section 2.

For the commercial and industrial sectors, most experts recommend a discount rate equal to the opportunity cost of capital. The opportunity cost of capital is the rate of return on the best alternative investment available. Unfortunately, these data are not readily available and vary for each investor and investment.

Another measure frequently employed to estimate a discount rate is the cost of capital (the average cost of capital is widely used but the marginal cost of capital is preferred; see the Cost of Capital subsection in Section 2). Here again, the cost of capital varies from one investor and investment to another, which limits its usefulness as a proxy for a general discount rate. However, it is possible to examine the average cost of capital to U.S. industry from 1976 to 1989. As calculated in Appendix C, this average cost of capital (based on historical returns to equity investors and after-tax interest paid on debt) is approximately $5 \%$ real (or $7 \%$ real before-taxes). ${ }^{4}$

Although these historical averages represent the actual average returns to investors, it should not be assumed that the historical returns represent the "hurdle" rate (or discount rate) used by investors to decide whether or not to undertake a specific project. Many investors in the private sector will be seeking a greater than average return. And, of course, many investments carry a higher than avcrage risk, dictating a greater promised return before the project will bc undertaken. On the other hand, there are also many who take a less than average return (i.e., they invest in T-Bills and lower risk bonds). In the absence of statistical data on discount rates used by industrial, transportation, and commercial investors for investments with risks similar to those of conservation and renewable energy investments, it is recommended that a real after-tax discount rate of $10 \%$ (add in expected inflation to estimate a nominal discount ratc) be used within the Office of Energy Efficiency and Renewable Energy for these sectors. Of course, if the analysis concerns a specific investor, the discount rate should be based on the investor's opportunity cost of capital for investments of similar riskiness.

In the residential sector, the cost of capital may not accurately represent actual discounting behavior. Residential customers weigh the opportunity cost of capital much greater than financial markets require (EPRI 1987). Recall that the opportunity cost of capital is the rate of return needed to induce investors to invest in a project of similar risk and duration. The residential sector seems to require a much higher rate of return on an investment than financial markets require. Possible explanations for this include uncertainty, short residency period (investment period), availability of capital, income, and noneconomic factors. Perhaps a homeowner does not know how much longer he or she will live at a present address, or a renter does not wish to invest in something that cannot be taken when he or she leaves. Hausman (1979), using data on the purchases of new air conditioners, calculated discount rates that households use

\footnotetext{
${ }^{4}$ The after-tax interest rate assumes that the highest marginal tax rate is paid by industry. In reality, however, the actual rate paid is frequently less, making the actual historical real returns to investors, after taxes, somewhere between $5.0 \%$ and $7.0 \%$.
} 
when purchasing energy-efficient units. His overall real discount rate was approximately $25 \%$. However, when income became a variable, he found considerable fluctuation in the discount rate (i.e., households with an annual income of $\$ 10,000$ had a real discount rate of $39 \%$, and those with an income of $\$ 50,000$ had a real discount rate of $5 \%$ ). The circumstances surrounding each residential customer are different, making it difficult to determine an appropriate discount rate for the residential sector. Nonetheless, a discount rate is required. When knowledge of a specific investor is unavailable, a $10 \%$ real rate is recommended, with other factors (i.e., noneconomic) considered explicitly.

Because the utility industry is largely regulated, the estimation of discount rates is more formalized and more data exists. Common utility practice is to employ a discount rate equal to the utility's Weighted Average Cost of Capital (WACC). The calculation of this WACC is explained in some detail in the next section. In the Electric Power Research Institute's (EPRI's) 1991 Technical Assessment Guide (EPRI June 1993), an after-tax nominal discount rate of $9.2 \%$ for investor-owned utilities (IOUs) is suggested in most cases because utilities perform analyses more often in current dollars than in constant dollars. The analyst should note that the $9.2 \%$ nominal discount rate may change, depending on the rate of inflation. In its calculations, EPRI assumed an annual inflation rate of $4.1 \%$, which is a long-term average.

The equivalent real after-tax discount rate is $4.9 \%$. This is significantly less than the $10 \%$ suggested for use in the nonutility private sector and is because, as a regulated industry, utilities have little competition in their service territories and their regulated rates help ensure return on investment. Thus, therc has historically been less risk involved in the utility sector than in other private sectors.

EPRI also suggests the use of utility before-tax discount rates of $10.8 \%$ nominal and $6.4 \%$ real. The difference between these and the after-tax discount rates presented previously reflects the fact that debt payments are deductible for income tax purposes. EPRI reports that most utilities employ an after-tax rate. Whether to use a before-tax or an after-tax discount rate will depend on the study itself. This topic is covered in more detail in the Taxes subsection in Section 2, where it is recommended that most EE utility analyses be conducted on an after-tax basis because income taxes can have varying effects on different alternatives.

Because $77 \%$ of all U.S. generating capacity is owned by IOUs (EEI Octobcr 1991), the after-tax $9.2 \%$ nominal discount rate (or the equivalent, $4.9 \%$ real) is recommended for use in the evaluation of $\mathrm{EE}$ technologies within the utility sector. However, the analyst should recognize that significant generating capacity is owned by municipal utilities and rural cooperatives that enjoy special tax status (and may therefore employ a lower nominal discount rate), and by independent power producers (IPPs) whose profits are not regulated (and who may use a higher discount rate that is closer to that of the industrial scctor).

Table 2-2 summarizes discount rates recommended for EE use when investor or investment-specific data are not available. These discount rates are consistent with those used in the National Energy Strategy released by the DOE in 1991.

The development of the nation's energy options requires investments now that will produce benefits well into the futurc. As an example, $R \& D$ costing billions of dollars may not produce benefits for many years (c.g., 30, 40, 50 years), and these benefits could potentially accrue for hundreds of ycars thercafter.

As discussed previously, the common approach for evaluating these projects is to discount the costs and benefits to their present values. For projects in which bencfits or costs occur well into the future, the discount rate used for the analysis will have a strong impact on the results. As an extreme example, the cost of nuclear waste and contamination may accrue several hundred if not thousands of years from now, and any positive discount rate would allow for even devastating costs to future generations to be insignificant in terms of present valuc (Lind 1982). 
Table 2-2. Recommended Discount Rates for Projects Lacking Investment-Specific Data

\begin{tabular}{|c|c|}
\hline Sector & $\begin{array}{c}\text { Real Discount Rate } \\
(\%)\end{array}$ \\
\hline Government & $3.0^{\mathrm{a}}$ \\
\hline Industry & 10.0 \\
\hline Transportation & 10.0 \\
\hline Commercial & 10.0 \\
\hline Residential & 10.0 \\
\hline Utility & $4.9^{b}$ \\
\hline \multicolumn{2}{|c|}{$\begin{array}{l}\text { a. This rate is for energy investment decisions that include } \\
\text { conservation or renewable energy alternatives. For other } \\
\text { projects, see OMB's recommended discount rate in Table } 2-1 \text {. } \\
\text { b. The before-tax discount rate to use is } 6.4 \% \text {. }\end{array}$} \\
\hline
\end{tabular}

The value of such a "social" discount rate has been a controversy for decades, and at this point, the experts have not agreed on such a rate. Many have argued that the social rate of discount should be identical to the current private sector discount rates to ensure that public investments with low rates of return would not supplant higher-return private investments. Others argue that the social rate should be lower than the private rate and equal to the consumption rate-the rate at which consumers are willing to displace consumption now for consumption in the future. A higher rate works against renewables and conservation technologies and generally favors conventional fossil fuel technologies. As such, it is recommended that, if needed, an appropriate social discount rate to use is the government rate outlined in Table 2-2. However, the analyst should be aware that the rates set by OMB and the Federal Energy Management Program could be a function of the current administration's agenda. For example, an administration favoring less government spending and fewer government projects would push for higher discount rates, thus making it more difficult for projects to pass the cost-effectiveness test (Lind 1982).

Discount rates are sometimes adjusted to reflect risk. The subject of risk-adjusted discount rates is covered in detail in the Uncertainty and Risk subsection in Section 2.

\section{Cost of Capital}

\section{Introduction}

The cost of capital is an important factor in the economic analyses of firms, utilities, and other business entities. The previous section illustrated that cost of capital is frequently used as the discount rate in economic analyses. The cost of capital has to be recovered by the investor to warrant his investment. The price of a good or service to a consumer in a competitive market or in a market subject to utility regulation will include a return roughly equal to the industry's cost of capital. Higher returns attract increased investment, whereas lower returns discourage investment and lead to inadequate supplies and sources of investment capital. 


\section{Discussion}

Capital is a necessary factor of production and has a cost. Estimating a firm's cost of capital involves determining the cost of the various capital components, then applying these costs to the capitalization ratio of the firm to arrive at a WACC. The more common components of capital are debt, preferred stock, and common equity.

Calculating the cost of debt and preferred stock is a relatively straightforward procedure. In the case of a regulated utility, common practice is to use the embedded ${ }^{5}$ cost (actual interest obligation of debt as a percentage of the principal amount outstanding and the annual dividend obligation of preferred stock as a percentage of the net proceeds from the sale of that stock) because the rate base of regulated utilities is embedded (Phillips 1988). EPRI's 1993 TAG recommends using a before-tax nominal cost of debt of 9.1\% and a nominal cost of preferred stock of $8.4 \%$ (EPRI June 1993).

Instead of calculating the cost of debt and preferred stock on an embedded basis, a competitive private firm would want to use the marginal cost or the cost of newly issued debt and preferred stock. This is the case because a competitive firm should finance projects in such a way that the Marginal Cost of Capital (MCC) is minimized. The firm should take on new projects only if the net present values of cash flows are positive when cvaluated using the MCC (Weston and Brigham 1981). The cost of new debt can be calculated by dividing the yearly interest amount, after accounting for income tax preferences, ${ }^{6}$ by the sales price of the debt, after accounting for any flotation costs. ${ }^{7}$ The cost of new preferred stock is calculated by dividing the stated dividend by the sales price of the issue after accounting for flotation costs (Ruegg and Petersen 1987).

Estimating the cost of equity for a firm is more complicated than calculating the cost of debt and preferred stock. For regulated utilities, EPRI's TAG 1993 recommends using a nominal cost of equity (common stock) of $13.0 \%$. Three approaches for determining the cost of equity are most commonly used: earnings/price (e/p) ratios, discounted cash flow (DCF) models, and the Capital Asset Pricing Model (CAPM). These methods can be applied to both regulated utilities and competitive firms. The usc of $\mathrm{e} / \mathrm{p}$ ratios and the CAPM is not as predominant as using DCFs and as such, they are not covered in this manual. For more information on the CAPM, see the Uncertainly and Risk subsection in Section 2. Weston covers both models in greater detail (Weston and Brigham 1981).

The equation for calculating the cost of equity (rate of return on common equity) using the DCF model is as follows:

$$
r_{e}=d / p+g
$$

Where:

$r_{e c} \quad=$ rate of return on common equity

$\mathrm{d} \quad=$ current dividend per share

$\mathrm{p} \quad=$ current market price per shate

$\mathrm{g} \quad=$ expected growth rate of dividends per share.

${ }^{5}$ Embedded is defined as average or fully distributed.

${ }^{6}$ Income tax preferences in this instance refers to the tax deductibility of the interest related to debt.

${ }^{7}$ Flotation costs refer to the costs required when acquiring debt. This may be in the form of commissions paid and other costs. 
Thus, if the stock of a firm pays a $\$ 2$ dividend that is expected to grow at an annual rate of $5 \%$ and the current market price of the stock is $\$ 24$, the rate of return on common equity is $13.3 \%$.

The overall WACC is based not only on the cost of the existing capital but also on the structure or distribution of the capital. The general WACC formulation is calculated by:

$$
\text { WACC }=r_{e c}\left[C_{e} \div\left(C_{e}+P_{s}+D\right)\right]+r_{c p}\left[P_{s} \div\left(C_{e}+P_{s}+D\right)\right]+(1-T) r_{d}\left[D \div\left(C_{e}+P_{s}+D\right)\right]
$$

Where:

$\mathrm{r}_{\mathrm{cc}} \quad=$ rate of return on common equity

$\mathrm{C}_{\mathrm{c}}=$ common stock and corporate retained earnings (Weston and Brigham 1981)

$\mathbf{P}_{\mathrm{s}} \quad=$ preferred stock

$\mathrm{D}=$ debt issues

$\mathrm{r}_{\mathrm{ep}} \quad=$ rate of return on preferred stock

$\mathrm{T}=$ corporate tax rate ${ }^{8}$

$\mathbf{r}_{\mathrm{d}} \quad=$ interest rate paid on debt.

As an example of using the WACC formula, suppose the capital structure of a regulated utility consists of $46 \%$ debt at an embedded after-tax nominal cost of $5.6 \%, 8 \%$ preferred stock at an embedded nominal cost of $8.4 \%$, and $46 \%$ common equity at a nominal cost of $13.0 \%$. Table $2-3$ shows the WACC calculation.

Table 2-3. WACC Calculation Table

\begin{tabular}{|lccc||}
\hline \multicolumn{1}{|c|}{ Security } & \% of Total & Cost (\%) & Return (\%) \\
\hline \hline Debt & 46 & $5.6^{\mathrm{a}}$ & 2.59 \\
Preferred Stock & 8 & 8.4 & 0.67 \\
Common Stock & 46 & 13.0 & $\frac{5.98}{\text { WACC }=9.2}$ \\
\hline & & & \\
\hline aThe EPRI TAG recommends a nominal before-tax cost of debt of $9.1 \%$ and an effective tax \\
rate of 38\%. This translates into an after-tax cost of debt of approximately 5.6\% because \\
interest is tax deductible; i.e., (1 - 0.38) (9.1).
\end{tabular}

In this example, the WACC is $9.2 \%$, which is the WACC recommended by EPRI for use in analyses related to electric utilities. As previously statcd, if this had bcen a private competitive firm, the correct cost components for debt and preferred slock would have been based on the cost of new issues. The WACC valuc derived would then be called the $\mathrm{MCC}$ or the weighted average cost of new capital

${ }^{8}$ The corporate tax rate includes both state and federal income tax rates. The effective lax rate, or combined state and fedcral tax rate, which accounts for the fact that state taxes are deductible on federal returns, can be calculated as: Effective Tax Rate $=$ State Tax Rate + Federal Tax Rate $(1-$ State Tax Rate). 
(WACNC). As was pointed out in the previous section, Appendix C displays historical WACNC values based on historical returns to equity investors and after-tax interest paid on debt to arrive at an average WACNC of approximately $5 \%$ real (or $7 \%$ real when the tax deductibility of interest is not accounted for $^{9}$ ).

\section{Present Value}

\section{Introduction}

Present value analysis is used to calculate today's worth of a transaction that will occur in the future to account for changing dollar valuations. In other words, present value is a measure of today's value of revenues or costs to be incurred in the future (Samuelson and Nordhaus 1985). Because present value is fundamental, it is important to understand the issues surrounding its components and what is being assumed in the present value analysis.

\section{Discussion}

The present value of a dollar received or paid in the future can be calculated by multiplying the future cash flow by a present value discount factor, used to discount future cash flows back to the present. The formulas for present value and the present value interest factor are as follows:

$$
\mathrm{PV}=\mathrm{PVIF}_{\mathrm{n}} \times \mathrm{F}_{\mathrm{n}} \quad \text { and } \quad \mathrm{PVIF}_{\mathrm{n}}=\frac{1}{(1+d)^{\mathrm{n}}}
$$

Where:

$$
\begin{array}{ll}
\text { PV } & =\text { present value } \\
\text { PVIF }_{n} & =\text { present value interest factor } \\
\mathrm{F}_{\mathrm{n}} & =\text { cash flow } \mathrm{n} \text { years in the future } \\
\mathrm{d} & =\text { annual discount rate. } .^{10}
\end{array}
$$

Therefore:

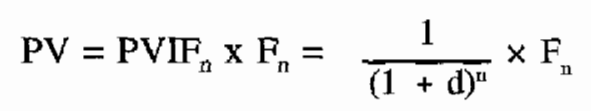

${ }^{9}$ The after-tax interest rate assumes that the highest marginal tax rate is paid by industry. In reality, however, the actual rate paid is frequently less than this, making the actual historical real returns to investors after taxes somewhere between $5.0 \%$ and $7.0 \%$.

${ }^{10}$ Although this manual presents only annual discount rates and cash flows, discount rates and cash flows can be expressed for any period (i.e., monthly). In fact, discount and interest rates can be expressed continuously (see Appendix E: Monthly and Continuous Discount Rates). 
As an example, assume a discount rate of $5 \%$ and a cash inflow of $\$ 1$ one year from now. Using the formula above, the present value is as follows:

$$
P V=\frac{1}{(1+0.05)} \times \$ 1=0.9524 \times \$ 1=\$ 0.95
$$

The $\$ 0.95$ is approximately the present value of the future cash inflow of $\$ 1$. Conversely, if $\$ 0.95$ was invested at a 5\% interest rate, it would be worth approximately $\$ 1$ one year from now. This example determines the present value of a cash flow exactly one year in the future. The same basic formula can be used to evaluate cash flows in any future period or from now to some point in the future. In this latter case, the present valuc is a sum of the present value of each future year's cash flow, i.e.,

$$
\mathrm{PV}=\sum_{\mathrm{n}=1}^{\mathrm{N}} \mathrm{PVIF}_{\mathrm{n}} \times F_{\mathrm{n}}
$$

For example, assume a cash inflow of $\$ 1$ one year from now and a cash inflow of $\$ 5$ two years from now at an annual discount rate of $5 \%$. The present value of this inflow is as follows:

$$
\begin{aligned}
& \mathrm{PV}_{1}=\frac{1}{(1+0.05)^{1}} \times \$ 1=0.9524 \times \$ 1=\$ 0.95 \\
& \mathrm{PV}_{2}=\frac{1}{(1+0.05)^{2}} \times \$ 5=0.9070 \times \$ 5=\$ 4.54
\end{aligned}
$$

Once these future cash inflows are converted to present value, they can be added. From the previous calculations, the following table can be constructed:

Table 2-4. Present Value Calculation Table

\begin{tabular}{|cccc|}
\hline Period & Cash Flow & PVIF & Present Value \\
\hline 1 & $\$ 1$ & 0.9524 & $\$ 0.95$ \\
2 & $\$ 5$ & 0.9070 & $\frac{\$ 4.54}{45}$ \\
\hline
\end{tabular}

The example in Table 2-4 required calculating the present value for each of two future cash flows. This calculation is necessary when each future cash flow is uneven or differs in amount. But when future cash flows are fixed in size and regularly occur over a specific number of periods, the situation is known as 
an annuity. For an annuity, another formula can be used for calculating present value. The formula for calculating the present value of an annuity is as follows ${ }^{11}$.

$$
P V=F \times \frac{\left.(1+d)^{N}-1\right)}{\left[d(1+d)^{N}\right]}
$$

Where:

$$
\begin{aligned}
& \mathrm{PV}=\text { present value } \\
& \mathrm{F} \quad=\text { cash flow in each of } \mathrm{N} \text { future years } \\
& \mathrm{d} \quad=\text { annual discount rate. }
\end{aligned}
$$

For example, assume a cash inflow of $\$ 100$ per year at the end of each year for the next 5 years at a discount rate of $10 \%$. The following calculation is obtained by applying the formula in Eq. (2-12):

$$
\mathrm{PV}=\$ 100 \times \frac{(1+0.10)^{5}-1}{\left[0.10(1+0.10)^{5}\right]}=\$ 100 \times 3.7908=\$ 379.08
$$

In this example, the present value of the annuity is $\$ 379.08$.

In thesc examples, the issue of real or nominal discount rates and dollars was not addressed. As was pointed out in the Discount Rates subsection in Section 2, a real discount rate excludes inflation, whercas a nominal value includes inflation. The important thing to remember when calculating present value is to use real discount rates if cash flows are in constant dollars and to use nominal discount rates if cash flows are in current dollars.

\section{Taxes}

\section{Introduction}

Taxes represent additional costs that are no different from, for example, labor and materials costs. As such, all relevant taxes should be included in an economic analysis. The most complete analysis of an investment in a technology or a project requires the analysis of each ycar of the life of the investment, taking into account relevant costs, including taxes.

In most circumstances, cash flow will be the basis for analyzing alternative investments. An after-tax cash flow should account for federal and state income taxes (if state income taxes are applicable). In most cases, analyses should be based on after-tax cash flows. As Stermole points out, the effects of income tax can vary widely from one alternative to another, so it is generally imperative to compare the relative cconomics of investment alternatives on an after-tax basis to have a valid economic analysis (Stermole 1984).

An illustration of the importance of after-tax analysis is noteworthy here. Suppose a fossil fuel plant with relatively low capital costs and high fuel costs is being compared to a solar plant with relatively high capital costs and no fuel costs. Depreciation for tax purposes will be a major factor in this analysis. The

\footnotetext{
${ }^{11}$ The present value interest factor, $\left[(1+d)^{\mathrm{N}}-1\right] /\left[\mathrm{d}(1+\mathrm{d})^{\mathrm{N}}\right]$, used in the calculation of net present value, is the reciprocal of the uniform capital recovery factor (UCRF).
} 
fuel costs for the fossil fuel plant will be expensed and recovered immediately. However, the solar plant with no fuel cost and higher capital costs will have to wait until capital costs are depreciated to recover costs. Another important factor in after-tax analysis is any energy investment tax credit that might be available to a solar plant. An after-tax analysis will account for depreciation differences and the effects of the investment tax credit and, as such, is key to the analysis in this example.

These examples deal with private entities deciding whether to invest in a technology. In these situations, taxes are a real cost that will have an impact on the decision. However, in analyses from a societal perspective, taxes are nothing more than transfer payments, with the exception of those designed to correct for externalities. ${ }^{12}$ An analysis could indicate that a given technology is beneficial from society's perspective, but tax distortions prevent that technology from being economically viable from an investor's viewpoint. Thus, in some instances it may be advantageous to analyze a project's viability both with and without taxes.

\section{Discussion}

The financial treatment of taxes is a very large and complicated subject. The scope of this manual is such that corporate income taxes for the federal and state levels and other relevant taxes, such as property tax and payroll tax, cannot be thoroughly defined or explained through examples. Rather, some important points are brought forth that an analyst should be aware of.

In performing after-tax analyses of investment alternatives, the analyst should be aware that the relevant tax considerations are what a company considers for tax purposes and not what a company considers for accounting or book purposes. In most cases, what a company does for accounting purposes or annual reports has no relevance to economic analyses. What the company does for tax purposes affects cash flow generation.

An equally important point is that for tax calculation purposes, all dollar values should be expressed in nominal values. This is important because taxes are applied to actual dollar values, and if an analysis were to apply tax rates to dollar values corrected for inflation, the results would be skewed.

It may be necessary to provide more detail for the analysis of a specific project or company. In these cases, there are other factors that should not be overlooked, such as the type of business organization. The three most common types of organizations are the sole proprietorship, the partnership, and the corporation. The tax treatment for these different types of organizations will vary.

For EE analyses in which investor-specific data are not available, the use of the highest tax bracket or marginal tax rate is appropriatc. This tax rate for corporations is $39 \%{ }^{13}$ for corporations with over $\$ 100,000$ taxable income; for individuals it also varies with income up to $36 \%$. State tax rates will vary. The marginal state tax rates for corporations as of October 1991 are provided in Table 2-5.

The analyst is advised to use these rates only as a quick guide and to further research state tax rates for a detailed analysis because rates may have changed and the marginal tax rates shown in the table may have different applications. For example, the 9.3\% state income tax rate for California is applied to California net income, whercas the $9.3 \%$ rate for Arizona is applied to federal taxable income. State and

\footnotetext{
${ }^{12}$ See the subsection Externalities in Section 5 for an explanation of externalities.

${ }^{13}$ Note that all examples in this manual use a $34 \%$ tax rate, which was the marginal corporate ratc before August 1993.
} 
federal taxes can be combined (to account for the deduction of state taxes on federal returns) to estimate an effective tax rate as follows ${ }^{14}$ :

$$
\text { Effective Tax Rate }=\text { State Tax Rate }+ \text { Federal Tax Rate }(1-\text { State Tax Rate })
$$

The analyst may also need to factor in special tax considerations that may apply to the analysis, such as energy tax credits, capital gains and losses, depreciable assets, net operating loss carrybacks and carryovers, dividends, interest deductions, and installment tax payments. Weston and Brigham (1981) cover these subjects in more detail in Managerial Finance.

Energy tax credits and depreciation are important components of the tax issue and warrant special attention. These subjects are covered in the next two sections.

\section{Renewable Energy Tax Credits}

Energy tax credits for technologies such as renewables can enhance after-tax cash flow and promote investment. An energy investment tax credit is an immediate reduction in income taxes equal to a percentage of the installed cost of a new investment. The tax code mandates that when an encrgy tax credit is taken, the depreciable base (capital sum to be recovered by depreciation) of the property for which the credit was taken must be reduced by $50 \%$ of the amount of the tax credit. Another key provision of the tax code allows for depreciation to be carried through to other businesses owned by that specific firm. This is important because income is usually not very large in the early years of renewable projects.

The Energy Policy Act (EPACT) of 1992 includes a 10\% tax credit applicable to solar and geothermal property used for the generation of electricity; however, public utilities are not eligible for this tax credit (CCH 1992). This tax credit was available prior to the EPACT as well, but EPACT extended it indefinitely. EPACT also includes a production tax credit applicable to wind systems and dedicaled biomass (crops grown specifically for energy production) systems that generate electricity. This credit provides a 10 -year, 1.5 cent $/ \mathrm{kWh}$ production tax credit.

State governments may also offer encrgy tax credits that are applicable to renewables when calculating state income taxes. State energy tax credits may vary considerably from those of the federal government's. Also, some states have property tax excmption laws that apply to renewable energy projects. The analyst should research the applicable federal and state energy tax credit rules at the onsel of an analysis to determinc appropriate levels, applicability, and special rules that may apply.

When applying a tax credit in an analysis, the analyst should be cautious because tax credits usually apply only to specific costs and not to the total cost of the project. For instance, federal investment tax credil rules do not allow credits to apply to transmission costs. States may have limitations as well. It is recommended that the analyst be certain of the costs the credits may be applied to.

Table 2-6 provides a summary of state tax credits and other financial incentives for solar technologics. An explicit definition of solar technologies is not provided because the table is not comprehensive. For example, a state may provide incentives for residential photovoltaics but not for utility solar-thermal systems. Because of these circumstances, the table should only be used for general information. The analyst should research further to identify more specific incentives.

\footnotetext{
${ }^{14}$ One implication of using an effective tax rate that includes both federal and state income tax is that the state depreciation rules are assumed to be the same as the federal depreciation rules.
} 
Table 2-5. Marginal State Income Tax Rates for Corporations as of December 31, 1993

\begin{tabular}{|c|c|c|c|}
\hline State & $\begin{array}{c}\text { Marginal } \\
\text { tax rate (\%) }\end{array}$ & State & $\begin{array}{c}\text { Marginal } \\
\text { tax rate }(\%)\end{array}$ \\
\hline Alabama & 5.0 & Montana & 6.75 \\
\hline Alaska & 9.4 & Nebraska & 7.75 \\
\hline Arizona & 9.3 & Nevada & - \\
\hline Arkansas & 6.5 & New Hampshire & 7.5 \\
\hline California & 9.3 & New Jersey & 7.25 \\
\hline Colorado & 5.0 & New Mexico & 7.6 \\
\hline Connecticut & 11.5 & New York & 9.0 \\
\hline Delaware & 8.7 & North Carolina & 7.75 \\
\hline District of Columbia & 10.0 & North Dakota & 10.5 \\
\hline Florida & 5.5 & Ohio & 8.9 \\
\hline Georgia & 6.0 & Oklahoma & 6.0 \\
\hline Hawaii & 6.4 & Oregan & 6.6 \\
\hline Idaho & 8.0 & Pennsylvania & 10.5 \\
\hline Illinois & 4.8 & Rhode Island & 9.0 \\
\hline Indiana & 3.4 & South Carolina & 5.0 \\
\hline lowa & 12.0 & South Dakota & - \\
\hline Kansas & 4.5 & Tennessee & 6.0 \\
\hline Kentucky & 8.25 & Texas & - \\
\hline Louisiana & 8.0 & Utah & 5.0 \\
\hline Maine & 8.93 & Vermont & 8.25 \\
\hline Maryland & 7.0 & Virginia & 6.0 \\
\hline Massachusetts & 9.5 & Washington & - \\
\hline Michigan & 2.35 & West Virginia & 9.0 \\
\hline Minnesota & 9.8 & Wisconsin & 7.9 \\
\hline Mississippi & 5.0 & Wyoming & - \\
\hline Missouri & 6.25 & & \\
\hline
\end{tabular}


Table 2-6. State Incentives for Solar Technologies

\begin{tabular}{|c|c|c|c|c|c|c|c|}
\hline State & $\begin{array}{c}\text { Tax } \\
\text { Credit }\end{array}$ & $\begin{array}{l}\text { Sales Tax } \\
\text { Exemption }\end{array}$ & $\begin{array}{c}\text { Property } \\
\text { Tax } \\
\text { Exemption }\end{array}$ & $\begin{array}{c}\text { Industry } \\
\text { Recruitment }\end{array}$ & Loan & Grant & Other \\
\hline Arizona & & $x$ & & $x$ & $x$ & & \\
\hline California & $10 \%$ & & & & $x$ & $x$ & \\
\hline Hawaii & $35 \%$ & & $x$ & $x$ & & & \\
\hline Idaho & & & & & $x$ & & Income Tax \\
\hline Indiana & & & $x$ & & & & \\
\hline lowa & & & $x$ & & $\mathrm{x}$ & & \\
\hline Massachusetts & $15 \%$ & $x$ & $x$ & & & $\mathrm{X}$ & Corporate Tax \\
\hline Minnesota & & $\mathrm{x}$ & $x$ & & & & $\begin{array}{l}\text { Accel. } \\
\text { Deprec. }\end{array}$ \\
\hline Mississippi & & & & & $x$ & & \\
\hline Montana & & & $x$ & & & & \\
\hline Nevada & & $x$ & $x$ & & & & \\
\hline New Hampshire & & & $x$ & & & $\mathrm{x}$ & \\
\hline New Jersey & & $x$ & & & & $\mathrm{x}$ & $\begin{array}{c}\text { Permit Fee } \\
\text { Ex. }\end{array}$ \\
\hline New York & & & $x$ & & & & \\
\hline North Carolina & $25 \%$ & & & $\mathrm{x}$ & & & \\
\hline North Dakota & $15 \%$ & & $\mathrm{x}$ & & & & \\
\hline Ohio & & & $x$ & & & & \\
\hline Oregon & $35 \%$ & & $\mathrm{x}$ & & $\mathrm{x}$ & & \\
\hline Pennsylvania & & & & & & $x$ & \\
\hline Puerto Rico & & & & & $x$ & & \\
\hline Rhode Island & & $x$ & & & & & \\
\hline South Dakota & & & $x$ & & $x$ & & \\
\hline Tennessee & & & & & $x$ & & \\
\hline Texas & & & $x$ & & & $x$ & $\begin{array}{l}\text { Accel. } \\
\text { Deprec. }\end{array}$ \\
\hline Utah & $25 \%$ & & & & & & \\
\hline Virginia & & & $\mathrm{x}$ & $x$ & & & \\
\hline Wisconsin & & & $x$ & & & $x$ & \\
\hline Wyoming & & & & & & $x$ & \\
\hline TOTALS: 28 & 7 & 6 & 16 & 4 & 9 & 8 & 5 \\
\hline
\end{tabular}


In some cases, it may be that taxes owed are less than the amount of the tax credit. The federal government will allow the company to carry the unused portion of the credit forward to the following year (carryover). For example, suppose a company invests in a solar technology to sell electricity to the grid. The initial investment is $\$ 2$ million. After the first year of operation, the company owes federal income taxes in the amount of $\$ 150,000$. The tax credit allows a reduction in taxes owed in the first year of operation equal to $10 \%$ of the initial investment cost, or $\$ 200,000$. Thus, taxes owed are reduced to a negative $\$ 50,000$, which could be carried over to the following year. However, these rules may not apply at the state level.

\section{Depreciation}

It is difficult to talk about income taxes without talking about depreciation. For tax purposes, depreciation is a means of recovering, through an income tax deduction, the cost of property used in a trade or business or of property held for the production of income (land is not depreciable). The capital sum to be recovered by depreciation is the "depreciable base," which when adjusted annually by the amount depreciable, becomes the "adjusted base." It is a bookkeeping entry and does not involve the outlay of cash; nor does it involve the actual deterioration of the physical asset. If federal investment tax credits are available, the depreciable base for federal tax purposes must be decreased by half of the tax credit.

Intcrnal Revenue Service (IRS) rules for depreciation have gone through changes over the last couple of decades, the most recent of which was the 1986 Tax Reform Act. Given the complicated nature of the subject, only the current tax rules (i.e., enacted with the 1986 Tax Reform Act) are reviewed in this manual. The IRS nules should be revisited often to assure that the rules reviewed here are still in practice. It is also important to note that only the current federal rules are discussed. If an analysis requires more accuracy or detail, state depreciation rules should be examined. Another important point is that given the nature of depreciation, annual depreciation allowances are always calculated in current dollars and as such, a nominal discount rate should be used when discounting depreciation cash flows.

The Modified Accelerated Cost Recovery System (MACRS) is the name given to the federal tax rules for recovering costs through depreciation. MACRS rules apply to most tangible property placed in service after 1986. MACRS consists of two systems, the General Depreciation System (GDS) and the Alternative Depreciation System (ADS). MACRS provides the following ways to depreciate property:

- Both the $200 \%$ and $150 \%$ declining balance (DB) methods over a GDS recovery period

- The $150 \%$ DB method over an ADS recovery period

- The straight line (defined later) method over an ADS or GDS recovery period.

The depreciation method used depends on the system used (GDS or ADS) and the class and type of property. The major differences between GDS and ADS are the recovery period and method of depreciation used to figure the deduction. The GDS is most commonly used and is the recommended system for EE analysts because it permits use of the declining balance method over a shorter recovery period, resulting in a greater deduction in the carlier years (IRS 1993). The ADS is used when it is desirable to extend an asset's depreciation period. For ADS the straight line method is used over an ADS recovery period. For cxample, consider a business in which taxable revenue is expected to be greater in future years than in earlicr years. In this case, a greater deduction in the earlier years is not as beneficial as an extended depreciation period.

The straight line (SL) annual deprcciation method is calculated using the following formula:

$$
\mathrm{D}_{\mathrm{n}}=\left(\mathrm{C}_{0}-\mathrm{NSV}\right) / \mathrm{N}
$$


Where:

$\mathrm{D}_{\mathrm{n}} \quad=$ annual depreciation allowance for year $\mathrm{n}$

$\mathrm{C}_{0}=$ original cost of the capital investment

$\mathrm{NSV}=$ net salvage value (i.c., the estimated salvage value of property, less the cost of removal)

$\mathrm{N}=$ depreciation period. $^{15}$

However, it is important to note that the previous formula applies only when the SL method is used independently throughout the entire recovery period of an asset. When using the DB depreciation method, the IRS rules require that SL depreciation be calculated in addition to DB and that the annual depreciation allowance switches to the SL method in the year in which SL provides a larger allowance than that of DB. For the DB method, the annual depreciation allowance is not constant; consequently, the asset's depreciable base must be recalculated in each recovery ycar to properly determine the new SL depreciation allowance. Therefore, the following formula must be used to calculate the SL depreciation allowance when testing for SL crossover using the DB method:

$$
D_{n}=B_{n-1} /[N-(n-1)]
$$

Where:

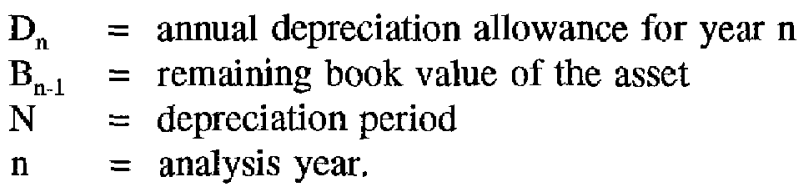

The DB depreciation method can be applied using either a $200 \%$ or $150 \%$ declining balance percentage. Property calaloged as 3-, 5-, 7-, or 10-year class property is depreciated using the $200 \%$ method; property cataloged as 15- or 20-year class property is depreciated using the $150 \%$ method. Salvage value is not allowed or considered when calculating depreciation using DB. The depreciation allowance for any year $\mathrm{n}$, using the DB method, can be computed with the following formula ( $\mathrm{Au}$ and $\mathrm{Au} \mathrm{1983):}$

$$
D_{n}=B_{n-1} r
$$

Where:

$\mathrm{D}_{\mathrm{n}} \quad=$ annual depreciation allowance for year $\mathrm{n}$

$\mathrm{r}=$ annual percentage ratc of depreciation applied to the remaining book value, $[(2$ or 1.5 , depending on whether the DB method is $200 \%$ or $150 \%) \div \mathrm{N}$,

$\mathrm{n} \quad=$ number of years the asset will be depreciated (depreciation period)

$\mathrm{B}_{\mathrm{n}-1}=$ remaining book valuc of the asset.

It is important to note that thesc depreciation formulas, as well as all of the examples that follow, assume that the IRS allows for a full year of depreciation in the year in which the property is placed in service. For simplicity, this assumption is made in the examples presented in this manual, but in actual practice, this assumption is not valid. For the first year of operation, the IRS actually allows for cither one-half year of depreciation (half-year convention) or an alternative amount based on which quarter of the year

${ }^{15} \mathrm{~A}$ useful life is the estimated life of the investment before it must be replaced. The depreciation period is the number of years allowed to recover the cost of an investment through depreciation. The analysis period is the number of years included in an analysis. 
the property was placed in service (mid-quarter convention). The mid-quarter convention is only allowed if more than $40 \%$ of the value of all assets placed in service during the ycar were done so during the last quarter of the year. The IRS has similar rules for the year in which a property is taken out of service before fully depreciated. If an analysis requires more accuracy or detail than what is provided in this manual, the IRS rules should be examined more closely.

In addition to the depreciation method, the depreciation period for the related technology or property must be determined. The IRS provides guidelines or recommended recovery periods for many different types of properties (see IRS Publication 534 [IRS 1993]). Examples of rccommended recovery periods using GDS methods include:

- Alternative energy property (nonutility generators) - 5 years

- Alternative energy property (public utility generators) - 7 years

- Nuclear production plant - 15 years

- Nuclear fuel assemblies - 5 years

- Hydro production plant - 20 years

- Steam production plant - 20 years

- Combustion turbine production plant - 15 years

- Transmission and distribution plant - 20 years

- Nonresidential real property - 31.5 years.

Recommended recovery periods using ADS methods include:

- Alternative energy property (nonutility generators) - 12 years

- Nuclear production plant - 20 years

- Nuclear fuel assemblies - 5 years

- Hydro production plant - 50 years

- Steam production plant - 28 years

- Combustion turbine production plant - 20 years

- Transmission and distribution plant - 20 years

- Nonresidential real property - 40 years.

The class life of property is determined by referring to Appendix B of IRS Publication 534 (IRS 1993). If an item is not described in the publication, such item should be deprecialcd using a 7-year recovery period under GDS, or a 12-year recovery period under ADS. Also, note that a particular project can have equipment with different depreciation schedules (such as in the case of the nuclear project). If there are any questions regarding the appropriate class life of an investment or a component of that investment, the IRS should be contacted.

Table 2-7 illustrates the $200 \%$ DB depreciation method. This example assumes a non-real-estate capital asset is purchased that has a 7 -year life and a book valuc of $\$ 10,000$, with no salvage value. The asset is depreciated at the $200 \%$ DB rate until the annual depreciation values using DB versus SL crossover in year five. At that time, the depreciation method switches from the DB method to the SL method and the remaining value of the asset is depreciated at the flat rate of $\$ 867.69$ per year. The last column in the table calculates the present value of accumulated depreciation (PVDEP), assuming an investor nominal discount rate of $12 \%$. After 7 years, the present value is only $\$ 7,202$. The difference between the $\$ 10,000$ original investment and the present value of depreciation $(\$ 7,202)$ represents that portion of the investment that is, in effect, unavailable to the investor as a tax deduction because of the time value of money. Shorter depreciation periods are thus preferred by most investors.

Clearly, there are noticcable tax benefits for using DB depreciation rather than SL depreciation. For example, suppose a machine is purchased for $\$ 100,000$ and has no expected salvage value and is to be 
depreciated over a 10 -year period. The cost of the machine must be charged against production over the machine's depreciation period. Using the formulas for SL and DB, first-year depreciation can be calculated as follows:

Table 2-7. DB Depreciation Method

\begin{tabular}{|c|c|c|c|c|c|c|}
\hline Year & $\begin{array}{c}\text { Net Book } \\
\text { Value }\end{array}$ & $\begin{array}{c}\text { Declining } \\
\text { Balance } \\
\text { Depreciation }\end{array}$ & $\begin{array}{c}\text { Test of } \\
\text { SL } \\
\text { Method }\end{array}$ & Depreciation & $\begin{array}{l}\text { Accumulated } \\
\text { Depreciation }\end{array}$ & $\begin{array}{c}\text { Present } \\
\text { Value } \\
\text { Accumulated } \\
\text { Depreciation } \\
\end{array}$ \\
\hline 1 & $\$ 10,000.00$ & $\$ 2,857.14$ & $\$ 1,428.57$ & $\$ 2,857.14$ & $\$ 2,857.14$ & $\$ 2,551.14$ \\
\hline 2 & $7,142.86$ & $2,040.82$ & $1,190,48$ & $2,040.82$ & $4,897.96$ & $4,178.08$ \\
\hline 3 & $5,102.04$ & $1,457.73$ & $1,020.40$ & $1,457.73$ & $6,355.69$ & $5,215.69$ \\
\hline 4 & $3,644.31$ & $1,041.23$ & $911.08^{\mathrm{a}}$ & $1,041.23$ & $7,396.92$ & $5,877.39$ \\
\hline 5 & $2,603.08$ & 743.74 & $867.69^{\mathrm{b}}$ & 867.69 & $8,264.61$ & $6,369.72$ \\
\hline 6 & $1,859.34$ & 531.24 & 867.69 & 867.69 & $9,132.30$ & $6,809.29$ \\
\hline 7 & $1,328.10$ & 379.46 & 867.69 & 867.69 & $10,000.00$ & $7,201.75$ \\
\hline Note: & $\begin{array}{l}\text { The depreciati } \\
\text { a. }(\$ 10,000- \\
\text { b. }(\$ 10,000-\$\end{array}$ & $\begin{array}{l}\text { rate is } 1 / 7 \times \\
55.69) / 4= \\
96.92) / 3=\end{array}$ & $\begin{array}{l}2857 . \\
08 . \\
69 .\end{array}$ & & & \\
\hline
\end{tabular}

$$
\begin{gathered}
\text { SL: } \quad D_{1}=\$ 100,000 \div 10=\$ 10,000 \\
D B: D_{1}=\$ 100,000 \times(2 \div 10)=\$ 20,000
\end{gathered}
$$

By using the DB depreciation method, the amount of allowable depreciation is $\$ 10,000$ morc in the first. year than it would have been had the SL depreciation method been used. Thus, taxable income is $\$ 10,000$ less in the first year. Faster depreciation is preferred because an after-tax dollar earned today is worth more than an after-tax dollar earned tomorrow (i.e., the time value of money).

\section{Fixed Charge Rate}

\section{Introduction}

A fixed charge rate (FCR) allows for quick determinations of the amount of revenue needed to cover investment costs for simple, straightforward investments. The FCR is defined as the amount of revenue per dollar of investment that must be collected annually from customers to pay the carrying charges on that investment (EPRI May 1987). Carrying charges include return on debt and equity, income and property tax, book depreciation, and insurance. For example, an FCR multiplied by the total capital requirement of a capital investment will calculate the revenue needed each year to support the investment. See Appendix $F$ for a detailed explanation of total capital requirements. 


\section{Discussion}

Use of a fixed charge rate does not allow for explicit consideration of project-specific financing. However, the discount rate can implicitly incorporate debt financing through the use of a weighted average cost of capital to a firm, as discussed earlier.

To capture tax considerations of the investor and the investment, the formula for calculating the annual fixed charge rate can take one of three forms: a no-tax investment scenario, a cost-after-tax-deductions investment scenario, or a before-tax-revenue-required investment scenario. The formulas are as follows:

No Tax:

$$
\mathrm{FCR}=\mathrm{UCRF}+\mathrm{p}_{1}+\mathrm{p}_{2}
$$

Cost After Tax Deductions:

$$
\mathrm{FCR}=\operatorname{UCRF}\left[1-(b)(T) \sum_{n=1}^{M} V_{n} /\left(1+d_{n}\right)^{n}-t_{c}\right]+\left(p_{1}+p_{2}\right)(1-T)
$$

Before Tax Revenue Required:

$$
\mathrm{FCR}=\frac{\operatorname{UCRF}\left[1-(b)(T) \sum_{n=1}^{M} V_{v} /\left(1+d_{n}\right)^{n}-t_{c}\right]+p_{1}+p_{2}}{(1-T)}
$$

Where:

$$
\begin{aligned}
& \text { FCR = fixed charge rate } \\
& \text { UCRF = uniform capital recovery factor defined as } \\
& 1 / \sum_{n=1}^{N} 1 /\left(1+d_{x}\right)^{n}
\end{aligned}
$$

where the discount rate $d_{x}=d_{r}$ or $d_{n}$, depending on whether it is desired to express the annual carrying charges in real or in nominal dollars

$\mathrm{M} \quad=$ depreciation period in ycars

b = fraction of depreciation base (depreciable fraction of capital costs)

$\mathrm{n} \quad=$ analysis ycar

$\mathrm{T}=$ marginal income tax rate of the investor (state and federal)

$\mathrm{V}_{\mathrm{n}} \quad=$ fraction of depreciable base that can be depreciated in year $\mathrm{n}$

$\mathrm{d}_{\mathrm{n}} \quad=$ nominal discount rate (must be used in conjunction with the nominal depreciation allowance)

$\mathrm{N} \quad=$ analysis period

$\mathrm{t}_{\mathrm{c}} \quad=$ tax credit

$\mathrm{p}_{1} \quad=$ annual insurance cost as a percentage of total plant investment in real or nominal dollars, depending on the form of the UCRF

$\mathrm{p}_{2} \quad=$ other taxes (i.e., property taxes) paid annually as a percentage of total plant investment in real or nominal dollars, depending on the form of the UCRF (Blum, Schweizer, and Morse 1989).

The no-tax formula is applicable to the following investors and investments: owner-occupied residences, nonprofit organizations, the government, and so forlh. The cost-after-tax-deductions formula is applicable 
to for-profit firms with profits from other activities against which the tax deductions can be applied. The after-tax cost is most relevant to energy-saving investments in which no energy product is produced for sale to customers. The before-tax-required-revenue formula is applicable to profit-seeking firms that desire to know how much they will have to charge for the energy they are supplying in order to recover their costs, as well as make their desired return (as defined by the discount rate used in the fixed-charge rate calculation). Any comparison between two investments should be conducted on the same tax basis, i.e., both with no tax, or both on a cost-after-tax basis, or both on a before-tax-revenue-required basis.

Note that the distinction between the formulas for the cost-after-tax-deductions and the required-revenue formula is simply the division of the former by the marginal income tax rate. It is also interesting to note that the no-tax formula and required-revenue formula would be identical if there were no tax credit and if the present value of depreciation $\left[b V_{n} /\left(1+d_{n}\right)^{n}\right]$ were equal to unity (i.e., if it were $d_{n}=0$ or $V_{0}=1$ ).

The fixed charge rate can be calculated on either a real or nominal basis by using a real or nominal discount rate in the uniform capital recovery factor. Regardless of which is used for the UCRF portion of the FCR, the discount rate employed to calculate the present value of depreciation in the FCR calculation should be a nominal discount rate because depreciation in each year is calculated in nominal dollars.

\section{Financing}

\section{Introduction}

Financial markets provide the mechanism through which firms obtain funding. Sources of funding can come from commercial banks, savings and loans, finance companies, insurance companies, pension funds, investment funds, investment bankers, brokers, dealers, households, governments, and other business firms. Funds are raised from these external sources and allocated to specific projects and assets. The cash flow cycle is then managed, and the funds are eventually returned to the financial sources (Weston and Brigham 1981).

A financial transaction results in the crcation of both an asset and a liability. The creation and transfer of these assets and liabilities form financial markets. These financial transfers can be in the form of loans, bonds, common stock, and preferred stock. When the obligations bought and sold have a maturity of less than 1 year, they are known as money markets, when the maturities are more than 1 year, they are known as capital markets.

It is important for the analyst to understand the two forms of financing: project specific and corporate. Project-specific financing can be defined as the arrangement of debt, equity, and credit enhancement for the construction or refinancing of a particular facility in a capital-intensive industry where lenders base credit appraisals on the projected revenues from the facility rather than on the assets or credit of the promoter of the facility. This financing relies on the assets of the facility, including revenue-producing contracts and cash flow, as collateral for the debt (") 1992). In contrast, internal or equity financing (corporate financing) can be characterized by the use of corporate credit and the general assets of the corporation as the basis for credit and collateral. Unlike project-specific financing, it is not tied to any specific projects.

\section{Discussion}

Financing is very much related to portfolio analysis and risk. A company wishes to have the optimum portfolio of financial assets and liabilities. In other words, it does not wish to obtain $100 \%$ of financing 
through debt or the issue of stock. A capital structure weighted heavily towards one end or the other could be too risky. A typical utility has a capital structure made up of about $50 \%$ long-term debt, $45 \%$ common stock, and $5 \%$ preferred stock.

Different forms of financing give rise to various risk levels. For instance, debt is a fixed charge and if earnings fluctuate, the firm's ability to make the obligated payments may be constrained. Debt is also a long-term commitment with a fixed maturity and is risky because the expectations and plans for the firm over the long run may change. On the other hand, debt is cost limited, and the cost of debt is normally lower than that of common stock. Also, the interest associated with debt financing is tax deductible.

Forms of long-term debt include bonds, mortgages, and debentures. A bond is a long-term promissory note. Usually these notes are issued in denominations of $\$ 1,000$. Bonds are payable in full at the end of their stated life. For example, the purchaser of a 10 -year $\$ 1,000$ bond with a stated coupon rate of $6 \%$ paid annually will receive $\$ 60$ per year through year ten and receive $\$ 1,000$ for redemplion of the bond at the end of year ten. Company assets are normally pledged as security for bonds issued. A debenture, on the other hand, is also a long-term bond but it is unsecured (no lien on specific property of the company as collateral) (Weston and Brigham 1981).

A mortgage is a pledge of company property as security for a loan. Most mortgage loans, or term loans, are granted as uniform payment loans, which are amortized in most cases. Amortization provides a gradual uniform stream of repayment, which safeguards both the lender and the borrower. For example, suppose a business borrows $\$ 10,000$ at $10 \%$ compounded annually to be repaid in 5 years. The annual payment due to the lender can be calculated by multiplying the uniform capital recovery factor

$$
\mathrm{UCRF}=\left[\mathrm{d}(1+\mathrm{d})^{\mathrm{n}}\right] /\left[(1+\mathrm{d})^{\mathrm{n}}-1\right]
$$

by the amount borrowed. In this example, UCRF equals

$$
\left[0.1(1+0.1)^{5}\right] /\left[(1+0.1)^{5}-1\right]=0.2638
$$

which when multiplied by the $\$ 10,000$ borrowed gives a uniform annual payment to the lender of $\$ 2,637.97$. Table 2-8 illustrates the amortization schedule for this example.

\begin{tabular}{|c|c|c|c|c|}
\hline Year & $\begin{array}{c}\text { (1) } \\
\text { Annual } \\
\text { Payment } \\
\text { (I x UCRF) }\end{array}$ & $\begin{array}{c}\text { (2) } \\
\text { Interest } \\
\left(\mathrm{d} \times \text { Col. } 4^{(\mathrm{n}-1)}\right) \\
\end{array}$ & $\begin{array}{c}\text { (3) } \\
\text { Repayment of } \\
\text { Principal } \\
\text { (Col. } 1 \text { - Col. 2) }\end{array}$ & $\begin{array}{c}(4) \\
\text { Principal Balance } \\
\text { (Col. } 4^{(n-1)}-\text { Col. 3) }\end{array}$ \\
\hline 0 & & & & $\$ 10,000.00$ \\
\hline 1 & $\$ 2,637.97$ & $\$ 1,000.00$ & $\$ 1,637.97$ & $8,362.03$ \\
\hline 2 & $2,637.97$ & 836.20 & $1,801.77$ & $6,560.25$ \\
\hline 3 & $2,637.97$ & 656.03 & $1,981.95$ & $4,578.30$ \\
\hline 4 & $2,637.97$ & 457.83 & $2,180.14$ & $2,398.16$ \\
\hline 5 & $2,637.97$ & 239.82 & $2,398.16$ & 0.00 \\
\hline Totals & $\$ 13,189.87$ & $\$ 3,189.87$ & $\$ 10,000.00$ & \\
\hline
\end{tabular}

Table 2-8. Amortization Schedule 
Appendix D provides formulas for calculating the portion of principal in each payment, the portion of interest in each paymenl, and the principal remaining in each period.

Common stock does not include an obligated fixed anmual charge and carries no fixcd maturily dates. Also, common stock can be sold more easily than debt because it is appealing to investors given the fact that common stock usually offers higher returns than that of debt and represents ownership in the company. With common stock there is no legal obligation to pay dividends. However, common stock extends ownership and voling rights as well as a share in income. Also, the cost of underwriting and distributing common stock (flotation costs) is usually higher than both debt and preferred stock.

Preferred stock, like common stock, does not include an obligated fixed annual charge and carries no fixed maturity dates. Preferred stock owners may not participate in voting and do not get equal participation of carnings; however, they do receive any dividends before common stock holders do. Preferred stock, on the other hand, must be sold on a higher yield than debt. Dividends associated with preferred stock are not tax deductible, making their cost differential great in comparison with debt.

These are only a few of the advantages and disadvantages of the different forms of financing. The financial manager must weigh these differences to make decisions about the optimal mix of financing for the firm.

In an economic analysis, financing should be considered only if it will make a difference when comparing alternatives. For instance, if the terms of financing are identical for the comparison of two alternative investments, then financing makes no difference and should not be included. On the other hand, if an investor wants to construct a plant and low-interest rate financing is available for only the solar plant but not for a conventional alternative, then financing is a critical part of the comparison and must be included. Financing must also be included in an analysis of cash flow requirements. When financing is included in an analysis, then annual cash flows must be used to compute most economic measures such as net present value (NPV), return on investment (ROI), and life-cycle cost (LCC). The simplifying assumptions of the FCR, as expressed earlier, are not appropriate when project-specific financing is included.

\section{Investor Perspective}

\section{Introduction}

The economic viability of an investment frequently will be different for different investors. For example, a demand-side management investment by a utility will be viewed differently by the utility, the customer receiving the demand-side system, customers not receiving systems, and the utility stockholders. Investor perspective refcrs to this difference in viewpoints.

\section{Discussion}

Although the differences among investors often seems intuitive, there are several points that dcserve explicit mention:

- An investment may be economical from the point of view of one investor or stakeholder but not from that of another.

- In any comparison of alternative investments, each alternative should be evaluated from the same perspective. For example, a commercial firm's levelized cost of energy (electricity) saved (after accounting for tax deductions) through an investment in a heat pump for space conditioning should not 
be compared directly to the before-tax cost of electric power to the firm. For a homeowner investor, this before-tax/after-tax issue is not relevant.

- It is perfectly legitimale to evaluate an investment from scveral perspectives. A municipal utility might calculate both the required revenue associated with a new distribution feeder line and the social cost/benefit ratio of the same line.

- Not only are the tax concerns and data different among investors, many other data also vary with the investor and the nature of the investment (e.g., discount rates, interest rates available on financing, energy supply costs, and so forth).

- Different measures of economic viability are used by different investors and for different types of investments. Utilities, for example, will typically compare and evaluate alternative generation sysicms by calculating the revenue required to recoup the costs of the systems, whereas homeowners might use simple payback calculations. Measures used will also vary within a market sector. An independent power producer may evaluate an investment through the internal rate of return, as opposed to a utility's evaluation through the required revenue measure.

Considerations such as taxes, data variations, and different measures for evaluation are discussed in more detail in the sections that follow.

\section{Uncertainty and Risk}

\section{Introduction}

Uncertainty refers to the analyst's state of information about a variable or parameter of interest, specifically when the quantity cannot be known perfectly. Uncertainty is often, but not always, associated with variables that will be revealed at a later time, such as the outcome of an experiment or next year's oil price.

A closely related concept is variability. Variability refers to a parameter varying across a group or population. For example, there is significant variability in retail clectricity prices by region in the United States. A parameter with variability may or may not be uncertain. For example, current retail electricity prices are variable but certain, whereas future electricity prices are both variable and uncertain.

A third concept is risk. A general definition of risk is the uncertainty associated with a key value criterion. An example of risk is the uncertainty in the net present value of a project. The relationship of a specified risk to the uncertainties and variabilities in project economics can be explored using the procedures discussed next.

\section{Discussion}

\section{Applications of Uncertainty Analysis}

Uncertainty arises in two contexts in economic analysis. It can arise when performing primary economic evaluations, such as an accept/reject decision of investing in a new technology; it can also arise when trying to predict the economic decisions of others such as predicting how consumers will react to an increase in electricity prices. 
Because the results of economic evaluations are frequently used in planning and policy making, signilicant uncertainties must be identified and treated explicitly. The most internally consistent (i.e., the uncertainty in specific variables is specifically addressed) and complete methodology to support such decision making under uncertainty is decision analysis, as described, for example, by Howard (Howard 1977; Howard 1990). Although a complete discussion of decision analysis is beyond the scope of this section, a brief description of steps to take when confronted with uncertainty in an economic analysis is provided.

In the second context, predicting economic decisions of others, analysts must sometimes model the response of consumers and other decision makers to uncertainties in a market. For example, energy consumers make appliance decisions under uncertain future fuel prices. The basis for many such market decisions are rudimentary (i.c., the appliance consumer does not perform an analysis accounting for uncertainty as advocated in this section). Analyses, when these consumer decisions are important, must in some way account for this less rigorous response to uncertainty. Simulation of a response by others to uncertainty may require using approximation methods, such as risk-adjusted discount rates.

\section{Uncertainty in Economic Evaluations}

Figure 2-1 shows an example of the single most important form for presenting uncertain information: a probability density function $(P D F)$. The probability density function represents a mathematical description of the probability or likelihood of an uncertain variable taking on a given value. ${ }^{16}$ Figure $2-1$ represents a common shape for variables that have positive values, such as prices and quantities. Very small values are unlikely. There is a maximum likelihood at some finite valuc and a long "tail," which represents small probabilities of very large values for the variable. The probability distribution over electricity price shown in Figure 2-1 will be used in an example later in this section.

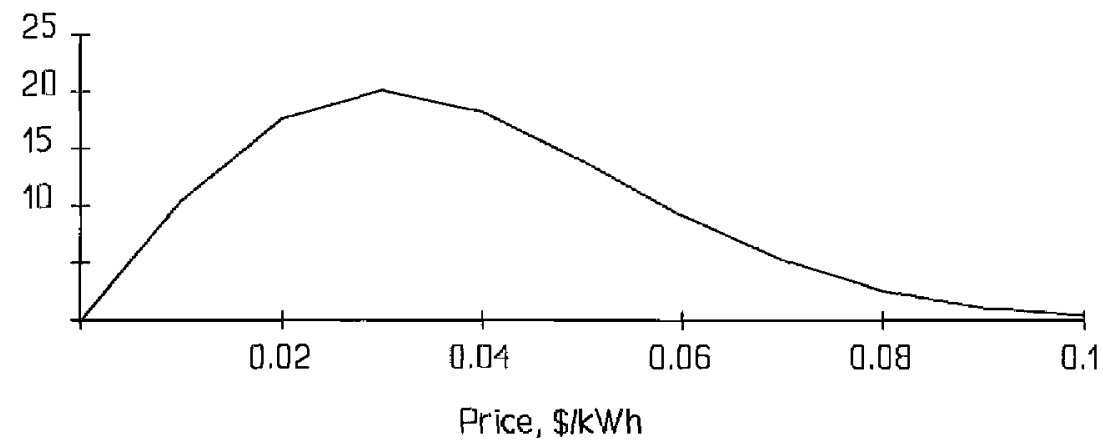

Figure 2-1. Probability density

\footnotetext{
${ }^{16}$ Technically, the probability of a random variable taking on any exact value (e.g., exactly 1.0 ) is zero. However, the probability of the variable lying in a small range around that value (e.g., between 0.99 and 1.01) is given by the area under the density function between those two values,

$$
\text { Probability }\left[a \_x \_b\right]=\int_{a}^{b} f(t) d t,
$$
}

where $f(\bullet)$ is the density function. 
Several advantages of this kind of representation for uncertain variables can be seen immediately. At the simplest level, presenting information in this form acknowledges that the value in question is uncertain. This recognition reduces the temptation to rely solely on detcrministic analysis--treating uncertain variables as if they were known with certainty. At the same time, developing a density function for key uncertain variables lays the foundation for an analysis that makes maximum use of the information the analyst does have about uncertain variables, imperfect as it may be. In addition, variables that have been described by probability distributions can be used as inputs to formal decision analysis.

Figure 2-2 illustrates an alternative presentation of the PDF. Here, the cumulative distribution, which corresponds to the probability density function shown in Figure $2-1$, is displayed. ${ }^{17}$ Figures $2-1$ and $2-2$ capture the uncertainty in a single variable. However, there will frequently be more than one uncertain variable in an economic evaluation. The (joint) density function of $\mathbf{r}$ such random variables could be represented by a graph similar to Figure $2-1$ but with $r+1$ dimensions instead of 2 . Often the uncertainty in one variable will be related to the uncertainty in another variable. For example, in the cconomic evaluation of a dual fuel combustion turbine capable of burning natural gas or oil, the price of the two fuels may be uncertain, and, some would argue, highly correlated. Economic evaluations with such a correlated or dependent ${ }^{18}$ variable must explicitly consider such correlation.

Variability can also be captured by the density and cumulative distribution functions of Figures 2-1 and 2-2. The magnitude of the density function is a function of the frequency with which the variable takes on each value over the population. For example, a density function portraying regional variations in the price homeowners pay for electricity will have its peak at the most frequently occurring price. Although there are some important distinctions between variability and uncertainty that can require different treatments, the steps described below for economic evaluations under uncertainty can also be applied to economic evaluations with inputs that vary over the population (c.g., variation in the consumer price of compact fluorcscent light bulbs).

${ }^{17}$ The probability density function and cumulative distributions contain exactly the same information. One can be derived from the other by means of the relationship

$$
\operatorname{Probabijity}(\leq T) \equiv \mathrm{F}_{s}(T)=\int_{-\infty}^{T} f(\tau) d \tau
$$

where $\mathrm{F}_{s}(\cdot)$ is the cumulative distribution and $\mathrm{f}(\cdot)$ is the probability density function. In the other direction, the relationship between these two functions is simply

$$
f(t)=\left.\frac{d F_{s}(\tau)}{d \tau}\right|_{\tau=t}
$$

${ }^{18} \mathrm{~A}$ pair of random (uncertain) variables $\mathrm{x}_{1}, \mathrm{x}_{2}$ are said to be independent if their joint density functions can be represented as the product of their individual (marginal) density functions as follows:

$$
f\left(x_{1}, x_{2}\right)=f\left(x_{1}\right) \cdot f\left(x_{2}\right)
$$

Where $f\left(x_{1}, x_{2}\right)$ is the joint density function over $x_{1}$ and $x_{2}$ taken together, and $f\left(x_{1}\right)$ and $f\left(x_{2}\right)$ are the marginal densities of the variables individually. Variables that are not independent are said to be dependent. The concept of independence generalizes in a straightforward way to sets of more than two variables. 


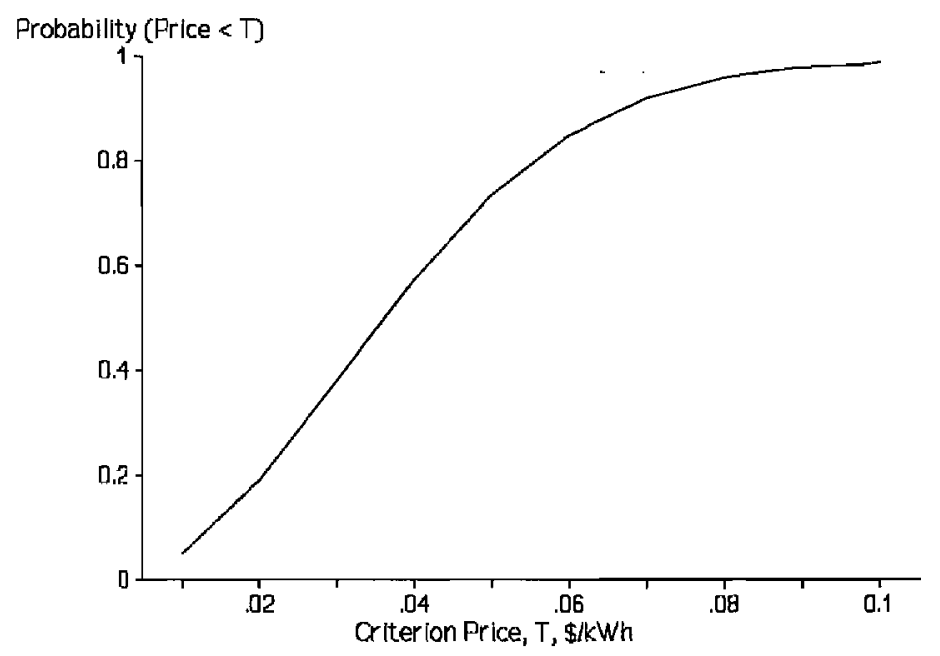

Figure 2-2. Cumulative distribution

Four steps should be taken to characterize the uncertainty in the economics of a given project.

1. Determine the economic measures.

2. Determine the parameters that cause the most varialion in the economic measures.

3. Assess probability for each critical parameter.

4. Determine the probability distribution.

The first step determines which economic measure or measures will be used for the evaluation (e.g., total life-cycle cost, levelized cost of energy, internal rate of return, and so on). The second step, known as deterministic sensitivity analysis, involves varying the project parameters over judgmentally determined ranges to reveal which parameters cause the most variation in the economic measure. In addition to identifying the most sensitive inputs, sensitivity analysis also provides insights into the range of possible outcomes and their likelihood.

For example, suppose that an organization is considering an investment in an independent power project. It is estimated that the plant will sell $1,500,000 \mathrm{kWh}$ annually at 4.0 cents per $\mathrm{kWh}$. This will generate $\$ 60,000$ in annual revenues. Annual operation and maintenance (O\&M) is estimated to be $\$ 20,000$. Thus, annual profit will be $\$ 40,000$. The initial plant investment will be approximately $\$ 250,000$ and last for 15 years. Discounting these constant dollar cash flows over a 15 -year life at a $6.0 \%$-real rate equates to a project NPV of $\$ 138,490$.

Suppose that the values used for the economic analysis are considered "most likely" and that several of the variables used for determining the NPV are uncertain. A sensitivity analysis to determine which of the uncertain variables significantly affects the results should be performed.

Table 2-9 illustrates the process of deterministic sensitivity applied to these variables. In the table, the "most likely" values for the parameters, as illusirated in the previous example, are depicted as the base case. In the last four columns, one variable at a time is varied - in the direction that will decrease NPV (indicated by highlighting). The range over which the values are varied is detcrmined simply by expert 
Table 2-9. Variables for the Example of Deterministic Sensitivity Analysis

\begin{tabular}{|c|c|c|c|c|c|}
\hline Parameters & $\begin{array}{c}\text { Base } \\
\text { Case } \\
\text { (Most } \\
\text { likely) }\end{array}$ & $\begin{array}{l}\text { Quantity } \\
\text { Varied }\end{array}$ & $\begin{array}{l}\text { Price } \\
\text { Varied }\end{array}$ & $\begin{array}{c}\text { O\&M } \\
\text { Varied }\end{array}$ & $\begin{array}{c}\text { Initial } \\
\text { Investment } \\
\text { Varied }\end{array}$ \\
\hline Quantity - kWh & $1,500,000$ & $100000 \%$ & $1,500,000$ & $1,500,000$ & $1,500,000$ \\
\hline Price $-\$ / k W h$ & $\$ 0.04$ & $\$ 0.04$ & $\$ 0 \% 3$ & $\$ 0.04$ & $\$ 0.04$ \\
\hline Annual Revenue & $\$ 60,000$ & $\$ 40,000$ & $\$ 45,000$ & $\$ 60,000$ & $\$ 60,000$ \\
\hline Annual $O \& M$ & $\$ 20,000$ & $\$ 20,000$ & $\$ 20,000$ & $\$ 28000$ & $\$ 20,000$ \\
\hline Annual Profit & $\$ 40,000$ & $\$ 20,000$ & $\$ 25,000$ & $\$ 38,000$ & $\$ 40,000$ \\
\hline PV(Profit) & $\$ 388,490$ & $\$ 194,245$ & $\$ 242,806$ & $\$ 369,065$ & $\$ 388,490$ \\
\hline Initial Investment & $\$ 250,000$ & $\$ 250,000$ & $\$ 250,000$ & $\$ 250,000$ & $\$ 275,000$ \\
\hline NPV & $\$ 138,490$ & $(\$ 55,755)$ & $(\$ 7,194)$ & $\$ 119,065$ & $\$ 113,490$ \\
\hline
\end{tabular}

judgment. Over these ranges, as illustrated, NPV is quite sensitive to price and quantity, and not very sensitive to $O \& M$ costs or project capital costs.

One useful extension of this type of sensitivity analysis for an individual variable is scenario analysis. Scenario analysis better defines the range of possible outcomes by deterministically varying a number of dependent variables simultaneously to allow for their correlations. For example, if the level of annual O\&M was related to the level of annual $\mathrm{kWh}$ sales, it would make sense to vary both parameters simultaneously to account for this interdependency.

The third step, probability assessment, is required only for those parameters to which the project economics are sensitive. In this step, each of the critical parameters is described in terms of a probability density function or its equivalent, and correlations between dependent variables must be determined. (An introduction to the practice of both deterministic sensitivity and probability encoding can be found in Howard 1977; 1990.) In our example, the deterministic sensitivity analysis indicated that the model is sensitive to price and quantity. Figure $2-1$ gave an example density function for price in this simple model. A density function for quantity must also be generated and is illustrated in Figure 2-3.

The implications of these input probabilities are worked out in the fourth and final step called change of variables. This procedure uses the given probability information about the project cost and performance parameters along with the deterministic model to determine the probability distribution governing the measure of the economic value of the project.

Several methods are available for accomplishing the change of variables. The most straightforward of these is the Monte Carlo procedure, in which the deterministic model is run a number of times, sampling from the input distributions (of all the random variables) each time to build up histograms that approximate the distributions of the measures of economic value (Hammersley 1965). Some shortcuts, such as Latin Hypercube Sampling, can be used to reduce the number of model runs that would be 


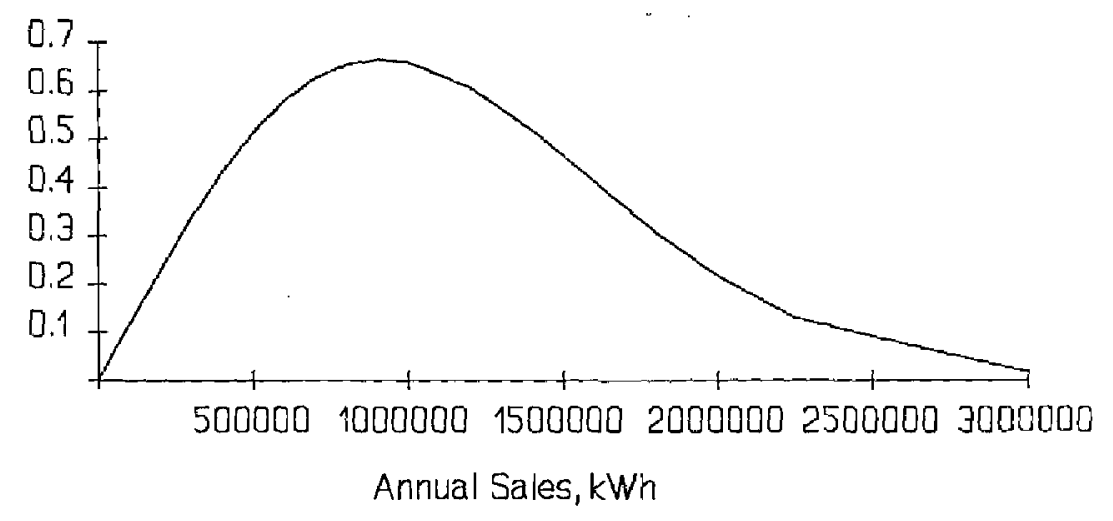

Figure 2-3. Probability distribution over quantity

required for Monte Carlo analysis. For economic analysis embodied in a spreadsheet, commercial add-ins are available to carry out both Monte Carlo and sampling procedures. ${ }^{19}$

The end result of these procedures will be probabilistic descriptions of the chosen economic measures applied to the project. These descriptions can be expressed in several ways, the two most common being the probability density function and the cumulative distribution, illustrated in Figures 2-1 and 2-2. The density function illustrates most directly which values of the economic value measure are more likely and how the relative likelihood changes over the range of possible values. The cumulative distribution, on the other hand, can be used directly to answer questions such as, "What is the probability that the value lies in a specified range?"

Figure 2-4 illustrates the probability distribution over the project NPV resulting from the simple model described previously. This information was generated by a commercial software package (Crystal Bail) using Monte Carlo simulation.

This analysis illustrates the importance of the probability density representation of the project's net present value. Looking at the project economics when all the variables are set at nominal values indicates a substantially positive NPV. However, the sensitivity analysis reveals the possibility that uncertainties in price and quantity could lead to a negative NPV. The summary in Figure 2-4 is the most revealing. The most likely values of NPV, as it turns out, are the negative ones. The cumulative distribution curve of Figure 2-4 would reveal that the odds are less than fifty-fifty of achieving a positive NPV. Even in this drastically oversimplified model, it would have been difficult to foresee this conclusion from the basic information about input variables.

\footnotetext{
${ }^{19}$ Crystal Ball, distributed by Decisioneering Software, Lakewood, Colorado, is one example of add-in software for performing uncertainty analysis. This package is an add-in for Excel and was used to develop the example shown in Figure 2-4.
} 


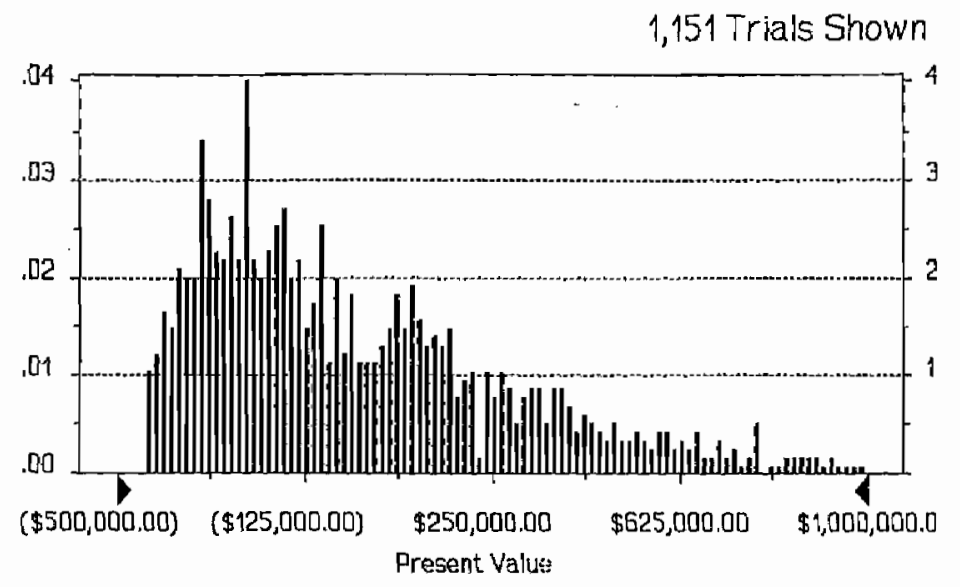

Figure 2-4. Profit forecast frequency chart

\section{Modeling Behavior of Others Under Uncertainty}

As mentioned in the previous section, uncertainty can arise when trying to predict the economic decisions or actions of others (e.g., how will electricity consumers react to an increase in electricity price). The normative approach to this modeling issue would be to assume that all parties within the population use the equivalent of decision analysis.

There are at least two major problems with this approach. First, the application of decision analysis within a market model would generally involve far too much effort to be practical. More importantly, there is considerable evidence that energy consumers often behave very differently from the strict economic rationality assumption taken in the normative model.

It is fair to say that no truly satisfactory solution to this modeling problem has emerged. Most common approaches begin with some kind of normative model and then adjust it in some way to make it better match observed data on consumer choice. For example, logit models are one way of handling the observed fact that the cheapest source does not capture 100\% of the market (Packey 1993). Multinomial logits can account for decision makers' consideration of factors other than simply the economic value of an investment while capturing the uncertainties and variabilities of decision makers and investments.

Another means of represcnting consumer behavior that deviates from the normative model is to increase the discount rate that consumers in the model use to evaluate energy equipment purchase decisions. Two rationales are commonly used for this approach. First, higher discount rates make projections of consumer choices look more like the observed data on these choices. However, such model projections still have trouble comparing well with observed data because factors other than energy costs are critical in purchase decisions.

Second, such higher discount rates are often used as an adjustment to capture the risk inherent in an investment. The risk-adjusted discount rate argument proceeds as follows. Investments in energy efficiency or renewable energy can be risky. One response to the evaluation of risky investments is the use of a discount rate higher than the one that is appropriate for risk-free investments (a risk-adjusted discount rate). Thus, the risk assumed by making investments that do not produce the anticipated returns is offset by investments producing this higher adjusted rate of return. 
There is considerable controversy in the financial community regarding the appropriateness of a riskadjusted discount rate approach. Increasing the discount rate is a poor substitute for explicitly capturing the uncertainty in input variables. Not only is the risk-adjusted discount rate approach inappropriate for EE analysis, but the extent of its use in others' evaluation of energy investments is not known. Thus, using it to simulate others' investment decisions is questionable. 


\section{Selection Criteria Guide}

This section presents some different measures of the economic value of an investment. The choice of which measure is used to evaluate an investment is determined by several factors. These factors include the investor's perspective, regulation, risk, financing, cash flow, comparison of mutually exclusive alternatives, similarity of alternatives' benefits, whether the investment is fully defined in terms of its size and use, and so forth. Most of the economic measures are valid for most investments, and it is usually a good idea to compute several of the measures to better evaluate the investment. However, certain measures are clearly inappropriate for some investments. The use of the internal rate of return to compare two projects with significantly different returns over time, for example, may result in inappropriate assumptions regarding the rate of return available through reinvestment of the cash inflow.

Table 3-1 is a quick reference for identifying the appropriate economic measure for different investment features and decision criteria. Letters in the table indicate whether the measure is recommended, generally not recommended, or commonly used. A blank cell signifies that the measure is acceptable. An " $R$ " signifies that the measure is recommended. However, this does not mean that the other economic measures are inappropriate. On the other hand, an " $N$ " means that the measure is generally not recommended and may yield incorrect results and conclusions. Finally, " $\mathrm{C}$ " denotes that the measure is commonly used to cvaluate investments with the specific feature. Inasmuch as each investment and investor is different, the best measures to use cannot be categorically stated within a matrix as simple as this onc. This matrix is simply a quick reference from which the reader can identify those measures he or she may want to investigate thoroughly.

To be more explicit, the entries in the matrix should be viewed as general rules for which there will be many exceptions. For example, according to the investment decisions portion of the matrix, (TLCC) and revenuc requirements (RR) are not listed as "recommended" for any decisions. Yet these two measures are clearly applicable for those cases in which the energy services provided by the alternatives are identical, or in which the energy service must be sccured and cost is, therefore, the only issue. These measures are not recommended in general simply becausc they do not consider benefits or returns.

A more detailed description of investment features and decision criteria in the matrix is in the next scction. Included is a description (definition) of each of the terms identificd as investment features and decisions. Also included is an explanation of each of the entries contained in the economic measure matrix; e.g., why was IRR recommended as opposed to not recommended for different investment features and decisions. In addition, each economic measure discussed includes a brief discussion of its use (whether recommended, commonly used, or not recommended) for different investment features and decisions. The matrix cannot include all possible investment feature and decision possibilities; nor can it include all possible combinations, e.g., acceptance or rejection of a mutually exclusive regulated investment.

\section{Explanations for the Economic Evaluation Measures Matrix}

\section{Investment Features}

Investment after return: A significant investment (net negative cash flow in the year) is required after the investor has received some cash inflow from the project.

Explanation of Entries: IRR is not recommended because a net negative investment after a positive return can result in multiple positive IRR values, and because downstream investments are improperly discounted, i.e. at the IRR and not at the investor's discount rate. MIRR is acceptable because it avoids both of these problems with IRR. 
Table 3-1. Overview of Economic Measures Applying to Specific Investment Features and Decisions ${ }^{a}$

\begin{tabular}{||l|l|l|l|l|l|l|l|l|l|l||}
\hline \multicolumn{1}{|c|}{ Investment Features } & NPV & TLCC & RF & LCOE & IRR & MIRR & SPB & DPB & B/C & SIR \\
\hline Investment after return & & & & & N & & & & & \\
\hline Fegulated investment & & & R & & & & & & & \\
\hline Financing & & & & & & & $\mathrm{N}$ & $\mathrm{N}$ & & $\mathrm{N}$ \\
\hline Risk & & & & & & & $\mathrm{C}, \mathrm{R}$ & $\mathrm{R}$ & & \\
\hline Social costs & $\mathrm{C}, \mathrm{R}$ & & & & & & & & $\mathrm{C}, \mathrm{H}$ & \\
\hline Taxes & & & & & & & $\mathrm{N}$ & $\mathrm{N}$ & & \\
\hline Combinations of investments & & & & & & & & & & \\
\hline
\end{tabular}

\begin{tabular}{||l|c|c|c|c|c|c|c|c|c|c||}
\hline \multicolumn{1}{|c|}{ Investment Decisions } & NPV & TLCC $^{\mathbf{b}}$ & RR $^{\mathbf{b}}$ & LCOE & IRR $^{\mathbf{b}}$ & MIRR & SPB & DPB & B/C & SIR \\
\hline Accept/reject & & $\mathrm{N}$ & $\mathrm{N}$ & & $\mathrm{C}$ & & & & & \\
\hline $\begin{array}{l}\text { Select from mutually exclusive } \\
\text { alternatives }^{b}\end{array}$ & $\mathrm{R}$ & $\mathrm{C}$ & & $\mathrm{N}$ & $\mathrm{N}$ & $\mathrm{N}$ & $\mathrm{N}$ & $\mathrm{N}$ & $\mathrm{N}$ & $\mathrm{N}$ \\
\hline $\begin{array}{l}\text { Ranking } \\
\text { (Limited budget) }\end{array}$ & & & & & & & & & & \\
\hline
\end{tabular}

R - Recommended

$\mathrm{N}$ - Not recommended

C. Commonly Used

A blank cell indicates that the measure is acceptable.

a. This table is intended to serve only as a rough guideline by which an analyst can identify those measures that warrant further investigation. Exceptions to each of the entries will occur.

b. Text discusses some of the exceptions.

\section{Economic Measures}

NPV - Net present value

TLCC - Total life-cycle cost

LCOE - Levelized cost of energy

RR - Revenue requirements

IRR - Internal rate of return
MIAR - Moditied internal rate of return

SPB - Simple payback period

DPB - Discounted payback period

$B / C$ - Benefit-to-cost ratio

SIR - Savings-to-investment ratio 
Regulated investment: The recovery of costs of an investment are regulated by a state or federal regulatory body.

Explanation of Entries: Required revenues are recommended because this is normally the basis on which such investments are defended to the regulators.

Financing: This entry refers to the evaluation of investments requiring project-specific debt financing (as opposed to those capitalized only through equity financing or corporate debt financing, accounted for by the discount rate, which reflects the cost of both equity and debt.)

Explanation of Entries: Payback measures may be used to get a quick sense of a project ignoring the financing. However, the explicit consideration of financing significantly complicates the analysis, eliminating the simplicity advantages of these measures. Thus, payback measures are not recommended when financing is to be explicitly considered. The savings-to-investment ratio is also not recommended because of the issue of whether the investment is defined as only the equity portion of the investment or the total investment.

Risk: All investments pose some risk that they will not provide the promised returns. For those investments with significant uncertainties, risks should be explicitly considered.

Explanation of Entries: Payback measures are recommended because they provide a quick assessment of the duration of the period during which the investor's capital is at risk. More formal evaluation of risk (e.g., decision analysis), as described in the manual, is also recommended.

Social costs: The full cost of an alternative, including both direct costs such as capital costs and O\&M costs as well as external costs such as environmental costs, i,e., all costs incurred by society are considered.

Explanation of Entries: Net present valuc and benefit/cost ratios are acceptable and are commonly used for the evaluation of investments from a social perspective, and therefore, are recommended measures.

Taxes: Taxes affect the value of most invesiments and should therefore be considered explicitly in all but the most rudimentary analyses. Taxes to be considered include state and federal income taxes, property taxes, and so forth.

Explanation of Entries: Inclusion of taxes in payback calculations complicates the analysis, eliminating the simplicity advantages of payback measures. Therefore, payback measures are not recommended.

Combinations of investments: Occasionally an investment in one energy technology will have an impact on the cost, performance, or value of another energy investment. For example, the use of additional insulation in a building's walls will decrease the value of a more efficient furnace. In these cascs, the investments should be cvaluated as a combined system, i.e., as a single investment, with the cost, perlormance, and value reflecting the attributes of the combined system.

Explanation of Entries: All measures are acceptable subject to the other considerations, as given for the other investment features and types of decisions.

\section{Investment Decisions}

Accept/reject: A single investment is under consideration. It can either be accepted or rejected. 
Explanation of Entries: TLCC and RR are not recommended because they provide no frame of reference as to what are acceptable costs and they do not consider benefits and returns. IRR is acceptable (within the constraints mentioned in the Investment Features portion of the matrix) and is commonly used for many accept/reject decisions because it allows a quick comparison with a minimum acceptable rate of return (hurdle rate) that represents the opportunity cost of capital to the investor.

Select from mutually exclusive alternatives: Only one set of investments can be selected. This might occur because the investments comprise different methods or designs for providing the same service or because different size systems are being considered to provide different levels of the same kind of service.

Explanation of Entries: If the returns and benefits are the same for all alternatives, then any one of the measures is acceptable. However benefits frequently vary in terms of the time of major returns, unequal lifetimes, services, or output. Because the choice of one alternative precludes taking advantage of the other alternatives, most measures are not recommended because they fail to recognize the difference in the size of the investments (e.g. LCOE, IRR, MIRR, payback, B/C, SIR); a large investment allows the investor to invest more of his or her assets at a favorable return (incremental analysis of the larger investment compared to the smaller investment can rectify this shortcoming of these mcasures). TLCC and RR are not listed as "recommended" because they do not explicitly consider returns and benefits. TLCC is commonly used to choose between energy efficiency investments that provide identical benefits. NPV is recommended because it explicitly detcrmines the value by giving larger projects credit for potentially larger returns.

Ranking: Ranking of investment alternatives is used to select one or more investments from a set of nonmutually exclusive investment alternatives. Usually the selections are constrained by budget, cash flow, or other resources. The objective of the analysis is to select the set of investments that will maximize the value to the investor from his or her available investment funds.

Explanation of Entries: TLCC and RR are not listed as "recommended" because they do not explicitly consider benefits and returns. IRR is not recommended because it implicitly assumes reinvestment of returns at the IRR, and therefore, overvalues projects with early returns. Unless risk is a major consideration, payback methods are not recommended because they ignore returns after payback. NPV is acceptable but requires the evaluation of cach combination of different investments that meets the resource constraints. LCOE, MIRR, B/C, and SIR are recommended because they provide the proper ranking of projects, which are then selected in the order of their rank until the resource budget is cxhausted. ${ }^{20}$

\footnotetext{
${ }^{20}$ For analyses in which the sum of the investment costs (i.e., resource requirements) of the high priority investments do not sum exactly to the budget (i.e., resource constraint), there is a possibility that some other combination of the low priority tasks that uses a larger portion of the budget will provide more value to the investor. For a small set of investment alternatives, the analyst can usually identify the optimum set by inspection of or by computing the NPV for all combinations; for larger numbers of alternatives, integer linear programming can be used.
} 


\section{Economic Measures}

This section includes an overview of the procedures involved when developing net present value (NPV), total life-cycle cost (TLCC), levelization, unadjusted and modified internal rate of return, simple payback (SPB), discounted payback (DPB), benefit/cost (B/C) ratios; savings/investment ratios (SIR), B/C ratios related to integrated resource planning, and consumer/producer surplus analyses. Evaluation software (the diskette is provided with this manual) has been developed to help analysts tackle investment problems that are traditionally difficult to evaluate manually. The evaluation software automates the exact equations for the first eleven economic measures in this section. It is hoped that this program will improve the speed and precision with which analysts apply the methods and procedures in this section.

The sclection criteria guide presented in the previous section relates to this section by suggesting which economic measures are most appropriate for a specific analysis. Different economic measures apply to different situations, and it is generally a good idea to use several when evaluating an investment.

The economic measures described in detail in this section can be used to compare alternative investments or projects. The methods for using these measures as comparison tools are fairly straightforward and are covered in more detail in the specific section dedicated to the measure. For example, cost-effective alternatives are those with the lowest TLCC, revenue requirements (RR), LCOE, SPB, and DPB; and the highest NPV, internal rate of return (IRR), modified internal rate of return (MIRR), B/C, and SIR. However, the analyst should be aware that when comparing alternatives, different measures may not always provide the same answer. For example, simple payback requirements reject an alternative that, while having a longer payback pcriod, has strong long-term returns.

Sometimes the objective of an evaluation will be to find the most cost-effective combination of separate investments. If the objective is to determine the most cost-effective combination of air-conditioner size and amount of insulation, then each combination should be evaluated collectively, not on a component-

by-component basis, because separate components of the combinations affect one another. So, when considering a more efficient air conditioner and the upgrading of insulation, the most cost-effective alternative is probably a combination of improvements to both the air conditioner and the insulation (Ruegg and Petersen 1987).

\section{Net Present Value}

\section{Introduction}

The NPV of a project is one way of examining costs (cash outflows) and revenues (cash inflows) together (Palm and Qayum 1985). A NPV analysis can be composed of many different cost and revenue streams. The analyst must know the form of the different streams (current or constant dollars), so the correct discount rate can be used for the present value analysis. Alternatively, the cash flows can be adjusted to reflect the form of the discount rate.

NPV analysis is recommended when evaluating investment features and decisions such as mutually exclusive projects and social costs. With mutually exclusive projects, NPV does not fail to recognize the difference in the size of investment alternatives (i.e., a large investment allows the investor to invest more at a favorable return). For social costs, NPV is not only acceptable but is commonly used when evaluating investments from a societal perspective. It is also recommended that NPV be used in most other evaluations as well, specifically as a secondary measure to check the validity of any primary measure used. 


\section{Discussion}

The formula for NPV can be expressed as:

$$
N P V=\sum_{n=0}^{N} \frac{F_{n}}{(1+d)^{n}}=F_{0}+\frac{F_{1}}{(1+d)^{1}}+\frac{F_{2}}{(1+d)^{2}}+\ldots+\frac{F_{N}}{(1+d)^{N}}
$$

Where:

$$
\begin{array}{ll}
\mathrm{NPV} & =\text { net present value } \\
\mathrm{F}_{\mathrm{n}} & =\text { net cash flow in year } \mathrm{n} \\
\mathrm{N} & =\text { analysis period } \\
\mathrm{d} & =\text { annual discount rate. }
\end{array}
$$

For example, assume an investment of $\$ 10,000$ made at the beginning of the year, no salvage value, and $O \& M \operatorname{costs}^{21}$ of $\$ 1,300$ in year zero, inflating at an assumed inflation rate of $3 \%$ per year thereafter. Furthermore, assume that the investment is not replaced, a 5-year double-declining depreciation schedule, a marginal federal income tax rate of $34 \%$, no state income tax, and a nominal discount rate of $12 \%$. In

\begin{tabular}{|c|c|c|c|c|c|c|c|}
\hline Year & $\begin{array}{l}\text { Investment } \\
\text { (a) }\end{array}$ & $\begin{array}{c}\text { O\&M Costs } \\
\text { (b) }\end{array}$ & $\begin{array}{l}\text { Revenues } \\
\text { (c) }\end{array}$ & $\begin{array}{c}\text { Depreciation } \\
\text { (d) }\end{array}$ & $\begin{array}{l}\text { Net Taxable } \\
\text { Income } \\
\text { (e) }=\text { (c-b-d) }\end{array}$ & $\begin{array}{c}\text { Federal } \\
\text { Income Tax } \\
(f)=\text { extax }\end{array}$ & $\begin{array}{c}\text { After-Tax } \\
\text { Cash Flow } \\
(\mathrm{g})=(c-a-b-f)\end{array}$ \\
\hline 0 & $\$ 10,000$ & $\$ 0$ & $\$ 0$ & $\$ 0$ & NA & NA & $\$-10,000$ \\
\hline 1 & 0 & 1,339 & 10,300 & 4,000 & $\$ 4,961$ & $\$ 1,687$ & 7,274 \\
\hline 2 & 0 & 1,379 & 10,079 & 2,400 & 6,300 & 2,142 & 6,558 \\
\hline 3 & 0 & 1,421 & 10,108 & 1,440 & 7,247 & 2,464 & 6,223 \\
\hline 4 & 0 & 1,463 & 10,130 & 1,080 & 7,587 & 2,580 & 6,087 \\
\hline 5 & 0 & 1,507 & 10,434 & 1,080 & 7,847 & 2,668 & 6,259 \\
\hline
\end{tabular}
addition, the investment produces 1000 units of energy in the first year of operation, 950 in the second, 925 in the third, and 900 in the fourth and fifth. The encrgy is sold for $\$ 10$ a unit in year zero, inflating at 3\% per year thereafter. Table 4-1 illustrates the current dollar after-tax cash flow calculation.

Table 4-1. Calculation of Current Dollar After-Tax Cash Flow

After-tax cash flows are now applied to the NPV formulation (discounted at $12 \%$ ) to calculate the NPV as shown in Table 4-2.

\footnotetext{
${ }^{21}$ For the purposes of this manual, O\&M represent annual operating, maintenance, and fuel expenses.
} 
Table 4-2. Net Present Value of Current Dollar Cash Flows

\begin{tabular}{|c|c|c|c||}
\hline \hline Period & Cash Flow & $\begin{array}{c}\text { Present Value } \\
\text { Interest Factor } \\
\text { (PVIF) }\end{array}$ & Present Value \\
\hline 0 & $\$(10,000)$ & & $\$(10,000)$ \\
1 & 7,274 & 0.8929 & 6,495 \\
2 & 6,558 & 0.7972 & 5,228 \\
3 & 6,223 & 0.7118 & 4,430 \\
4 & 6,087 & 0.6355 & 3,868 \\
5 & 6,259 & 0.5674 & 3,551 \\
& & & NPV $=\$ 13,572$ \\
\hline
\end{tabular}

The positive NPV of $\$ 13,572$ shows that the investment is economical. The investor would have been indifferent as to whether to make the investment had the NPV been zero, whereas a negative NPV would have indicated that the returns are worth less than the initial cash outflow and the investment is not a good one.

The results of this example would have been the same if constant dollars had been used instead of current dollars. For example, assume the same parameters as those in the previous example, except this time assume constant dollar O\&M costs $(\$ 1,300$ per year in base year dollars) and a constant dollar sales price ( $\$ 10$ per unit in base year dollars). Because depreciation in each year is calculated as a percentage of the initial investment, it is necessary to convert cash flows for depreciation from current to constant dollars using the inflation rate; i.e., constant depreciation ${ }_{n}=$ current depreciation $_{n} \times(1 \text { - inflation rate })^{n}$. Table 4-3 illustrates the constant dollar after-tax cash flow.

Table 4-3. Constant Dollar After-Tax Cash Flow

\begin{tabular}{|c|c|c|c|c|c|c|c|}
\hline Year & $\begin{array}{c}\text { Investment } \\
\text { (a) }\end{array}$ & $\begin{array}{c}\text { O\&M } \\
\text { Costs } \\
\text { (b) }\end{array}$ & $\begin{array}{l}\text { Revenues } \\
\text { (c) }\end{array}$ & $\begin{array}{c}\text { Depreciatlon } \\
\text { (d) }\end{array}$ & $\begin{array}{l}\text { Net Taxable } \\
\text { Income } \\
\text { (e) }=\text { (c-b-d) }\end{array}$ & $\begin{array}{c}\text { Federal } \\
\text { Income Tax } \\
\text { (f) }=(e \times \text { tax })\end{array}$ & $\begin{array}{c}\text { After-Tax } \\
\text { Cash Flow } \\
(g)=(c-a-b-f)\end{array}$ \\
\hline 0 & $\$ 10,000$ & $\$ 0$ & $\$ 0$ & $\$ 0$ & NA & NA & $\$-10,000$ \\
\hline 1 & 0 & 1,300 & 10,000 & 3,880 & 4,820 & 1,639 & 7,061 \\
\hline 2 & 0 & 1,300 & 9,500 & 2,258 & 5,942 & 2,020 & 6,180 \\
\hline 3 & 0 & 1,300 & 9,250 & 1,314 & 6,636 & 2,256 & 5,694 \\
\hline 4 & 0 & 1,300 & 9,000 & 956 & 6,744 & 2,293 & 5,407 \\
\hline 5 & 0 & 1,300 & 9,000 & 927 & 6,773 & 2,303 & 5,397 \\
\hline
\end{tabular}

After-tax cash flows are now applied to the NPV formulation-discounted at $8.74 \%$; i.e., $\Gamma(1+$ nominal discount rate $) /(1+$ inflation rate $)]-1=1.12 / 1.03-1=8.74-$ to calculate NPV, as shown in Table 4-4. 
Table 4-4. Net Present Value of Constant Dollar Cash Flows

\begin{tabular}{|c|c|c|c||}
\hline \hline Period & Cash Flow & $\begin{array}{c}\text { Present Value } \\
\text { Interest Factor } \\
(\mathbf{1} / \mathbf{1}+\mathbf{d})\end{array}$ & Present Value \\
\hline 0 & $\$(10,000)$ & & $\$(10,000)$ \\
\hline 1 & 7,061 & 0.9196 & 6,495 \\
\hline 2 & 6,180 & 0.8457 & 5,228 \\
\hline 3 & 5,694 & 0.7777 & 4,430 \\
\hline 4 & 5,407 & 0.7152 & 3,868 \\
\hline 5 & 5,397 & 0.6577 & 3,551 \\
\hline
\end{tabular}

The NPV calculation results in the same answer regardless of the dollar basis. This will always be the result if proper discount rates are applied to appropriate cash flows.

Although the positive NPV indicates that this is a good investment, the analyst must be carcful because good investments are not necessarily the best ones. Refer to Section 3, Selection Criteria Guide, for guidance as to the appropriate application of economic measures to use for different investment types.

\section{Total Life-Cycle Cost}

\section{Introduction}

Total life-cycle cost (TLCC) analysis is used to evaluate differences in costs and the timing of costs between alternative projects. TLCCs are the costs incurred through the ownership of an asset over the asset's life span or the period of interest to the investor (Brown and Yanuck 1980). Only those costs relevant to the decision should be included in the analysis. TLCC analysis considers all significant dollar costs over the life of the project. These costs are then discounted to a base year using present value analysis. Any revenue generaled from the resale of the investment is also discounted to the base year and subtracted from present value costs.

TLCC is not recommended for economic evaluation to decide whether to accept or reject an investment because TLCC provides no frame of reference for what are acceptable and unacceptable costs, and TLCC does not address benefits and returns. TLCC can be used for ranking or selecting among mutually exclusive alternatives that provide exactly the same benefits and returns.

TLCC analysis is composed of many different costs, and, as with NPV analysis, the analyst must know the form of the cash flows (current or constant dollars), so the correct discount rate can be applied. If the cash flows are not discounted using appropriate rates, the analysis will be flawed. 


\section{Discussion}

Analyses associated with the governmental sector, nonprofit organizations, or the owner-occupant residential sector do not need to include income taxes because the government and nonprofit organizations do not pay income taxes and residential customers make investments for the service those investments provide to them, not to generate taxable profits (unless financed with home mortgage or home equity funding). Normally, analyses associated with one of these aforementioned groups will include life-cycle cost, whereas private industry will be more concerned with the NPV of a particular investment. The formula for calculating TLCC is as follows:

$$
\operatorname{TLCC}=\sum_{n=0}^{N} \frac{C_{n}}{(1+d)^{n}}
$$

Where:

$$
\begin{array}{ll}
\text { TLCC }= & \text { present value of the TLCC } \\
\mathrm{C}_{\mathrm{n}}= & \text { cost in period } \mathrm{n}: \text { investment costs include finance charges as appropriate; expected } \\
& \text { salvage value; nonfuel O\&M and repair costs; replacement costs; and energy costs } \\
\mathrm{N} & =\text { analysis period } \\
\mathrm{d} & =\text { annual discount rate. }
\end{array}
$$

As an example, in addition to the parameters assumed in the previous NPV example, assume that the investor is a nonprofit organization with an investment of $\$ 10,000$; no salvage value; and $0 \& M$ costs of $\$ 1,300$ in year zero, inflating at an assumed inflation rate of $3 \%$ per year thereafter. Also assume the investment is not replaced, no income taxes, and a nominal discount rate of $12 \%$. Table $4-5$ illustrates this cxample.

Table 4-5. Current Dollar TLCC Evaluation

\begin{tabular}{|c|c|c|c|c||}
\hline Year & Investment & $\begin{array}{c}\text { Discounted } \\
\text { Investment }\end{array}$ & $\begin{array}{c}\text { Current } \\
\text { Dollar } \\
\text { O\&M Costs }\end{array}$ & $\begin{array}{c}\text { Discounted O\&M } \\
\text { Costs } \\
\text { (w/ 12\% nominal) }\end{array}$ \\
\hline 0 & $\$ 10,000$ & $\$ 10,000$ & $\$ 0$ & $\$ 0$ \\
1 & 0 & 0 & 1,339 & 1,196 \\
2 & 0 & 0 & 1,379 & 1,100 \\
3 & 0 & 0 & 1,421 & 1,011 \\
4 & 0 & 0 & 1,463 & 930 \\
5 & 0 & 0 & 1,507 & 855 \\
\hline NPV & & $\$ 10,000$ & & $\$ 5,091$ \\
\hline TLCC $=\$ 15,091$ &
\end{tabular}

The TLCC for the example in Table 4-5 is $\$ 15,091$. As with NPV, this result is the same whether calculated using current or constant dollars, but the discount rate and cash flows will be different. In year zero constant dollars, annual O\&M costs are $\$ 1,300$, which must be discounted the real discount rate of $8.74 \%$ 
Table 4-6. Constant Dollar TLCC Evaluation

\begin{tabular}{||c|c|c|c|c||}
\hline Year & Investment & $\begin{array}{c}\text { Discounted } \\
\text { Investment }\end{array}$ & $\begin{array}{c}\text { Constant Dollar } \\
\text { O\&M Costs }\end{array}$ & $\begin{array}{c}\text { Discounted } \\
\text { O\&M Costs } \\
\text { (w/ 8.74\% real) }\end{array}$ \\
\hline 0 & $\$ 10,000$ & $\$ 10,000$ & $\$ 0$ & $\$ 0$ \\
1 & 0 & 0 & 1,300 & 1,196 \\
2 & 0 & 0 & 1,300 & 1,100 \\
3 & 0 & 0 & 1,300 & 1,011 \\
4 & 0 & 0 & 1,300 & 930 \\
5 & 0 & 0 & 1,300 & 855 \\
\hline NPV & \multicolumn{7}{|l}{$\$ 10,000$} & & $\$ 5,091$ \\
\hline TLCC $=\$ 15,091$ &
\end{tabular}

Inasmuch as the costs associated with most conservation and renewable energy technologies can be classified as either investment costs or O\&M costs (to include fuel), the formula for TLCC for a nonprofit organization can be expressed as

$$
\mathrm{TLCC}=\mathrm{I}+\mathrm{PVOM}
$$

Where:

$$
\begin{aligned}
\mathrm{I}= & \text { initial investment } \\
\text { PVOM = } & \text { present value of all O\&M costs, or } \\
& \text { PVOM }=\sum_{n=1}^{N} O \& M_{n} /(1+d)^{n} .
\end{aligned}
$$

Analyses of investments by for-profit organizations must consider taxes in TLCC calculations. Similar to the different forms of the fixed charge rate (see the Fixed Charge Rate subsection in Section 2), TLCC can be calculated in three different ways, depending on how taxes are treated, as shown in Table 4-7.

The simplest calculation, which ignores taxes altogether, is appropriate for residential (owner-occupant), nonprofit corporations, and government investments (shown in column 1 of Table 4-7). Actual costs (after tax deductions), as shown in column 2, are appropriate for all investmenis for which taxes are relevant, and it can be assumed that the tax deductions provided by the investment can be realized against income from the investment or other sources. Column 3 expands from the after-tax costs of column 2 to the before-tax revenue required to cover those costs. These required revenues are frequently used in the utility sector and are discussed in more detail in the subsection, Revenue Requirements, in Section 4.

Returning to the previous TLCC example, suppose the firm is a private investor and income taxes are a relevant cost. Once again, assume the same parameters as in the NPV example with an investment of $\$ 10,000$ made at the beginning of the year; no salvage value; and O\&M costs of $\$ 1,300$ per year (current dollars) in year zero, inflating at $3 \%$ per year thereafter. Also assume the investment is not replaced, a 
Table 4-7. TLCC Variations

\begin{tabular}{|c|c|c|c|}
\hline & $\begin{array}{c}\text { (1) } \\
\text { No Taxes }\end{array}$ & $\begin{array}{c}\text { (2) } \\
\text { Cost After Tax } \\
\text { Deductions }\end{array}$ & $\begin{array}{c}\text { (3) } \\
\text { Before-Tax } \\
\text { Revenue Required }\end{array}$ \\
\hline Formula & $1+$ PVOM & $\begin{array}{l}\text { I - }(T \times P V D E P)+ \\
\operatorname{PVOM}(1-T)\end{array}$ & $\begin{array}{l}{[1-(T \times P V D E P)+} \\
P V O M(1-T)] /(1-T)\end{array}$ \\
\hline Application & $\begin{array}{l}\text { Residential, non- } \\
\text { profits, government }\end{array}$ & $\begin{array}{l}\text { Commercial, } \\
\text { industrial }\end{array}$ & Utility sector \\
\hline 1 & $=$ initial investment & & \\
\hline PVOM & $=$ present value O\&M costs & & \\
\hline $\mathrm{T}$ & $=$ income tax rate & & \\
\hline PVDEP & $=$ present value of depreciation & & \\
\hline
\end{tabular}

5-year double-declining depreciation schedule, a marginal federal income tax rate of $34 \%$, no state income tax, and a nominal discount rate of $12 \%$. To find the after-tax cost to the investor, the formula in column 2 can be used to calculate a TLCC of $\$ 10,705$. This is illustrated in Table 4-8.

If the for-profit investor is a ulility, the before-tax revenues required to cover the after-tax costs may be desired. In accordance with the formula in column 3 of Table 4-7, this can easily be accomplished by dividing the after-tax costs by $(1-T)$ to yield a TLCC of $\$ 16,220$.

Table 4-8. After-Tax TLCC Evaluation

\begin{tabular}{||c|c|c|c|c|c|c||}
\hline \hline Year & Investment & $\begin{array}{c}\text { Discounted } \\
\text { Investment }\end{array}$ & Depreciation & $\begin{array}{c}\text { Discounted } \\
\text { Depreciation }\end{array}$ & $\begin{array}{c}\text { O\&M } \\
\text { Costs }\end{array}$ & $\begin{array}{c}\text { Discounted } \\
\text { O\&M Costs }\end{array}$ \\
\hline 0 & $\$ 10,000$ & $\$ 10,000$ & & $\$ 0$ & $\$ 0$ \\
1 & 0 & 0 & $\$ 4,000$ & $\$ 3,571$ & 1,339 & 1,196 \\
2 & 0 & 0 & 2,400 & 1,913 & 1,379 & 1,100 \\
3 & 0 & 0 & 1,440 & 1,025 & 1,421 & 1,011 \\
4 & 0 & 0 & 1,080 & 686 & 1,463 & 930 \\
5 & 0 & 0 & 1,080 & 613 & 1,507 & 855 \\
\hline$N P V$ & \multicolumn{7}{|l|}{$\$ 10,000$} & & & $\$ 5,091$ \\
\hline TLCC $=10,000-(0.34 \times 7,809)+(5,091 \times 0.66)=\$ 10,705$ & \\
\hline
\end{tabular}

Using TLCC calculations to evaluatc the cost-effectivencss of energy efficiency investments requires calculating a TLCC both with and without the investment. For example, a 75-watt incandescent light bulb operaling 6 hours per night throughout the year will require $164.25 \mathrm{kWh}$ annually to operate. At 6 cents per $\mathrm{kWh}$ this equates to $\$ 9.86$. If it is assumed that electricity costs remain at 6 cents per $\mathrm{kWh}$ and a bulb needs replacing once a year at a cost of $\$ 1$ per bulb, a TLCC (using a $12 \%$ nominal discount rate) is 
calculated to be $\$ 39.56$ for 5 years (assuming the bulb is purchased at the beginning of each year, and the electricity is paid for at the end of each year). An alternative would be to purchase a more efficient 40watt fluorescent bulb that will last for 5 years. Under the same usage patterns as the alternative, the 40watt bulb will require $87.6 \mathrm{kWh}$ per year to operate. Assuming a $\$ 15$ initial investment and the constant 6 cents per $\mathrm{kWh}$ for purchasing the electricity, a TLCC of $\$ 33.95$ is calculated. Thus, the net savings, on a TLCC basis, of installing the more efficient 40 -watt bulb is $\$ 5.61$.

\section{Revenue Requirements}

\section{Introduction}

Revenue requirements (RRs) are often calculated in regulated industries, such as the electric power markets, for a firm (utility) as a whole. The discussion here is directed toward the revenues required to cover the costs associated with a specific project, not a firm.

The RR is the total revenue that must be collected from customers to compensate a firm for all expenditures (including taxes) associated with a project. It is actually no different than the before-tax revenue required of the TLCC outlined earlier. The RR economic measure is recommended as an appropriate measure when evaluating a regulated investment. The gencral decision rule for utilities is to choose the alternative for which the present value of the multiperiod investment revenue requirement is the lowest (assuming the services provided are identical) (Charles River Associates 1986). Businesses apply the RR method to project costs over an investment's useful life.

Bccausc RR is normally the basis on which regulated investments are defended, it is the recommended measure for evaluating such investments. $R R$ is not recommended for economic evaluation when deciding whether to accept or reject an investment because RR provides no frame of reference for what are acceptable or unacceptable costs and benefits and returns are not addressed.

\section{Discussion}

The formulation of the revenue requirements approach was laid out in the Total Life-Cycle Cost subsection in Section 4 as the before-tax revenues required, or

$$
\mathrm{RR}=\mathrm{TLCC}=\frac{1-(\mathrm{T} \times \mathrm{PVDEP})+\operatorname{PVOM}(1-\mathrm{T})}{(1-\mathrm{T})}
$$

Where:

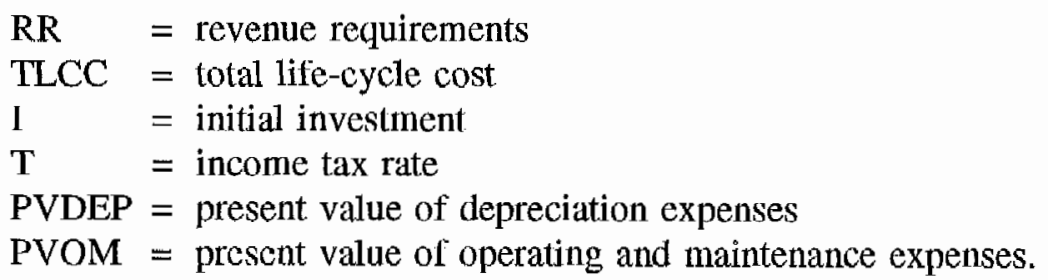

As was calculated in an example in the Total Life-Cycle Cost subsection, the before-tax required revenuc calculated was $\$ 16,220$. The same result is shown in Table 4-9 on a year-by-year basis. 
Investment decisions using revenue requirements are made by comparing the present value RR of alternatives that accomplish the same desired result. The alternative with the lowest RR is considered to be more economical.

Table 4-9. Before-Tax TLCC Evaluation

\begin{tabular}{|c|c|c|c|c|c|c|}
\hline Year & Investment & $\begin{array}{l}\text { Discounted } \\
\text { Investment }\end{array}$ & Depreciation & $\begin{array}{l}\text { Discounted } \\
\text { Depreciation }\end{array}$ & $\begin{array}{l}\text { O\&M } \\
\text { Costs }\end{array}$ & $\begin{array}{l}\text { Discounted } \\
\text { O\&M Costs }\end{array}$ \\
\hline 0 & $\$ 10,000$ & $\$ 10,000$ & & & $\$ 0$ & $\$ 0$ \\
\hline 1 & 0 & 0 & $\$ 4,000$ & $\$ 3,571$ & 1,339 & 1,196 \\
\hline 2 & 0 & 0 & 2,400 & 1,913 & 1,379 & 1,100 \\
\hline 3 & 0 & 0 & 1,440 & 1,025 & 1,421 & 1,011 \\
\hline 4 & 0 & 0 & 1,080 & 686 & 1,463 & 930 \\
\hline 5 & 0 & 0 & 1,080 & 613 & 1,507 & 855 \\
\hline NPV & & $\$ 10,000$ & & $\$ 7,809$ & & $\$ 5,091$ \\
\hline
\end{tabular}

Revenue requirements are an example of a present value that can be annualized (discussed in the Annualized Value subsection). The annualized revenue requirement can be obtained as follows:

$$
L(R R)=P V(R R) \times U C R F=P V(R R) \times \frac{d(1+d)^{N}}{(1+d)^{N}-1}
$$

Where $d$ is either the real or nominal discount rate, depending on whether a real or nominal annualized required revenue is sought.

Returning to the example with $\mathrm{RR}=\$ 16,220$, the nominal annualized required revenue, assuming the same $12 \%$ discount rate, is $\$ 4,500$. These are the current dollar revenues that must be collected in each of the 5 years of the life of the investment to cover all costs, including taxes.

\section{Levelized Cost of Energy}

\section{Introduction}

The levelized cost of energy (LCOE) allows alternative technologies to be compared when different scales of operation, different investment and operating time periods, or both exist. For example, the LCOE could be used to compare the cost of energy generated by a renewable resource with that of a standard fossilfueled generating unit.

\section{Discussion}

The LCOE is that cost that, if assigned to every unit of energy produced (or saved) by the system over the analysis period, will equal the TLCC when discounted back to the base year. LCOE is recommended for use when ranking alternatives given a limited budget simply because the measurc will provide a proper ordering of the alternatives, which may then be selected until the budget is expended. LCOE is not recommended when selecting among mutually exclusive alternatives because differing investment sizes 
are not considered (i.e., an investor will choose to invest more in an alternative with more favorable returns). This shortcoming may be corrected by applying LCOE to the incremental costs of the alternatives. The LCOE can be calculated using the following formula:

$$
\begin{gathered}
\sum_{n=1}^{N} \frac{Q_{n} \times \operatorname{LCOE}}{(1+d)^{n}}=\text { TLCC, or } \\
\operatorname{LCOE}^{22}=\operatorname{TLCC} \div\left\{\sum_{n=1}^{N}\left[Q_{n} \div(1+d)^{n}\right]\right\}
\end{gathered}
$$

Where:

$$
\begin{array}{ll}
\text { LCOE } & =\text { levelized cost of energy } \\
\text { TLCC } & =\text { total life-cycle cost } \\
\mathrm{Q}_{\mathrm{n}} & =\text { energy output or saved in year } \mathrm{n} \\
\mathrm{d} & =\text { discount rate } \\
\mathrm{N} & =\text { analysis period. }
\end{array}
$$

Thus, the treatment of taxes in the TLCC calculation will carry over to the LCOE. For example, the LCOE can be calculated for the same example as was provided in the Total Life-Cycle Cost subsection for the private investor sceking his or her after-tax cost. In addition to the assumptions made in the TLCC example, assume the investment produces 1000 units of energy in the first year of operation, 950 in the second, 925 in the third, and 900 in the fourth and fifth. Recall from the previous example that the TLCC was calculated, after tax deductions, as $\$ 10,705$. The remaining task is to calculate the discounted value of the annual energy output or energy saved; i.e., $\sum_{n=1}^{N}\left[Q_{n} \div(1+d)^{n}\right]$. Applying this formula to the example using a nominal discount rate of $12 \%$, the discounted value of energy output is 3391 units. Thus, $\mathrm{LCOE}=\$ 10,705 / 3,391=\$ 3.16$ in current dollars.

Once the TLCC is calculated, the LCOE can be figured in either current or constant dollars, regardless of the discount rates used to derive the TLCC. The form of the LCOE will be determined by the form of the discount rate used in the denominator of the equation $\Sigma_{n=1}^{N}\left[Q_{n} \div(1+d)^{n}\right]$. In the previous example, a nominal discount rate was used in the denominator; thus, the resulting LCOE values are current values. For the same example, the LCOE based on a $8.74 \%$ real discount rate is $\$ 2.91$ in constant dollars.

It is important to note that if the system output (Q) or savings remains constant over time, the equation for LCOE can be reduced as follows:

$$
\mathrm{LCOE}=(\mathrm{TLCC} / \mathrm{Q})(\mathrm{UCRF})
$$

Where:

TLCC $=$ total life-cycle cost

$\mathrm{Q} \quad=$ annual energy output or saved

UCRF = the uniform capital recovery factor, which is equal to $\frac{d(1+d)^{N}}{(1+d)^{N}-1}$.

${ }^{22}$ Even though it may appear in this formula that quantities are being discounted, this is actually a direct result of the algebra carried through from the previous formula in which revenues were discounted. 
Using the data from the previous example but this time assuming an annual output of 1000 units per year and a nominal discount rate of $12 \%$, the LCOE is equal to (TLCC/Q) (UCRF). The UCRF for this example is

$$
\left[0.12(1+0.12)^{5}\right] /\left[(1+0.12)^{5}-1\right]=0.277
$$

Thus, the LCOE is equal to $\$ 10,705 / 1,000 \times 0.277=\$ 2.97$.

Although $\$ 2.97$ is the levelized after-tax cost, the before-tax revenues required to cover all costs is

$$
\$ 16,220 / 1,000 \times 0.277=\$ 4.50[\text { also } \$ 2.97 /(1-0.34)=\$ 4.50] \text {. }
$$

This means that if the energy units are sold for $\$ 4.50$ per unit in current dollars over the next 5 years and the company sells 1000 energy units per year of operation, the investor will be able to pay the applicable income tax, earn $12 \%$ after taxes, and recoup the initial investment and annual O\&M costs.

Suppose that a constant dollar LCOE was required for this example. The only difference required is to calculate the UCRF using a real discount rate, which in this case is $8.74 \%$ (carrying forward the previous assumption of a $12 \%$ nominal discount rate with $3 \%$ inflation). The UCRF then becomes

$$
\left[0.0874(1+0.0874)^{5}\right] /\left[(1+0.0874)^{5}-1\right]=0.255
$$

Thus, the LCOE is equal to $\$ 16,220 / 1,000 \times 0.255=\$ 4.14$.

This constant dollar example illustrates a shortcut LCOE calculation. The shortcut methodology for estimating the before-tax-revenues-required LCOE requires the assumptions that the project not only have constant output, but also constant $O \& M$ and no financing. If these assumptions can be made, the shortcut can be used with the application of the following formula:

$$
\mathrm{LCOE}=\frac{1 \times \mathrm{FCR}}{\mathrm{Q}}+\frac{\mathrm{O} \& \mathrm{M}}{\mathrm{Q}}
$$

Where:

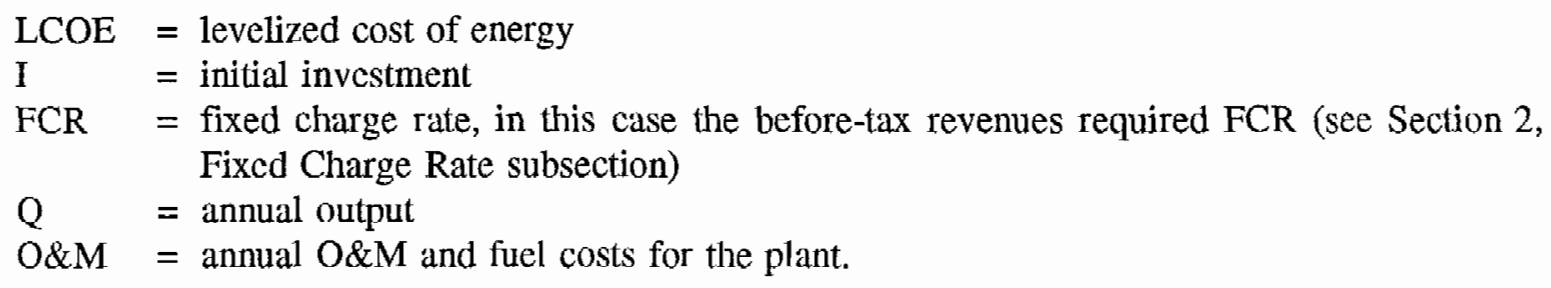
Fixcd Charge Rate subsection)

$\mathrm{Q} \quad=$ annual output

$\mathrm{O} \& \mathrm{M}=$ annual $\mathrm{O \& M}$ and fuel costs for the plant.

Continuing with the before-tax-revenues-required example with constant output and an FCR of 0.284 , which can be calculated from the formula provided in the Fixed Charge Rate subsection in Section 2, the quick estimate of beforc-tax-revenues-required LCOE can be calculated as:

$$
\operatorname{LCOE}=(10,000 \times 0.284) / 1,000+(1,300 / 1,000)=\$ 4.14,
$$

which is the same as the LCOE calculated from the TLCC.

If the investment is an encrgy efficiency investment, LCOE only makes sense in the context of the energy saved. Although TLCCs can be calculated for each energy-consuming system, LCOE should not be 
calculated for an individual encrgy-consuming system, ${ }^{22}$ but rather for the incremental cost and savings attributable to the energy-efficient system. This can be accomplished by levelizing the difference in the nonfuel (electricity) life-cycle costs of the two systems.

For example, consider the energy efficiency example provided in the Total Life-Cycle Cost subsection of Section 4:

- Alternative A: a 75-watt incandescent light bulb operating 6 hours per night for a total energy requirement of $164.25 \mathrm{kWh}$ per year, an unchanging 6 cents per $\mathrm{kWh}$ price of electricity, bulb replacement once a year at a cost of $\$ 1$ per bulb. The nonfuel costs of this system are $\$ 4.03$ $\left(1+1 / 1.12+1 /[1.12]^{2}+1 /[1.12]^{3}+1 /[1.12]^{4}\right)$, or the discounted cost of purchasing a new bulb at the beginning of each year.

- Alternative B: a 40-watt fluorescent bulb that lasts for the entire 5 years operating under similar conditions for a total energy requirement of $87.6 \mathrm{kWh}$ per year, a $\$ 15$ initial investment, and a constant price of electricity of 6 cents per $\mathrm{kWh}$. The nonfuel cost of this option is just the $\$ 15$ cost of the fluorescent bulb at the beginning of the analysis period.

With a UCRF of 0.277 , the "nominal levelized cost of energy saved" for this example is $([15-4.03] / 76.65) \times 0.277=0.04 \$ / \mathrm{kWh}$. This 4 cents per $\mathrm{kWh}$ can then be compared ${ }^{23}$ to the nominal levelized cost of electricity, or 6 cents $^{24} \mathrm{per} \mathrm{kWh}$ in this example, to determine whether the energy efficiency investment is economical. In this example, the cost per unit required to save energy $(\$ 0.04 / \mathrm{kWh})$ is cheaper than it is to purchase the energy $(\$ 0.06 / \mathrm{kWh})$, and thus the more efficient bulb should be purchased. Alternatively, were the cost of electricity to drop below 4 cents per kWh, the most cost-effective investment would change to alternative $A$.

To gain a better understanding of the concept of nominal and real LCOE, examine Figure 4-1. It depicts the cost over the life of an investment and the resulting LCOE in both nominal and real terms. The cash flow lines show how nominal and rcal costs are equal in the base year, whereas in the future, real costs (i.e., inflation-adjusted) are lower than nominal costs. Likewise, the LCOE is lower in real terms than in nominal. The choice of real or nominal LCOE depends on the purpose of the analysis. Most short-term studies are shown in current dollars, whereas long-term studies are frequently computed in real dollars to adjust for many years of inflation. A current-dollar analysis will more closely resemble future cash flows (especially when the investment is largely financed), and a constant-dollar analysis paints a clearer picture of actual cost trends. Regardless of the method chosen, the most economical option will not change as long as all options are evaluated using the same method.

\footnotetext{
${ }^{22}$ There is no reasonable value to use for "Q," the annual output in the $L C O E$ equation. To use the energy consumed by the system would be to penalize (increase the LCOE) for less energy consumption.

${ }^{23}$ Care should be taken to ensure that taxes are treated equally for each investment. For this light bulb case, taxes are assumed not to be relevant because the investor is a homeowner. If the investor were a profit-making firm, the full cost of electricity (6 cents in the example) should be compared with the before-tax LCOE; or, alternatively, the after-tax cost of electricity to the firm $(\$ 0.06[1-\mathrm{T}])$ should be compared with the LCOE after-tax deductions.

${ }^{24}$ Since, in this example, the cost of electricity as expressed in nominal dollars does not changc, it is the same as the nominal levelized cost of electricity.
} 


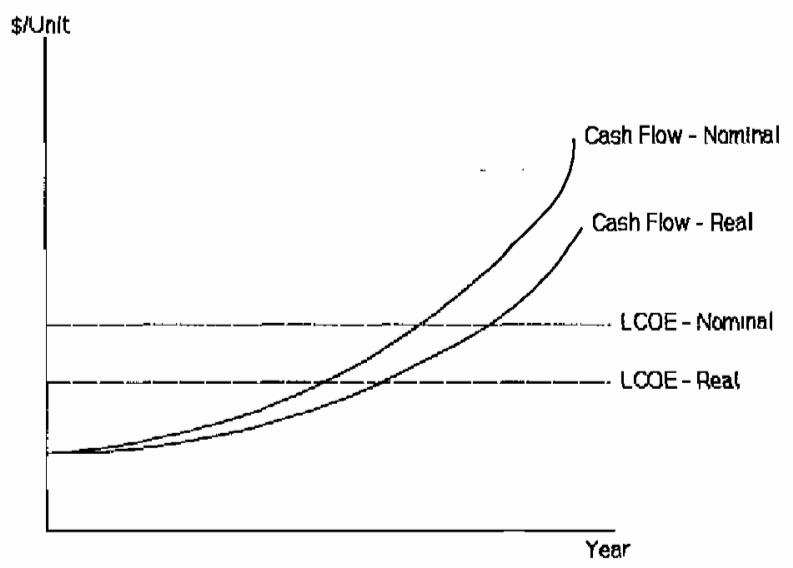

Figure 4-1. Levelized cost of energy cash flows

\section{Annualized Value}

\section{Introduction}

The annualizing process transforms a string of cash flows $\left(F_{n}\right)$ into equivalent annual streams. Cash lows are discounted to their net present value and then annualized by multiplying the present value of the cash flow by the uniform capital recovery factor (UCRF); i.e., $\left[d(1+d)^{n}\right] \div\left[(1+d)^{n}-1\right]$. This is similar to the annualization of required revenues mentioned at the end of the Revenue Requirements subsection and can be done with a single equation that combines the NPV and capital recovery factor calculations.

$$
\begin{aligned}
& \mathrm{NPV}=\sum_{\mathrm{n}=1}^{\mathrm{N}} F_{\mathrm{n}} /(1+\mathrm{d})^{\mathrm{n}} \\
& \mathrm{AV}=\text { UCRF } \times \text { NPV }=\text { UCRF } \times \sum_{\mathrm{n}=1}^{\mathrm{N}} \mathrm{F}_{\mathrm{n}} /(1+\mathrm{d})^{\mathrm{n}}
\end{aligned}
$$

Where:

$$
\begin{array}{ll}
\mathrm{NPV} & =\text { net present value } \\
\mathrm{AV} & =\text { annualized value } \\
\mathrm{F}_{\mathrm{n}} & =\text { cash flow in period } \mathrm{n} \\
\mathrm{UCRF} & =\text { uniform capital recovery factor } \\
\mathrm{d} & =\text { discount rate. }
\end{array}
$$

\section{Discussion}

This formula can be simplified if the cash flow $F_{n}$ is escalating at a constant rate $\Delta P$.

$$
\begin{aligned}
N P V & =\Sigma_{n=1}^{N}\left[F_{0}(1+\Delta P)^{\mathrm{n}}\right] /(1+d)^{\mathrm{n}} \\
& =F_{0} \Sigma^{N}{ }_{n=1}^{N} k^{n} \\
& =F_{0}\left[k\left(1-k^{n}\right) /(1-k)\right]
\end{aligned}
$$




$$
\begin{array}{ll}
\mathrm{AV} & =\mathrm{UCRF} \times \mathrm{NPV} \\
\mathrm{AV} & =\mathrm{UCRF} \times \mathrm{F}_{0}\left[\mathrm{k}\left(1-\mathrm{k}^{\mathrm{n}}\right) /(1-\mathrm{k})\right]
\end{array}
$$

Where:

$$
\begin{array}{ll}
\mathrm{F}_{0} & =\text { cash flow to be annualized } \\
\mathrm{k} & =[(1+\Delta \mathrm{P}) \div(1+\mathrm{d})]
\end{array}
$$

Note that if there is no escalation in price (i.e., $\Delta \mathrm{P}=0$ ), then $A V=F_{0}$. Also note that the formula for annualized cost assumes that the price cscalation is measured in the same type of dollars (either constant or current) as is used for the discount rate, $d$.

\section{Internal Rate of Return}

\section{Introduction}

The internal rate of return (IRR) for an investment that has a series of future cash flows $\left(F_{0}, F_{1}, \ldots F_{n}\right)$ is the rate that sets the NPV of the cash flows cqual to zero. The IRR analysis allows for the comparison of a wide variely of investment activities. However, IRR is not recommended when evaluating investments in which further investment after return is required because downstream investments are improperly discounted and multiple positive IRR values can occur. IRR is commonly used for accept/reject decisions, allowing a quick comparison with a minimum acceptable rate of return (hurdle rate). IRR is not recommended when selecting among mutually exclusive alternatives because the values of differing investment sizes are not considered (an investor will choose to invest more in an alternalive wilh more lavorable returns). This shortcoming may be corrected by applying IRR on an incremental basis. IRR is also not recommended when ranking projects because IRR implicitly assumes reinvestment: of returns at the IRR.

The viability of a project is usually assessed with IRR by comparing the IRR of the project with a "hurdle rate" that represents the IRR of the next best alternative (the opportunity cost of capital). IRR also has the advantage that it can be used to directly compare the after-tax return on readily available financial instruments, such as bonds, thereby providing the investor with a quick qualitalive assessment of the project.

\section{Discussion}

IRR equals the rate for which:

$$
0=N P V=\Sigma_{n=0}^{N}\left[F_{n} \div(1+d)^{n}\right]
$$

Where:

NPV = net present value of the capital investment

$\mathrm{F}_{\mathrm{n}} \quad=$ cash flows received at time $\mathrm{n}$

$\mathrm{d} \quad=$ rate that equates the present value of positive and negative cash flows when used as a discount rate.

Table 4-10 illustrates the after-tax cash flows resulting from the use of the same example as was used in the Net Present Value subsection. This example involved the following assumptions: an investment of $\$ 10,000$ made at the beginning of the year; no salvage value; O\&M costs of $\$ 1,300$ in year zero, inflating 
at an assumed inflation rate of $3 \%$ per ycar thereafter; the investment is not replaced; 5-year doubledeclining depreciation schedule; a marginal federal income tax rate of $34 \%$; no state income tax; production of 1000 units of energy in the first year of operation, 950 in the second, 925 in the third, and 900 in the fourth and fifth; and energy sold for $\$ 10$ a unit in year zero, inflating at $3 \%$ per year thereafter.

Table 4-10. After-Tax IRR

\begin{tabular}{|c|c|c|c|c|c|c|c|}
\hline Year & $\begin{array}{l}\text { Investment } \\
\text { (a) }\end{array}$ & $\begin{array}{c}\text { O\&M Costs } \\
\text { (b) }\end{array}$ & $\begin{array}{c}\text { Revenues } \\
\text { (c) }\end{array}$ & $\begin{array}{c}\text { Depreciation } \\
\text { (d) }\end{array}$ & $\begin{array}{c}\text { Net Taxable } \\
\text { Income } \\
\text { (e) = (c-b-d) }\end{array}$ & $\begin{array}{c}\text { Federal } \\
\text { Income Tax } \\
(f)=\text { ex tax }\end{array}$ & $\begin{array}{c}\text { After-Tax } \\
\text { Cash Flow } \\
\text { (g) }=(c-a-b-f)\end{array}$ \\
\hline 0 & $\$ 10,000$ & $\$ 0$ & $\$ 0$ & $\$ 0$ & NA & NA & $\$-10,000$ \\
\hline 1 & 0 & 1,339 & 10,300 & 4,000 & $\$ 4,961$ & $\$ 1,687$ & 7,274 \\
\hline 2 & 0 & 1,379 & 10,079 & 2,400 & 6,300 & 2,142 & 6,558 \\
\hline 3 & 0 & 1,421 & 10,108 & 1,440 & 7,247 & 2,464 & 6,223 \\
\hline 4 & 0 & 1,463 & 10,130 & 1,080 & 7,587 & 2,580 & 6,087 \\
\hline 5 & 0 & 1,507 & 10,434 & 1,080 & 7,847 & 2,668 & 6,259 \\
\hline
\end{tabular}

An IRR equal to $61 \%$ is calculated when the formula is applied to the after-tax cash flow scenario (successive approximation methods can be used to find the rate that equates the present value of cash flows to zero). In other words, the present value of this after-tax cash flow scenario is zero if a discount rate of $61 \%$ is assumed. In this scenario, if the investor's hurdle rate is higher than $61 \%$, then the investor will more than likely invest his or her money elsewhere; whereas, if the hurdle rate is lower than $61 \%$, the investor may view the investment as a good opportunity. It is also important to note that the $61 \%$ IRR is actually the nominal IRR and should be stated as such. This is the case because the cash flows on which the IRR was calculated were in current dollars. If the dollars had been constant, the IRR would have been a real IRR.

The equation for IRR is a polynomial of degree $\mathrm{N}$ and, as such, the analyst must be aware that there are $\mathrm{N}$ different roots, or solutions, to the equation. However, when the investment pattern is normal (i.e., the initial investment or cash outflow is followed by a stream of cash inflows), all solutions are either negative or imaginary, except for one positive solution. On the other hand, if the cash flow is such that large outflows occur during or near the end of the life of the investment, then the possibility of multiple positive roots arises (Palm and Qayum 1985).

Because of the complexity of the required calculations and multiple potential roots, some soltware for personal computers requires a guess at the IRR prior to calculation (Lotus 1991). For situations in which there is a close approximate value, this poses little difficulty to the analyst. However, when the analyst does not have an approximate value, this could pose a problem and add doubt to the resulis.

IRR analysis may not fully consider the pattern of investments and returns over time. For example, two investment projects with an IRR of $17 \%$ might be considered cqual, but if there are different analysis periods for the two projects (c.g., 20 years for project A and 3 years for project B), a decision maker might not be indifferent regarding the choice of A or B. That is, an investor may find a sustained 20-year revenue stream at $17 \%$ more desirable than a 3-year payment flow at the same rate. 
Another shortcoming of IRR is that it may overstate profitability. An implicit assumption contained in an IRR calculation is that all interim proceeds from the investment are reinvested at a rate equal to the IRR. A previous IRR example provided an IRR of $61 \%$; however, it may be unrealistic to believe that the interim cash flows will be reinvested at a rate equal to $61 \%$.

Another caution for the analyst is to be aware that when using IRR as the sole measure to compare alternative projects, the less profitable alternative may be chosen. For example, two projects with a life of 3 years and an initial investment of $\$ 10,000$ are compared. The cash flows for the two projects are different, as illustrated in Table 4-11. A nominal discount rate of $12 \%$ is used to calculate NPVs for this example.

As illustrated in Table 4-11, if IRR was the sole measure used to decide on alternatives, Project B would be chosen over Project $A$ when, in fact, Project $A$ is the more profitable alternative using the discount rate of $12 \%$ for the NPV analysis. Worth noting is the fact that Project B might be perceived as less risky since the returns occur sooner than those of Project A.

Table 4-11. Results of Using IRR as a Sole Measure

\begin{tabular}{||crc||}
\hline Year & Project A & Project B \\
\hline 0 & $\$-10,000$ & $\$-10,000$ \\
1 & 3,000 & 9,000 \\
2 & 5,000 & 4,000 \\
3 & 10,000 & 2,000 \\
\hline IRR & $28.9 \%$ & $31.8 \%$ \\
NPV & $\$ 3,782$ & $\$ 2,648$ \\
\hline
\end{tabular}

Given these potential problems with IRR, it is recommended that IRR be used only when performing an accept/rcject analysis for single projects. The IRR is acceptable in this instance becausc when IRR is greater than the hurdle rate, the actual yield when accounting for reinvestment at the hurdle rate will also be greater than the hurdle rate (Ruegg and Marshall 1990).

\section{Modified Internal Rate of Return}

\section{Introduction}

For projects of different scale and lives, it is possible for different ranking criteria, such as NPV and IRR, to producc conflicting results because of differing reinvestment assumptions. The NPV method assumes reinvestment at the discount rate, whereas the IRR method assumes reinvestment at the IRR rate. The modified internal rate of return (MIRR) accounts for varying reinvestment rates and should be used in these circumstances. MIRR is calculated by assuming that all cash inflows received before the end of the analysis period are reinvested at the discount rate until the end of the analysis period. The terminal (future value) amount at the end of the analysis is then discounted back to the base year. The discount rate that will equate the present value (in the base year) of the terminal amount to the present value of all investment costs is the MIRR. 
MIRR is not recommended when selecting among mutually exclusive alternatives because the values of differing investment sizes are not considered (i.e., an investor will choose to invest more in an alternative with more favorable returns). This shortcoming may be corrected by applying MIRR on an incremental basis. Because MIRR will provide the proper ranking of projects to be selected to maximize total rcturn given a limited budget, MIRR is recommended when ranking alternatives.

\section{Discussion}

The formula ${ }^{25}$ for calculating an MIRR is as follows:

$$
\begin{aligned}
& \text { MIRR }=\text { solution for } r \text { in the following equation: } \\
& \text { MIRR }=r \text {, where } \sum_{n=0}^{N} \frac{F n_{n}}{(1+d)^{n}}=\sum_{n=0}^{N} \frac{F p_{n}(1+d)^{N-n}}{(1+r)^{N}}
\end{aligned}
$$

Where:

$$
\begin{array}{ll}
\text { MIRR } & =r, \text { modified internal rate of return } \\
\mathrm{Fn}_{\mathrm{n}} & =\text { net negative cash flows at time } \mathrm{n} \\
\mathrm{F} \mathrm{p}_{\mathrm{n}} & =\text { net positive cash flows at time } \mathrm{n} \\
\mathrm{d} & =\text { rate of return of rcinvestment } \\
\mathrm{N} & =\text { life of investment. }
\end{array}
$$

Recall that the IRR of the after-tax cash flows in the example from the Internal Rate of Return subsection was $61 \%$. Remember that IRR assumes that all interim cash flows are reinvested at the IRR - in this case $61 \%$. As an example of MIRR, assume that all interim cash flows are instead reinvested at $12 \%$. Table 4-12 illustrates the application of MIRR versus IRR.

Table 4-12. MIRR versus IRR

\begin{tabular}{||c|c|c|c||}
\hline Year & $\begin{array}{c}\text { After-Tax } \\
\text { Cash Flows }\end{array}$ & $\begin{array}{c}\text { Future Value in } \\
\text { Year 5 }\end{array}$ & $\begin{array}{c}\text { Cash Flow } \\
\text { for MIRR }\end{array}$ \\
\hline 0 & $\$-10,000$ & & $\$-10,000$ \\
1 & 7,274 & 11,446 & \\
2 & 6,558 & 9,214 & \\
3 & 6,223 & 7,806 & \\
4 & 6,087 & 6,817 & 41,542 \\
5 & 6,259 & 6,259 & $32.9 \%$ \\
\hline IRR & $61.2 \%$ & & \\
MIRR & &
\end{tabular}

\footnotetext{
${ }^{25}$ In the formula provided here the present value of negative cash flows and the future value of positive cash flows are calculated using the minimum rate of return. In some cases, different rates are used when performing these calculations.
} 
As illustrated in Table 4-12, the future value of the after-lax positive cash flows is $\$ 41,542$. The discount rale, which equates this to the original $\$ 10,000$ investment over the 5-year period, is $33 \%$. Again, given the example, the MIRR should actually be labeled as a nominal MIRR of 33\% because the after-tax cash flows were in current dollars. If the dollars were constant, the interim cash flows would be reinvested at the real rate of $8.74 \%$, and the resulting MIRR of $29.2 \%$ would be a real rate.

As stated earlier, MIRR can be used to evaluate projects having different scales or lives. As an example, assume two alternative projects, $X$ and $Y$, each costing $\$ 15,000$, which will be invested at the beginning of year one. Project $X$ returns $\$ 7,000$ at the end of ycars one, two, and three; and Project $Y$ returns $\$ 3,000$ at the end of years one through ten. Assume a discount rate of $10 \%$. In this example, the NPVs of each cash flow stream is $\$ 2,408$ for Project $X$ and $\$ 3,434$ for Project $Y$. On the other hand, the IRR is $18.9 \%$ for Project $\mathrm{X}$ and $15.1 \%$ for Project $\mathrm{Y}$. Thus, Project $\mathrm{Y}$ is the best alternative when using an NPV analysis and Project $X$ is the best alternative when using IRR analysis. This result ignores the fact that cash inflows from Project $X$ can be reinvested over the remaining 7 years of the analysis period. Given the different project lives, the analyst should calculate an MIRR. This can be done by assuming a reinvestment rate of $10 \%$ for Project X.

The first step is to calculate terminal values for Project $X$ under alternative reinvestment rates. For Project $X$, the future value of the $\$ 7,000$ annuity for 3 years is calculated. This is then reinvested at the discount rate of $10 \%$ for the remaining 7 years of the analysis to arrive at a terminal value (future value) of $\$ 45,152$. In the case of Project $Y$, the future value of the $\$ 3,000$ annuity for 10 years is calculated to arrive at a terminal value of $\$ 47,813$. Next, calculate the discount rate, which will equate the terminal values, when discounted back to the base year, with the invesiment.

$$
\begin{aligned}
& \text { Project X: } \$ 45,152 /(1+d)^{N}-\$ 15,000=0 \\
& \text { MIRR }=11.7 \% \\
& \text { Project Y: } \$ 47,813 /(1+d)^{N}-\$ 15,000=0 \\
& \text { MIRR }=12.3 \% .
\end{aligned}
$$

The MIRR in this example reveals that given a reinvestment rate of $10 \%$ for Project X, Project Y should be undertaken, not Project $X$. This result matches the results of the previous cxample of NPV analysis.

Sometimes a project will require investment near the middle or end of an analysis period after positive cash inflow has occurred, or there may simply be negative cash flows near the middle and end of the analysis period. This situation can lead to multiple positive solutions for ordinary IRR calculations. MIRR should be used in these situations.

\section{Simple Payback Period}

\section{Introduction}

Simple payback (SPB) is a quick, simple way to compare alternative projects. It is relatively easy to utilize and as such is a very popular financial tool. Simple payback is the number of years necessary to recover the project cost of an investment under consideration.

SPB is commonly used and recommended when risk is an issue (i.e., significant uncertainties are present) because SPB allows for a quick assessment of the duration during which an investor's capital is at risk. SPB is not recommended when cvaluating alcernatives involving financing and tax fealures because their 
inclusion complicates the analysis and looses the advantages of simplicity. SPB is also not recommended for selecting among mutually exclusive alternatives because the values of differing investment sizes are not considered; i.e., an investor will choose to invest more in an alternative having more favorable returns. This shortcoming may be corrected by applying SPB on an incremental basis. When ranking projects, SPB is not recommended because it ignores returns after payback.

The SPB can be expressed as the first point in time at which:

$$
\sum_{n} \Delta I_{n} \leq \sum_{n} \Delta S_{n}
$$

Where:

SPB $=$ minimum number of years required for the nondiscounted sum of annual cash flows net annual costs to equal or exceed the nondiscounted investment costs

$\Delta \mathrm{I} \quad=$ nondiscounted incremental investment costs (including incremental finance charges)

$\Delta \mathrm{S} \quad=$ nondiscounted sum value of the annual cash flows net annual costs.

\section{Discussion}

One drawback to the SPB method is that it ignores the time value of money. That is, the use of SPB implies that there are no opportunity costs to the investor (i.e., the investor's discount rate is zero) (Ruegg 1987). However, the simple payback method is easy to understand and calculate, and can be useful if there are uncerlainties, such as uncertain tenure or life of the technology. When there is a high degree of uncertainty associated with future cash flows, SPB gives an indication of how long one's assumptions must hold to ensure that at least the principal is returned to the investor.

\section{Discounted Payback Period}

\section{Introduction}

The discounted payback period (DPP) is the number of years necessary to recover the project cost of an investment while accounting for the time value of money.

DPB is recommended when risk is an issue (i.e., significant uncertainties are present) because DPB allows for a quick assessment of the duration during which an investor's capital is at risk. DPB is not recommended when evaluating alternatives involving financing and tax features because their inclusion complicates the analysis and looses the advantages of simplicity. DPB is also not recommended when selecting among mutually exclusive alternatives because differing investment sizes are not considered (i.e., an investor will choose to invest more in an alternative with more favorable returns). This shortcoming may be corrected by applying DPB on an incremental basis. When ranking projects, DPB is not recommended because it ignores returns after payback. 


\section{Discussion}

DPB can be expressed as that time in which:

$$
\sum_{\mathrm{n}}\left[\Delta \mathrm{I}_{\mathrm{n}} \div(1+\mathrm{d})^{\mathrm{n}}\right] \leq \sum_{\mathrm{n}}\left[\Delta \mathrm{S}_{\mathrm{n}} \div(1+\mathrm{d})^{\mathrm{n}}\right]
$$

Where:

DPB = minimum number of years required for the discounted sum of annual net savings to equal the discounted incremental investment costs

$\Delta \mathrm{I} \quad=$ incremental investment costs

$\Delta \mathrm{S}=$ annual savings net of future annual costs (i.e., $\Delta \mathrm{S}$ equals the incremental energy costs, incremental nonfuel operation, maintenance, and repair costs, incremental repair and replacement costs, minus the incremental salvage costs)

$\mathrm{d}=$ annual nominal discount rate (Ruegg 1987).

As an example of the difference between SPB and DPB, assume the following:

\begin{tabular}{lcc} 
& \multicolumn{1}{c}{ SPB } & DPB \\
Incremental Investment Cost Differential & $\$ 18,000$ & $\$ 18,000$ \\
Annual Net Savings & $\$ 3,000$ & $\$ 3,000$ \\
Discount Rate & - & $6.88 \%$ \\
Payback Period & 6 ycars & 8 years
\end{tabular}

A disrcgard for the time value of money is not a limitation of discounted payback (Brown and Yanuck 1980). The DPB differs from the SPB in that the DPB analysis uses the present values of the changes in investments and savings. Thus, when accounting for the time value of money, the payback period is longer, as illustrated abovc. As in any present value analysis, the cash flows or net savings in DPB can occur at times other than the end of the year. Alternative assumptions such as mid-year, mid-month, or beginning-of-the-month cash flows will affect the results of the analysis. See Appendix E and Koomey (1990) for further clarification.

\section{Benefit-to-Cost Ratios}

\section{Introduction}

Benefit-to-cost $(\mathrm{B} / \mathrm{C})$ analysis is conducted and $\mathrm{B} / \mathrm{C}$ ratios are derived to ascertain whether and to what degree the benefits of a particular project excecd the costs. Such analyses are more frequently performed for projects that involve the public interest. They range from direct government investments in public works (such as infrastructure, parks, or public power projects) to private investments by utilities in which the impacts on the ratepayers, investors, and the environment all may have to be considered to determine if the action is appropriate.

Because $\mathrm{B} / \mathrm{C}$ ratios are commonly used when evaluating investments from a societal perspective, they are recommended for use when evaluating projects in which social costs prevail. B/C ratios are not recommended when selecting among mutually exclusive alternatives because the values of differing investment sizes are not considered; i.e., an investor will choose to invest more in an alternative with more favorable returns. This shortcoming may be corrected by applying $\mathrm{B} / \mathrm{C}$ ratios to the incremental 
benefits/costs of the alternatives. $\mathrm{B} / \mathrm{C}$ ratios can also be used when ranking projects if benefits predominate, particularly from a public policy perspective.

\section{Discussion}

The $\mathrm{B} / \mathrm{C}$ ratio is the ratio of discounted benefits to discounted costs at a given point in time (base year). The denominator of the $\mathrm{B} / \mathrm{C}$ ratio includes all costs. Operations, maintenance, fuel, finance costs, and properly taxes should be included. The numerator of the $\mathrm{B} / \mathrm{C}$ ratio includes all savings, revenues, and other benefits. Externalities can be positive (benefit) or negative (cost). Some impacts of a program action, such as local economic development and environmental impacts, may be difficult to quantify. To the extent that the externality can be quantified, the externality value should be included when appropriate (i.e., a positive exiernality added to the benefits and a negative externality included in costs). Quantifying externalities is covered in more detail in the Special Considerations subsection in Section 5. The determining factor in $\mathrm{B} / \mathrm{C}$ analysis is whether the $\mathrm{B} / \mathrm{C}$ ratio is equal to (or greater than) 1 .

The mathematical formula for $\mathrm{B} / \mathrm{C}$ ratios is:

$$
\mathrm{B} / \mathrm{C}=[\mathrm{PV}(\text { All Benefits) }] \div[\mathrm{PV}(\text { All Costs) }]
$$

Where:

PV (All Benefits) = present value of all positive cash flow equivalents

PV (All Costs) = present value of all negalive cash flow equivalents.

An example for the calculation of the B/C ratio follows. The calculation includes three steps: (1) the PV calculation of the cost stream, (2) the PV calculation of the benefit stream, and (3) the calculation of the ratio.

Step 1 - Present value of a strcam of costs

$\begin{array}{ll}\text { Discount rate } & 8.00 \% \\ \text { Cash flow per year } & \$ 3,000 \\ \text { Time periods } & 3\end{array}$

$\begin{array}{lccc}\text { Time period } & 1 & 2 & 3 \\ \text { Amount } & \$ 3,000.00 & \$ 3,000.00 & \$ 3,000.00\end{array}$

Present value of an annual $\$ 3,000$ payment for 3 years $=\$ 7,731.29$

Step 2 - Present value of a stream of benefits

$\begin{array}{ll}\text { Discount rate } & 8.00 \% \\ \text { Cash flow } & \text { Varies over time } \\ \text { Time period } & 4\end{array}$




$\begin{array}{lcccc}\text { Time period } & 1 & 2 & 3 & 4 \\ \text { Amount } & \$ 1,000.00 & \$ 2,000.00 & \$ 3,000.00 & \$ 4,000.00\end{array}$

Present value of 4 years of irregular revenues $=\$ 7,962.22$

$\begin{array}{cc}\text { Step } 3 \text { - Calculation of the } \mathrm{B} / \mathrm{C} \text { ratio } \\ \text { PV of benefits } & \$ 7,962.22 \\ \text { PV of costs } & \$ 7,731.29 \\ \text { B/C ratio } & 1.029869\end{array}$

The $\mathrm{B} / \mathrm{C}$ ratio of the investment alternative in this example is 1.03 . The higher the ratio, the greater the average dollar benefit per dollar of cost.

Like analyses using IRR, B/C ratio analyses may provide results inconsistent with those of NPV analyses. As with IRR, B/C ratio analysis is acceptable for accept/reject decisions of single projects. However, if the $\mathrm{B} / \mathrm{C}$ ratio is calculated using incremental benefits and costs, it can be used to design and size projects. For example, consider the project size alternatives in Table 4-13.

Table 4-13. Project Size Alternatives

\begin{tabular}{||c|c|c|c||}
\hline Size Alternative & Total Cost (\$PV) & $\begin{array}{c}\text { Total Benefits } \\
\text { (\$PV) }\end{array}$ & NPV \\
\hline 0 & $\$ 0$ & $\$ 0$ & $\$ 0$ \\
A & 10,000 & 15,000 & 5,000 \\
B & 12,000 & 18,000 & 6,000 \\
C & 14,000 & 19,000 & 5,000 \\
\hline
\end{tabular}

To apply the $\mathrm{B} / \mathrm{C}$ test for comparing the alternatives in this example, the alternatives would be arranged in order of increasing costs, as displayed in Table 4-13. Next, the $\mathrm{B} / \mathrm{C}$ ratio for incremental benefits and costs is calculated. The incremental costs of Alternative A over the costs of doing nothing is $\$ 10,000$, and the incremental benefits are $\$ 15,000$. Thus the incremental $\mathrm{B} / \mathrm{C}$ ratio is 1.5 . Alternative $\mathrm{A}$ is now the baseline, and the incremental $B / C$ ratio of Alternative $B$ over Alternative $A$ is calculated as $1.5(3,000 / 2,000)$. Because the incremental $B / C$ ratio of Alternative $B$ is greater than 1 , it now becomes the new baseline. The incremental $B / C$ ratio of Allcrnative $C$ to the new baseline is calculated as $0.5(1,000 / 2,000)$. Alternative $\mathrm{C}$ does not become the new baseline because the incremental $\mathrm{B} / \mathrm{C}$ ratio is less than 1. In this example, the most cost-effective project size is Alternative $B$, based on the incremental B/C. The NPV values are displayed in Table 4-13 simply to show that Alternative B is in fact the most profitable project (Ruegg and Marshall 1990). 


\section{Savings-to-Investment Ratios}

\section{Introduction}

A variation of the $\mathrm{B} / \mathrm{C}$ ratio, known as the savings-to-investment ratio (SIR), is used when benefits occur primarily as cost reductions ( $\mathrm{Au}$ and $\mathrm{Au}$ 1983). Although SIR is basically a B/C ratio, there is a computational difference. $\mathrm{B} / \mathrm{C}$ ratios are typically calculated with all benefits in the numerator and all costs in the denominator. In the calculation of SIR, only the principle investment costs are included in the denominator. All other costs are subtracted from the benefits in the numerator. This, in esscnce, makes the numerator a measure of net savings.

\section{Discussion}

The SIR ratio is recommended in ranking analyses if costs predominate, simply because SIR can properly rank projects to be selected until the budget is exhausted. SIR is not recommended for use when projectspecific debt financing is present because of the issue of whether the investment is defined as only the equity portion of the investment or the total investment. SIR is also not recommended when selecting among mutually exclusive alternatives because differing investment sizes are not considered (i.e., an investor will choose to invest more in an alternative with more favorable returns). This shortcoming may be corrected by applying SIR on an incremental basis.

The formula for the calculation of the SIR is as follows:

$$
\mathrm{SIR}=\mathrm{PV}(\mathrm{NS}) \div \mathrm{PV}(\mathrm{IRS})
$$

Where:

$$
\begin{aligned}
\text { SIR } \quad= & \text { savings investment ratio } \\
\text { PV(NS) = } & \text { present value of net savings of the activity (i.e., lotal savings mimus all } \\
& \text { incremental operation and repair costs not dirccly attributed to incremental } \\
& \text { investment costs) } \\
\text { PV(IRS) = } & \text { present value of the sum of incremental investment costs plus incremental } \\
& \text { replacement costs minus incremental salvage values. }
\end{aligned}
$$

The higher the SIR ratio, the greater the average savings per dollar expended. For example, an SIR of 2 can be interpreted to mean that the investment will save $\$ 2$ on average for every $\$ 1$ invested, over and above the required rate of return reflected in the discount rate.

The constraints for B/C ratios outlined earlier also apply to the SIR. The SIR can be used in accept/reject decisions for single projects. SIRs should not and cannot be used reliably to find optimal sizes or designs of investment alternatives unless the analysis is based upon incremental rather than total savings and costs. An SIR computed using total savings and costs tends to reach its maximum value before the most optimal design or size is reached (Ruegg 1987). The most cost-effective value is reached once the incremental savings equal the incremental costs (i.e., the incremental SIR declines to a valuc of unity). 


\section{Integrated Resource Planning/Demand-Side-Management Ratio Tests}

\section{Introduction}

Integrated resource planning (IRP) is a resource planning process that considers the cntire utility chain, from how customers consume electric power (demand-side management [DSM]), to the alternatives available for adding generation capacities (supply-side options). As of June 1993, utilities in at least 46 states either had functioning IRP strategies or were considering, developing, or implementing an IRP process. $^{26}$

The IRP concept is broader than traditional resource planning in several ways (Logan, Neil, and Taylor 1994):

- IRP considers different analysis perspectives, evaluating the overall consequences of a program from the viewpoint of the utility company, the participating consumer, the nonparticipating consumer, and society as a whole.

- Public involvement methods and environmental concerns are considercd in the development of the plan.

- DSM options consider the full potential of cost-effective conservation, marketing, and load management programs.

- Supply-side options include both traditional and alternative generating sourccs.

- IRP carefully analyzes the uncertainties and risks posed by different DSM and supply-side options and by external factors (Goldman, Hirst, and Krause 1989).

Including renewable energy resources in IRP requires that utility planners properly consider the relevant attributes of different renewable energy resources. Table 4-14 lists the resource attributes usually considered in the IRP process. Key attributes for renewable resources are identified with a superscript " $\mathrm{a}$."

The Western Area Power Administration (WAPA) has developed the Resource Planning Guide (WAPA 1993) to assist its customers in the development of IRP. The guide addresses each phase of the IRP process. The quality of a particular IRP process depends on how well the following phases are linked, as well as on the quality of the data and analysis used within each phase:

\section{- Situation Analysis:}

The situation analysis phase identifies problems, needs, and opportunities related to a specific utility profile. The utility profile is based on such indicators as customer mix, historical loads, projected growth, and wholesale rates. The information collected in this phase results in a list of DSM and supply-side oplions based on the utility's profile and a list of relevant resource attributes for each resource oplion.

\footnotetext{
${ }^{26}$ Utilities have for years undertaken forms of least-cost and resource planning to some degree in their operations but not to the extent and without the specific regulatory context that is now prevalent.
} 
- Screening Analysis:

The screcning analysis phase helps determine which DSM and supply-side options to consider in the IRP plan. DSM screening analysis indicates whether a program is "good" and for whom it is good. The end results of DSM screening analyses are B/C ratios for each DSM option. The end results of supply-side screening analyses are levelized costs for each option.

- Plan Integration:

The plan integration phase incorporates DSM alternatives into the IRP process. There are three basic integration methods (WAPA 1993): (1) static analysis, (2) the integration method, and (3) the load forecast adjustment method. Any of these methods can be used; however, the utility should choose the one that best applies to its particular situation. The following four areas must be concentrated on during this phase:

1. Determining the mix, size, and timing of resources to select the least-cost plan.

2. Deriving the resource plan according to several conflicting objective functions.

3. Ensuring that the plan will provide equal reliability whether DSM or supply-side options are included.

4. Incorporaling the hourly effects of DSM programs, program costs, revenue impacts, and market penetration rates.

- Financial Analysis:

In the financial analysis phase, the utility determines how the IRP will affect its financial situation by examining: (1) revenue versus expenses, (2) cash flow and financing requirements, (3) financial ratios (such as the operating ratio), and (4) customer rate increase constraints.

- Risk Analysis:

The assumptions made during the IRP process must be made for variables that contain uncertainty. In this risk analysis phase, risks are assessed by monitoring changes in output variables as input variable assumptions arc changed. Risk analysis can be performed by assigning probabilities or using sensitivity analysis, as outlined in Section 2.

\section{- Implementation:}

The implementation phase is the final phase in the IRP process and varies among utility companies. Generally, the analyst presents conclusions and recommendations to the utility director, board, or council. The utility then submits the IRP to its regulatory body. Once the IRP is adopted (usually not in its original form), the neccssary implementation steps are performed. 
Table 4-14. Resource Attributes

\begin{tabular}{|c|c|}
\hline Attributes & Renewable Energy Technologies \\
\hline $\begin{array}{l}\text { Capability } \\
\text { Peak capability } \\
\text { Energy capability } \\
\text { Seasonal/hourly profile }\end{array}$ & $\begin{array}{l}\text { Hydro, solar, and wind options typically have pronounced seasonal } \\
\text { profiles. Solar and wind options also have pronounced hourly } \\
\text { profiles. }\end{array}$ \\
\hline $\begin{array}{l}\text { Availabillty } \\
\text { intermittence } \\
\text { Forced outages } \\
\text { Maintenance requirements }\end{array}$ & $\begin{array}{l}\text { Hydro capability is dependent on hydrological conditions. Plants on } \\
\text { the same river system are tightly correlated. Wind and solar are } \\
\text { intermittent. }\end{array}$ \\
\hline $\begin{array}{l}\text { Efficiency } \\
\text { Heat rate }\end{array}$ & $\begin{array}{l}\text { Efficiency is generally not an issue for renewables because they } \\
\text { typically rely on zero- or low-cost energy sources. }\end{array}$ \\
\hline $\begin{array}{l}\text { Dispatchabillty } \\
\text { Fully dispatchable } \\
\text { Curtailable } \\
\text { Base-loaded }\end{array}$ & $\begin{array}{l}\text { Run-of-river hydro is nondispatchable. Pondage hydro is } \\
\text { dispatchable. Wind is nondispatchable. Solar themal is } \\
\text { dispatchable. Other solar options are nondispatchable. Biomass, } \\
\text { landfill methane, and municipal solid waste (MSW) options are } \\
\text { typically nondispatchable. Geothermal is typically nondispatchable. }\end{array}$ \\
\hline $\begin{array}{l}\text { Location }^{\ominus} \\
\text { Delivery point }\end{array}$ & $\begin{array}{l}\text { Connected at transmission or distribution level. Can be targeted to } \\
\text { defer transmission or distribution upgrades. }\end{array}$ \\
\hline $\begin{array}{l}\text { Modularity } \\
\text { Incremental size } \\
\text { Construction/Preconstruction lead time }\end{array}$ & $\begin{array}{l}\text { Incremental sizes and lead times of renewable energy technologies, } \\
\text { except for MSW, are typically smaller and shorter than for } \\
\text { conventional options. Lead times for MSW are } 3 \text { to } 4 \text { years. }\end{array}$ \\
\hline $\begin{array}{l}\text { Costs } \\
\text { Construction } \\
\text { O\&M } \\
\text { Fuel } \\
\text { Decomissioning costs }\end{array}$ & $\begin{array}{l}\text { Typically no fuel costs, except biomass. These technologies provide } \\
\text { diversification of the fuel supply portfolio. }\end{array}$ \\
\hline $\begin{array}{l}\text { Incentives } \\
\text { Tax credits } \\
\text { Shareholder incentives } \\
\text { Emission allowance incentives }\end{array}$ & $\begin{array}{l}\text { The } 1992 \text { National Energy Policy Act provides a } 1.5 \text { cents/kWh tax } \\
\text { credit for renewable energy producers. The } 1990 \text { Clean Air Act } \\
\text { Amendments provide bonus emission credits for renewable energy } \\
\text { production. }\end{array}$ \\
\hline $\begin{array}{l}\text { Risk-Diversity } \\
\text { Startup delay } \\
\text { Construction cost overun } \\
\text { Fuel costs } \\
\text { O\&M costs } \\
\text { Reliability problems } \\
\text { Premature retirement } \\
\text { Diversity }\end{array}$ & $\begin{array}{l}\text { Less mature technologies may have greater construction and } \\
\text { operating risks than conventional technologies. Renewable } \\
\text { resources generally enhance diversity, except for hydro additions to } \\
\text { a predominantly hydro system. }\end{array}$ \\
\hline $\begin{array}{l}\text { External Costs" } \\
\text { Air and water emissions } \\
\text { Land use } \\
\text { Waste disposal } \\
\text { Public safely }\end{array}$ & $\begin{array}{l}\text { Land use and fish habitats are significant issues for hydro } \\
\text { generation. Noise and visual impacts are issues for wind energy } \\
\text { resources. }\end{array}$ \\
\hline \multicolumn{2}{|c|}{$\begin{array}{l}\text { a. Key attributes for renewable resources. } \\
\text { b. Applicable only to investor-owned utilities. } \\
\text { c. External costs are defined to exclude impacts that are accounted for in other cost categories. } \\
\text { Source: D. Logan, C. Neil, A. Taylor. (1994) Modeling Renewable Energy Rosources in Integrated Resource Planning, } \\
\text { National Renewable Energy Laboratory, NRELTP-462-6436. }\end{array}$} \\
\hline
\end{tabular}




\section{Discussion}

Assessing the cost-effectiveness of DSM and supply-side program options occurs during the screening analysis phase of the IRP process. Below we have described five widely used "standard practice" DSM cost-effectiveness tests. We have focused on demand-side options because many analysts are unfamiliar with the technical and policy problems of DSM options. As with any B/C ratio test, options with ratios greater than or equal to one are considered economically justified. The following $\mathrm{B} / \mathrm{C}$ formulas, along with detailed information related to DSM analyses, can be found in EPRI's Principles and Practice of DemandSide Management (EPRI 1993).

\section{Participant Test: Participant Perspective}

The Participant Test provides a measure of the quantifiable benefits and costs of a DSM program to a typical participating customer; it does not consider impacts on the utility. The intent of this perspective is to measure the economic and financial characteristics inherent to a program with the purpose of atlracting customers. The benefits to the participant are equal to the sum of any participant incentives paid, any reduction in bills, and any federal or state tax deductions or credits. Participant costs include any other out-of-pocket costs associated with the particular program. The Participant Test can be expressed as follows:

$$
\begin{gathered}
\text { Participant Test }=\mathrm{B}_{\mathrm{p}} \div \mathrm{C}_{\mathrm{p}}, \\
\mathrm{B}_{\mathrm{p}}=\sum_{\mathrm{i}=1}^{\mathrm{N}}\left\{\left[\mathrm{I}_{\mathrm{i}}+\left(\Delta \mathrm{E}_{\mathrm{i}} * \mathrm{CR}_{\mathrm{j}}\right)\right] \div(1+\mathrm{d})^{\mathrm{i}}\right\} \\
\mathrm{C}_{\mathrm{p}}=\Sigma_{\mathrm{i}=1}^{\mathrm{N}}\left\{\mathrm{DC}_{\mathrm{j}} \div(1+\mathrm{d})^{\mathrm{i}}\right\}
\end{gathered}
$$

Where:

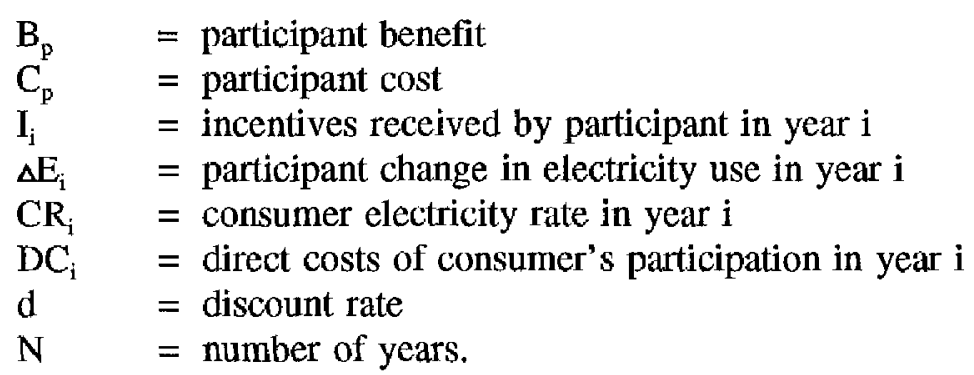

For example, consider a residential DSM program involving energy-efficient dishwashers, where the utility company offers a one-time $\$ 200$ rcbate when its residential customers purchase energy-efficient dishwashers at $\$ 600$ (assume standard dishwashers can be salvaged at $\$ 100$, thus, the incremental consumer participation cost is $\$ 500$ ). The washers have a 10 -year life span and save $1000 \mathrm{kWh}$ per year. In addition, assume a real discount rate of $6 \%$ and a constant dollar electricity rate (consumer's cost) of $\$ 0.08$ per $\mathrm{kWh}$ over the entire 10-year period. The Participant Test for this example is calculated as follows:

$$
\text { Participant Test }=\$ 788.80 \div \$ 500=1.58
$$

Where:

$$
\begin{aligned}
& \mathrm{B}_{\mathrm{p}}=\$ 200+\sum_{\mathrm{i}=1}^{10}\left[(1,000 \mathrm{kWh} / \text { year } * \$ 0.08 / \mathrm{kWh}) \div(1+0.06)^{\mathrm{i}}\right]=\$ 788.80 \\
& \mathrm{C}_{\mathrm{p}}=\$ 600-\$ 100=\$ 500 .
\end{aligned}
$$


The participant test B/C ratio is greater than 1; thus, this program is cost-effective from the participant's perspeclive. Because the participant test is an indication of the attractiveness of this program to customers, it is also an indication of the general level of program participation that can be expected.

\section{Total Resource Cost Test: Utility and Ratepayer Perspective}

The Total Resource Cost (TRC) Test provides a measure of the net resource expenditure of a DSM program from the point of view of the utility and its ratepayers as a whole. Resource benefits include the utility's avoided supply costs. Resource costs include the utility's and participants' direct costs. Because the utility and its ratepayers are taken as a whole, incentives and revenue changes are ignored. This test is also called the All Ratepayers Test.

The TRC Test can be expressed as follows:

$$
\begin{gathered}
\text { TRC Test }=\mathrm{B}_{\mathrm{t}} \div \mathrm{C}_{\mathrm{t}}, \\
\mathrm{B}_{\mathrm{t}}=\sum_{\mathrm{i}=1}^{\mathrm{N}}\left[\left(\Delta \mathrm{E}_{\mathrm{i}} * \mathrm{MC}_{\mathrm{i}}\right) \div(1+\mathrm{d})^{\mathrm{i}}\right] \\
\mathrm{C}_{\mathrm{t}}=\sum^{\mathrm{N}}{ }_{\mathrm{i}=1}\left[\left(\mathrm{DC}_{\mathrm{i}}+\mathrm{UC}_{\mathrm{j}}\right) \div(1+\mathrm{d})^{\mathrm{i}}\right]
\end{gathered}
$$

Where:

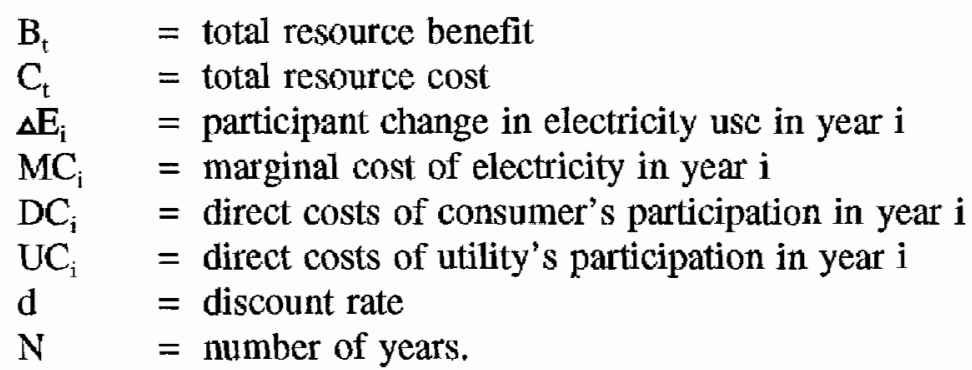

Assume the same parameters as those in the Participant Test example. In addition, assume a one-time direct utility participation cost of $\$ 100$ in the start-up year and a constant dollar marginal clectricity cost (utility's cost) of $\$ 0.06$ per $\mathrm{kWh}$. The marginal cost should include the utility's avoided energy and capacity costs for generation, transmission, and distribution.

The TRC Test for this example is calculated as follows.

$$
\text { TRC Test }=\$ 441.60 \div \$ 600=0.74
$$

where:

$$
\begin{aligned}
& \mathrm{B}_{\mathrm{t}}=\sum_{\mathrm{i}=1}^{10}\left[(1,000 \mathrm{kWh} / \text { year } * \$ 0.06 / \mathrm{kWh}) \div(1+0.06)^{\mathrm{i}}\right]=\$ 441.60 \\
& \mathrm{C}_{\mathrm{t}}=\$ 500+\$ 100=\$ 600
\end{aligned}
$$

Because the TRC test $\mathrm{B} / \mathrm{C}$ ratio is less than 1, this DSM program is not economical from the combined perspeclives of the utility and the ratepayers. It is important. to note that if the incentives paid in a DSM program are exactly equal to the full cost of the equipment to the customer and there are no tax credits, the TRC Test and the Utility Cost Test (described later) yield the same results. 


\section{Ratepayer Impact Measure Test: Nonparticipant Perspective}

The Ratepayer Impact Measure (RIM) Test is a measure of the difference between the change in total revenues paid to a utility and the change in total costs paid by a utility. If the change in revenues is larger or smaller than the change in total costs (RR), then rate levels have to change because of the program. This test is also called the Nonparticipant Test.

The RIM Test can be expressed as follows:

$$
\begin{gathered}
\text { RIM Test }=B_{\mathrm{r}} \div \mathrm{C}_{\mathrm{r}}, \\
\mathrm{B}_{\mathrm{r}}=\Sigma_{{ }_{\mathrm{i}=1}^{\mathrm{N}}\left[\left(\Delta \mathrm{E}_{\mathrm{i}} * \mathrm{MC}_{\mathrm{i}}\right) \div(1+\mathrm{d})^{\mathrm{i}}\right]} \\
\mathrm{C}_{\mathrm{T}}=\sum_{\mathrm{i}=1}^{\mathrm{N}}\left\{\left(\mathrm{I}_{\mathrm{i}}+\mathrm{UC}_{\mathrm{i}}+\Delta \mathrm{E}_{\mathrm{i}}{ }^{*} \mathrm{CR}_{\mathrm{i}}\right) \div(1+\mathrm{d})^{\mathrm{i}}\right\}
\end{gathered}
$$

Where:

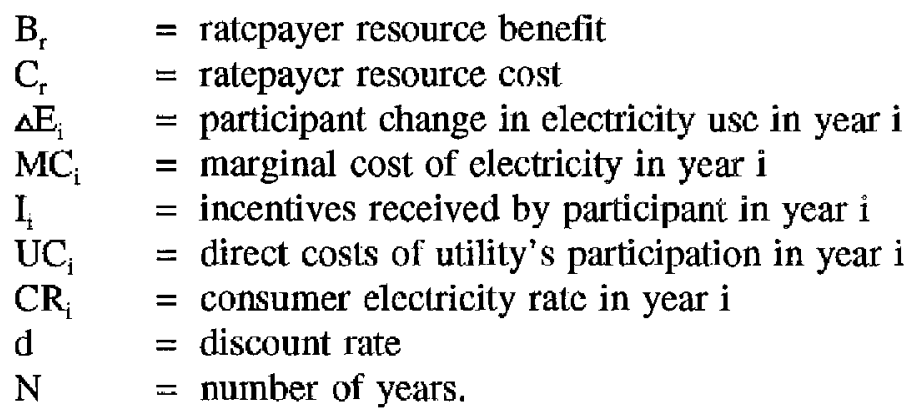

For example, assume the same parameters as those in the TRC Test example. The RIM Test for this example is calculated as follows.

$$
\text { RIM Test }=\$ 441.60 \div \$ 888.80=0.49
$$

Where:

$$
\begin{aligned}
& \mathrm{B}_{\mathrm{r}}=\sum_{\mathrm{i}=1}^{10}\left[(1,000 \mathrm{kWh} / \text { year } * \$ 0.06 / \mathrm{kWh}) \div(1+0.06)^{\mathrm{i}}\right]=\$ 441.60 \\
& \mathrm{C}_{\mathrm{r}}=\$ 200+\$ 100+\Sigma^{10}{ }_{\mathrm{i}=1}\left[(1,000 \mathrm{kWh} / \text { year } * \$ 0.08 / \mathrm{kWh}) \div(1+0.06)^{\mathrm{i}}\right]=\$ 888.80
\end{aligned}
$$

The RIM Test B/C ratio is less than 1, thus, this DSM program is not cost-effective from the ratepaycr perspective because rate levels will increase as a result of this program. If consumer electricity rates are higher than marginal clectricity costs, few programs pass this test. In dollar terms, the two largest components of this tcst are the changes in supply costs and the changes in total revenues. If rates are higher than marginal costs, the benefit of avoided supply costs is overshadowed by the cost of revenue losses.

\section{Utility Cost Test: Utility Perspective}

On the utility side, a DSM program could alter the daily operation of generation and, ultimately, could change the generation, transmission, and distribution systems and administration practices. The benelits from the utility perspective are the avoided supply costs resulting from program implementation. The costs associated with the program can be characterized as customer incentives and direct utility participation costs. 
The utility perspective can be expressed as follows:

$$
\begin{gathered}
\text { UC Test }=B_{u} \div C_{u}, \\
B_{u}=\sum_{i=1}^{N}\left[\left(\Delta E_{i} * M C_{i}\right) \div(1+d)^{i}\right] \\
C_{u}=\sum^{N}{ }_{i=1}\left[\left(I_{i}+U C_{i}\right) \div(1+d)^{i}\right]
\end{gathered}
$$

Where:

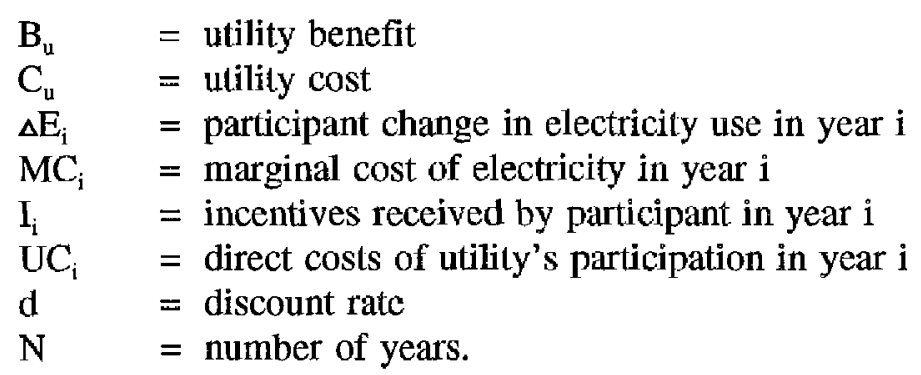

For example, assume the same parameters as those in the RIM Test example. The Utility Cost (UC) Test for this example is calculated as follows.

$$
\text { UC Test }=\$ 441.60 \div \$ 300=1.47
$$

Where:

$$
\begin{aligned}
& \mathrm{B}_{\mathrm{r}}=\sum_{\mathrm{i}=1}^{10}\left[(1,000 \mathrm{kWh} / \text { year } * \$ 0.06 / \mathrm{kWh}) \div(\mathrm{I}+0.06)^{\mathrm{i}}\right]=\$ 441.60 \\
& \mathrm{C}_{\mathrm{r}}=\$ 200+\$ 100=\$ 300 .
\end{aligned}
$$

Because in the long run, total costs to the utility (RR) equal total revenues (total energy bills paid by customers), this test measures the change in the total amount paid in utility bills across all customers. In gencral, a UC Test ratio of less than 1 indicates an increase in the utility's cost due to the implementation of a DSM program. This results in an increased electricity rate that will subsequently increase the total amount paid in utility bills. Similarly, a UC test ratio greater than 1 indicates a decrease in the utility's cost, which will subsequently decrease the total amount paid in utility bills (i.e., lowers customer rates).

\section{Societal Test: Societal Perspective}

The Societal Test is a measure of the net benefits of a DSM program from the point of view of society as a whole. This test attempts to capture all benefits and costs of a DSM program, including externalitics. It is generally agreed that external benefits and costs are difficult to identify and quantify. Refer to the Electric Power Research Institute's (EPRI's) Principles and Practice of Demand-Side Management (EPRI 1993), or the Externalities subsection in Section 5, for discussions regarding incorporating externalities into DSM planning. Benefits associated with the societal perspective include direct and indirect benefits. The direct benefits are the avoided supply costs, whereas the indirect benefits include factors such as increased labor or economic activity and environmental benefits. Direct costs include all consumer and utility expenses associated with the program, whereas indirect costs include items such as decreased labor or economic activity and environmental costs. 
The Societal Test can be expressed as follows:

$$
\begin{gathered}
\mathrm{B} / \mathrm{C} \text { (societal) }=\mathrm{B}_{\mathrm{s}} \div \mathrm{C}_{\mathrm{s}} \\
\mathrm{B}_{\mathrm{s}}=\Sigma_{\mathrm{i}=1}^{\mathrm{N}}\left[\left(\Delta \mathrm{E}_{\mathrm{i}} * \mathrm{MC} \mathrm{C}_{\mathrm{i}}\right)+\left(\mathrm{B}_{\mathrm{ext}}\right)_{\mathrm{i}}\right] \div(\mathrm{l}+\mathrm{d})^{\mathrm{i}} \\
\mathrm{C}_{\mathrm{s}}=\sum_{\mathrm{i}=1}^{\mathrm{N}}\left\{\left[\mathrm{DC}_{\mathrm{i}}+\mathrm{UC}_{\mathrm{i}}+\left(\mathrm{C}_{\mathrm{cst}}\right)_{\mathrm{i}}\right] \div\left(1+\mathrm{d}_{\mathrm{s}}\right)^{\mathrm{i}}\right\}
\end{gathered}
$$

Where:

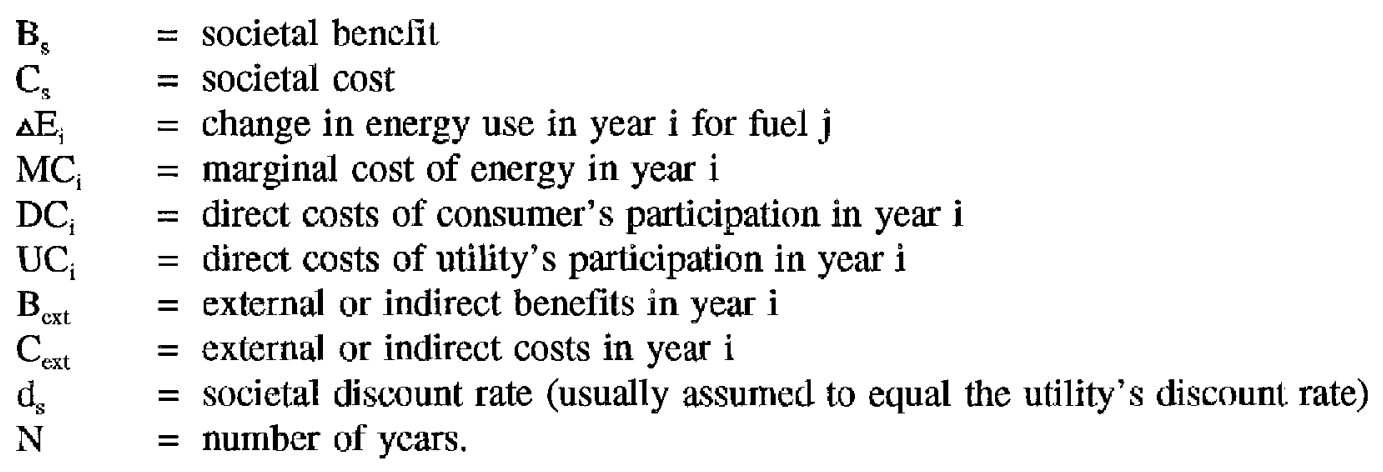

Since its beginnings, DSM has evoked arguments concerning the appropriate screening analysis criteria in the selection of programs. A large portion of the debate pits the advocates of the RIM test against the advocates of the TRC test. Actually, the selection of DSM programs requires consideration of both tests because DSM programs need to address the twin goals of efficiency and equity.

EPRI proposes the following sequential methodology for the selection of DSM programs:

- Eliminate all programs that do not pass the TRC Test.

- Implement all programs that pass the RIM Test.

- Redesign the remaining programs that pass the TRC Test but fail the RIM Test, to minimizc their impact on nonparticipants.

The explanations and definitions provided in this section for the use of $\mathrm{B} / \mathrm{C}$ analysis with IRP have been brief. This section is included in the manual to provide analysts with an awareness of IRP and B/C analyses in actual practice. For more information, please refer to Principles and Practice of Demand-Side Management (EPRI 1993).

\section{Consumer/Producer Surplus}

\section{Introduction}

The implications of research, development, and demonstration (RD\&D) and other policy actions of the DOE Office of Energy Efficiency and Renewable Energy extend beyond the results that may be recorded in a conventional economic analysis, which usually is confined to evaluating the direct impacts on the provider and user of an energy service. There are polential environmental impacts, national security 
benefits and issues, regional and/or rural economic development impacts, national economic benefits (such as consumers' and producers' surplus), and impacts on other federal, state, or local programs.

In voluntary markets, it is generally accepted that some consumers are willing to pay more for a given quantity of a product than they must pay. The difference betwcen the total amount of money a consumer would be willing to pay for a given quanlity of a commodity minus the total expendilures that are necessary to acquire that quantity of the commodity is called the consumer's surplus (Leftwich and Eckert 1985). Conversely, it is generally accepted that some producers are willing to accept less for a given quantity of a product than they receive. The difference between the total amount of money a producer receives for a given quantity of a commodity minus the total expenditures that are necessary to produce that quantity of the commodity is called the producer's surplus.

\section{Discussion}

Figure 4-2 illustrates the concepts of consumer surplus and producer surplus using traditional demand and supply curves.

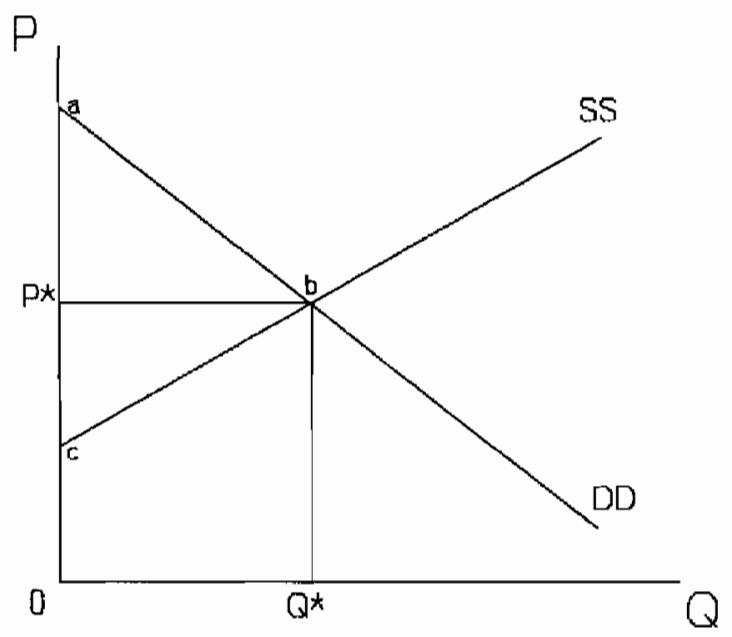

Figure 4-2. Consumer and producer surplus

At the market position $\left(\mathrm{P}^{*}, \mathrm{Q}^{*}\right)$, the market clears for the quantity $\mathrm{Q}^{*}$, selling for the price $\mathrm{P}^{*}$. The area $a b Q * O$ describes the total value the consumer holds for this particular quantity of this commodity. The total amount of money paid for the commodity is $\mathrm{P}^{*} \mathrm{bQ} \mathrm{Q}^{*} \mathrm{O}$. The value held by the consumer for this quantity of the commodity $\left(\mathrm{Q}^{*}\right)$ over and above the total amount paid is abP*, or the consumer surplus.

Because this is a voluntary market, the seller's costs and normal profits ${ }^{27}$ are included in the seller's supply curve. Otherwise, the seller would not be willing or able to produce and supply the quantity of the commodity represented. The total amount of revenucs the producer receives for the sale of $\mathrm{Q}^{*}$ amount of product is $\mathrm{P}^{*} \mathrm{~b} \mathrm{Q}^{*} \mathrm{O}$. The amount the producer would have been willing to accept for $\mathrm{Q}^{*}$ is $\mathrm{cOQ}^{*} \mathrm{~b}$. The amount of money paid to the producer for $\mathrm{Q}^{*}$ of the product over and above the amount the producer would be willing to have sold $\mathrm{Q}^{*}$ for is cbP*. This is also called the producers surplus ( $\mathrm{Au}$ and $\mathrm{Au}$ 1983).

27 Normal profits are defined by the opportunity costs for the producer. 
Now assume the previous case is the U.S. encrgy market. Let federal policy be such that additional cnergy suppliers enter into the market (e.g., additional renewable energy resource producers). This results in the encrgy's market supply curve (from SS) shift to the right (to SS'), as shown in Figure 4-3. Let all income effects, which result from the change in the price of energy, be allowed for in the price/quantity relationship for the commodity (i.e., the demand curve DD). ${ }^{28}$ The new market clearing position with the additional energy suppliers is $\mathrm{Q}^{* *}$, at a price of $\mathrm{P}^{* *} . \mathrm{P}^{* *} \mathrm{dQ}^{* *} \mathrm{O}$ represents the total amount paid for the quantity $\mathrm{Q}^{* *}$. The area adP** describes the new consumer surplus. The new producer surplus is represented by the area $\mathrm{dgP}^{* *}$.

If the welfare of a society includes both consumer and producer surplus, then the total additional consumer surplus captured by the consumer (indicated by $\mathrm{P}^{*}$ bdP**) as a result of the lowering of the price of a commodity does not represent the net increase in welfare to society. $\mathrm{P*}$ bdP** does not represent a net increase in society's well-bcing becausc the area $\mathrm{P}^{*}$ beP** was previously included in payments made to the suppliers. Thus, the part of this amount representing producer surplus $\left(\mathrm{P}^{*} \mathrm{bh} \mathrm{P}^{* *}\right)$ was simply shifted from the surplus of producers in the society to the consumers. As such, it does not represent a total increase in well-being for the society but merely a reallocation of surplus.

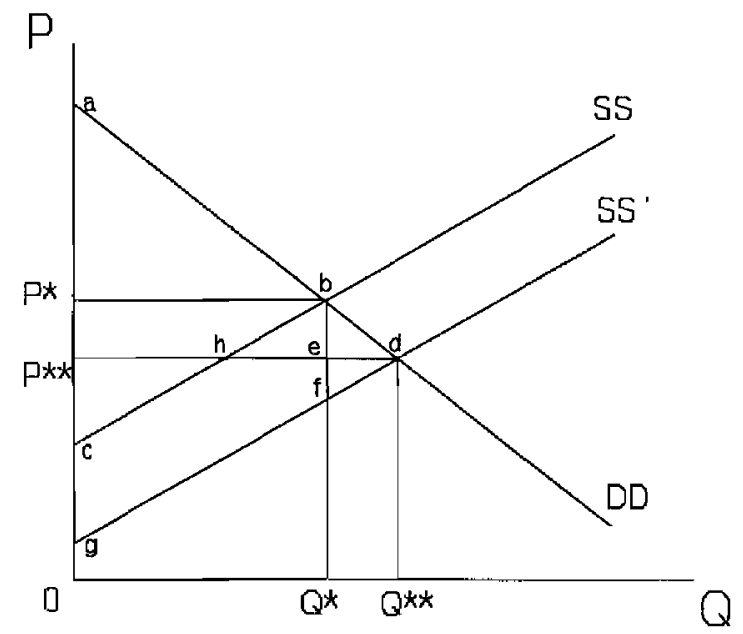

Figure 4-3. Consumer and producer surplus with additional supply

The change in welfare for the society that resulted from the lowering of the price of energy can be described as the area adg $-\mathrm{abc}=\mathrm{cbdg}$. These results provide some interesting insights into potential societal benefits from policy actions. For example,

- If the price of a commodity or service is reduced as the result of RD\&D investments, the investment cost can be compared to the additional consumer surplus (cbdg) produced (the supply curves are flat in this example so there is no producer surplus) to obtain the first order estimate of the benefit of the RD\&D. If, for example, RD\&D investment in efficient refrigerators lowered their price by $\$ 100$ per unit, increasing sales from 100,000 per year to 150,000 , the added consumer surplus would be $\$ 10$ million (cbeg) plus $\$ 2.5$ million (bde). (See Figure 4-4.)

28 Technically speaking, this is referred to as a constant real income demand curve (Leftwich and Eckert 1985). 
- If the price of a commodity or service is reduced by a subsidy, there may be a net loss in consumer welfare (see Figure 4-4). If there are no cost reductions as the result of economies of scalc, and the price declines by the amount of the subsidy, the burden (czdg) must be absorbed elsewhere in the economy and will exceed the gain in consumer's surplus (cbdg) for the subsidized good or service. If the overall benefits to society as a result of the subsidy are greater than the area represented by triangle (bzd), then the subsidy is deemed a good one. Again, the supply curves are assumed to be flat.

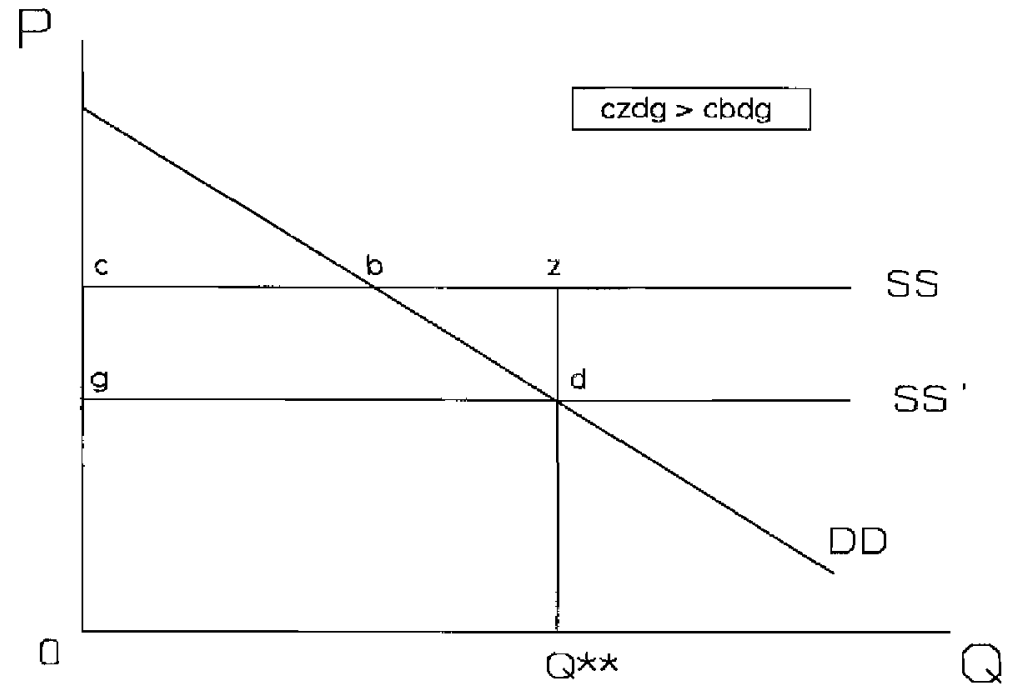

Figure 4-4. Consumer and producer surplus with subsidy price changes 


\section{Special Considerations for Energy Efficiency and Renewable Energy Systems}

This section is included to identify special situations that might occur during an EE analysis and to provide guidance when these situations arise. Remember also that the Selection Criteria Guide, Section 3, offers further advice concerning which economic measures are appropriate to use, given some of these same special considerations. This scclion will address system boundaries, optimal sizing, externalities, government investments, backup and hybrid systems, storage, O\&M expense, capacity and energy values, major repairs and replacements, salvage valuc, unequal lifetimes, retrofits, clectricity rates, and program evaluation.

\section{System Boundaries}

Many times il is necessary to include the entire system in an analysis. For example, suppose the analyst must compare a wind system with a conventional peak-load generating system. These alternatives offer potentially different services, and in order for the comparison to make sense the entire utility system may have to be evaluated.

The need to extend a system's boundary beyond the direct boundary may occur in end use markets as well as in utility investments. For example, a daylighting system will have different impacts on the space heating and cooling requirements of a building than those of a conventional lighting system. These different impacts can be addressed either by including the entire heating, ventilating, and air conditioning systems in the analysis (which may, in turn, require that the building shell be included) or, more simply, by including only the value of the impacts (determined exogenously from the lighting analysis). A dollar value credit or cost can be appended to the annual operating cost of the daylighting system to account for these space conditioning impacts.

\section{Sizing a System}

Equipment sizes for most systems should be individually designed to fit the particular situation. As such, the particular parameters and concerns rclevant to the sizing of conservation and renewable energy technology equipment will not be discussed here. If the engineering analysis has been done correctly, then the economic analysis for determining optimum size is simply the same as the economic analysis used in making other mutually exclusive decisions. Once the range of acceptable alternatives has been established, the various sizes are compared one with another. It is important to include the cost of backup systems, should they be necessary for a particular technology. The standard measures used for analysis are the levelized cost of energy (LCOE) and the savings/investment ratio (SIR).

\section{Externalities}

As mentioned in the Integrated Resource Planning/DSM Ratio Test subsection in Section 4, utilities in at least 46 states, as of June 1993, were engaged in some form of formal IRP planning in the regulatory setting. Many of these recent IRP planning guidelines include instructions on how to handle externalities. Some assign costs to specific externalities, which can be used in analyses. The analyst should consult the applicable public utility commission to see how externalities are handled in that particular stale. A good source of information has been developed by Koomey (July 1990), which outlines how different analysts and state regulatory agencies have treated externalities and compared them on a consistent basis. 
For nonutility investments, the approach is a little less clear. If the costs or benefits associated with the externality cannot be measured, the analyst may have no choice but to leave them out of a quantitative analysis and simply mention them in a qualitative analysis. If it is deemed necessary to quantify the externality, the analyst may go one step further and express the externality in units other than money, such as units of particulates per unit of output in the case of pollution. This method at least provides the decision maker with information about the size of the externality.

If the analysis requires further quantitalive measures, it may be necessary to assign a dollar amount to the costs and benefits. In this case, the valucs arrived at by state commissions for utility applications may be usable. After all, an emission such as sulfur dioxide has the same cost (to socicty) regardless of its source. If similar costs and benefits have not been valued by the state commission, it may be necessary to establish a "willingness to pay" in order to receive the benefit or forego the cost. Surveys, experiments, simulation, and so on can be used to arrive at a willingness to pay. Willingness to accept payment may also have to be considered because the amount of money a person is willing to pay to receive a benefit or forego a cost may be entirely different than the amount of money a person is willing to accept to incur a cost or forego a benefit. Another approach is to make analogies between similar products. For example, the value of public land use could be estimated by prices paid in recent private land sales nearby.

It is also a good idea to conduct a sensitivity analysis of the results with respect to the measured cost and benefits of the extcrnalitics. Many times the values assigned to specific externalities are provided as a range, and a sensitivity analysis on this range of values should be performed. In some cases, the inclusion of such costs and benefits will reinforce the results of the analysis in the absence of the costs and benefits. In these cases, they may be appropriate to exclude.

Again, judgment from the analyst is needed. Perhaps this level of detail is not warranted or perhaps the externality at issue will not make a difference in the ultimate decision. Regardless of the stance taken, both a qualitative discussion and a sensitivity analysis is recommended.

\section{Government Investments}

Recall from the Discount Rates subsection in Section 2 that discount rates are calculated annually by the federal government for use in analyses associated with government projects and, more specifically, government projects dealing with conservation and renewable energy systems. The 1995 value, in real terms, for all federal projects that have the option to use energy conservation or renewable energy is $3 \%$.

For many government investments, the perspective should be broadened to include not only the costs and benefits to the government and any direct beneficiaries but also to indirect beneficiaries. For example, government research on photovollaics will benefit everyone, not just the photovoltaic industry and its customers, because increased photovoltaic use will reduce overall demand, thus reducing prices of conventional fucls. However, some economic evaluations of government investments will require a private investor perspective. For example, once the government makes the decision to sponsor photovoltaic research, an economic evaluation from a private investor perspective should be performed to determine if the new technology will succeed in the marketplace.

Another point is that "government" includes more than the federal arena. It includes city, county, and state governments, which may need to account for factors such as investment tax credits.

\section{Backup and Hybrid Systems}

It is important to consider all costs in the analytic process. If an option requires a backup unit, the cost (capital, operation, maintenance, and so forth) and output of the backup unit should be included. As an 
example, assume that the climate is such that an electric heat pump cannot provide adequale space heat for a dwelling on a significant number of days in the winier months, requiring a backup space heating unit. Thus, for comparison purposes among space heating options, the correct cost for the heat pump is not just the direct cost associated with the heat pump but also the costs associated with the backup space heating unit.

The introduction of a backup unit in a renewable energy system, such as a solar energy system, raises the issue of the size of the solar energy portion of the system and the solar fraction provided. To determine the optimal solar fraction, the life-cycle cost of the entire system (including backup) should be computed for different solar fractions and the results compared.

As shown by the ordinate on the left in Figure 5-1, the optimal solar system size will correspond to the minimum life-cycle cost. For solar fractions smaller than the optimal, the cost of the conventional fuel will make the system's total life-cycle cost (TLCC) higher, while for larger solar fractions, the increased capital cost associated with the solar panels will make the system's TLCC higher. As shown by the ordinate on the right in Figure 5-1, the optimal solar fraction is also the point at which the marginal cost per unit of output from the solar energy system equals the marginal cost per unit of output of the conventional alternative.

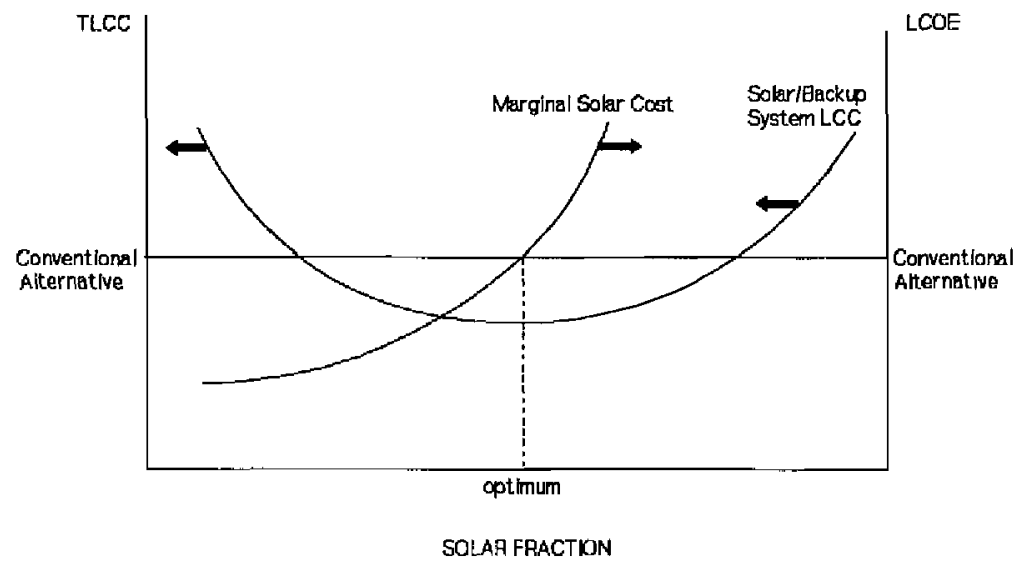

Figure 5-1. Solar fraction optimization

A renewable energy system for electric utility applications with a backup system is often referred to as a hybrid system. For these electric hybrid systems, the size of the two components (renewable and conventional backup) is sometimes dictated by regulation; i.e., the Public Utilities Regulatory Policies Act. (PURPA) requires that no more than $25 \%$ of the power be generated by fossil fucls in order to be classified as a qualifying facility.

\section{Storage}

The purpose of storage is to generate and store energy during low-cost, off-peak periods, so it can be discharged during high-demand, on-peak periods. There are many forms of energy storage. In an active solar system for domestic hot water, the tank associated with the backup system may serve as storage, or another tank may be required. A passive solar system may use storage in the form of the mass of the building itself, or use mass added specifically for storage purposes. Similarly, thermal storage may be 
added to a building, not in conjunction with a renewable energy system but as part of a DSM program, to reduce the electric heating (or cooling) peak demand in an all-electric house.

Storage may enhance the value of intermittent renewable energy technologies for electricity generation such as photovoltaics or wind because they may be considered more dispatchable. On the other hand, significant storage within a utility system may reduce the peak supply required, and consequently, reduce the value of a technology like photovoltaics, whose time of availability will frequently match the time of the peak utility load in a summer-peaking utility. Thus, to fully evaluate the economies of storage for an elcctricity-generating technology, storage must be cxamined within the utility system as a whole, not simply as a component of the generating system.

Simpler comparisons among different storage technologies must consider a number of the altributes of storage technologies. The LCOE of the electricity stored and discharged is probably the more important measure, but other factors such as charge/discharge rate and the capacity or amount of energy that can be stored in any single charge may be equally important.

\section{Operation and Maintenance}

There is no absolute standard as to which costs are included in O\&M costs. Costs that are normally included in $O \& M$ are frequently recurring labor and materials costs required to keep a system in operation. Infrequent major repair and replacement usually should be considered separately. However, as mentioned in the Major Repairs and Replacements subsection in Section 5, these major replacement costs can be annualized and included. with O\&M costs. This occurs more frequently in the analyses of systems for which energy is a minor cost component.

Regardless of which costs are included in O\&M, they can be broken into the following categories: those costs that occur only when the system is operating, variable O\&M costs, and those fixed costs that do not vary with the output of the system but rather are required to keep the system in an operable state. Energy costs are typically variable O\&M costs, whereas labor costs are frequently fixed O\&M costs.

For mature technologies, estimalion of future O\&M costs is generally based on historical performance. For mature conventional fossil fuel systems, it is often assumed that annual O\&M costs (excluding fossil fuel costs) will equal about $1 \%$ to $2 \%$ of the system's initial capital cost. However, for conservation and renewable cnergy systems that are typically in the carly stages of technical and market development, $O \& M$ costs are more difficult to estimate. For these new technologics, widespread use over an extended period of time has not generally occurred. This is especially true when reliability problems have increased past O\&M costs because the unreliable systems usually are quickly replaced by manufacturers with more teliable systems. Sometimes the improved, more reliable systems are also more expensive, making the simplistic rule that annual O\&M equals $2 \%$ of capital costs even more fallacious.

Whatever the O\&M costs are for the first year of operation of a system, they will most likely increase (in nominal dollars) with inflationary pressures and as the system gets older and more maintenance is required. Here again, it is difficult to estimate how rapid the increase over time will be. The typical assumption that O\&M costs will increase at the same rate as inflation is reasonable in the absence of any data to the contrary. 
This assumption is easily implemented in a real-dollar LCOE calculation, as follows (see the subsection Levelized Cost of Energy in Section 4):

$$
\mathrm{LCOE}=\frac{\mathrm{I} \times \mathrm{FCR}}{\mathrm{Q}} \pm \frac{\mathrm{O} \& \mathrm{M}}{\mathrm{Q}}
$$

where $O \& M$ is the annual $O \& M$ cost, including energy cost, $Q$ is annual output, FCR is the fixed charge rate, and $I$ is the initial investment.

However, the use of this simple formula for the calculation of the nominal LCOE (when FCR is calculated with a nominal discount rate) would implicitly assume that $O \& M$ costs do not increase with inflation and are unchanging in current dollars.

\section{Capacity and Energy Value}

Up to this point, economic analyses of energy systems have been discussed as if the value of such systems could be captured through a single economic measure, such as LCOE or net present value (NPV). For these measures, the usual assumption is that one unit of energy is just like any other. However, energy has more value if it can be made available whenever it is needed by the consumer. Similarly, reductions in energy use are more valuable if they occur at the time of peak consumption. ${ }^{29}$ Thus, energy delivered at the time of peak use is more valuable than that delivered at any other time. The amount of energy that can be delivered reliably by a system at the time of peak demand is a measure of the capacity value of the system, whercas the amount of energy delivered over the course of a year, independent of coincidence with peak demand, is a measure of the energy value of the system.

When comparing two systems having varying energy output or consumption, it is imporlant to recognize any such diflerences and to alter the comparison sufficiently to ensure that the two systems are effectively supplying the same service. For some systems, such as the heat pump example presented in the Backup and Hybrid Systems subsection in this section, it is sufficient to include a backup system. For the utility sector, one similar approach has been to pair an intermitlent renewable technology like a windmill with a peaking unit such as a combustion turbine to makc an cconomic comparison with a conventional generating system that has a much greater availability than the wind mill alone. In this case, if the windmill/combustion turbine system is the more economic alternative, the analysis is complete, and the windmill/turbine is the preferred alternative. However, if, as is often the case, the conventional unit alone appears to be the more cost-effective alternative, one must be careful in drawing conclusions from the comparison for two reasons:

1. The availability of wind is highly random but in many locations shows some time-of-day patterns (this is especially true for some of the existing California wind farms). Thus, a true test of the capacity and energy value of intermittent renewable energy technologies (i.e., wind and PV), as well as of many DSM technologies, must take into account the time of day of the power demands and the resource availability.

2. The pairing of the windmill with the combustion turbine is suboptimal. Given that a utility grid is operated not as individual units but as a system, the value and economic competitiveness of the windmill can really be accurately estimated only within the context of the utility system as a whole.

\footnotetext{
${ }^{29}$ The concept of energy and capacity values applies to encrgy consuming as well as encrgy supply technologies.
} 
For both of these rcasons, accurate evaluation of intermittent renewable electricity generating technologies and many DSM technologies requires the modeling of the utility system as a whole to compute the required revenues of the utility with and without each of the technology options. This can be an extensive modeling process, and it has the drawback that one must pick a specific utility generation mix/load to achieve results that are essentially valid for only that specific situation.

To summarize, the three alternatives presented here are as follows.

1. Compare on the basis of energy value only.

2. Pair an intermittent technology with a conventional technology to compare with a conventional technology that will provide an equal service.

3. Evaluate the required revenues of a utility with and without each of the technology alternatives.

The method used depends on the purpose of the analysis, the relative economic strength and value of each technology option, and the resources available to conduct the analysis.

It is difficult to discuss capacity and energy values without mentioning avoided costs. In 1978, PURPA was passed. This act requires utilities to purchase power from qualifying facilities (QFs) at a price equal to the specific utility's avoided costs for energy and capacity. A QF is a cogeneration facility or a small power production facility (producing electricity by means of biomass, waste, geothermal, or renewable wind, solar, or hydro). ${ }^{30}$ The Federal Energy Regulatory Commission (FERC) defines avoided costs as "the incremental cost to an electric utility of the electric energy or capacity or both which, but for the purchase from the qualifying facilities, such utility would generate itself or purchase from another source."

Avoided costs can be in the form of avoided capacity costs or avoided encrgy costs or both. Avoided capacity cost is the change in a utility's generation, transmission, and distribution capacity costs as a result of a portion of the utility's capacity being supplied by a QF. Avoided capacity costs are normally provided on a dollar per kW basis. Avoided energy costs are those energy costs avoided when purchasing a $\mathrm{kWh}$ from a $\mathrm{QF}$. When the overall amount of energy purchased from the QF is small compared to the utility's total system output, avoided energy costs will mimic the utility's marginal energy costs. Avoided energy costs are typically provided on a per-kWh basis. Rate structures incorporating avoided costs will be different for specific utilities. Some will incorporate both avoided capacity and avoided energy costs, while others might have one number that accounts for both.

When performing an analysis in which avoided cost is a variable, the analyst should be aware that avoided cost calculation techniques will vary across utilities and states, and that the values for any given utility will change over time. For example, a utility may have a large base-load unit as its avoided plant on which avoided costs are based. However, 2 years from now, the utility may revise its capacily expansion plans so that the large base-1oad unit is no longer needed in the near future and, instead, plan to use a smaller peaking unit. Thus, the avoided costs are changed.

Equally important is the fact that the PURPA rules governing electricity purchases at avoided costs offer room for discretion. For example, some utilities will negotiate specific contracts with cogenerators that

\footnotetext{
${ }^{30}$ To qualify under PURPA, QFs must have less than a $50 \%$ equity interest held by electric utilities, electric holding companies or subsidiaries, or combinations of the two. A small power production QF may not exceed $80 \mathrm{MW}$ (although this restriction has been temporarily lifted) and must use the fuels listed above for at least $75 \%$ of the total energy input.
} 
have prices different than the utility's avoided costs. PURPA, FERC, and many statc regulations will support negotiated contracts. State regulators have the freedom to provide incentives for cogeneration as long as PURPA and FERC regulations are not violated.

On the subject of avoided costs, the analyst must remember to include avoided transmission and distribution (T\&D) costs when applicable. Studies have shown that $T \& D$ benefits can be large enough to make DSM or conservation programs cost-effective, even for programs not considered cost-effective prior to the inclusion of T\&D benefits (Krause, Busch, and Koomey 1992).

\section{Major Repairs and Replacements}

Many renewable and conservation systems have components that will need to be repaired or replaced during the analysis period. If these are annual adjustments, such as an air filter, costs should be included in the annual operating cost estimates. On the other hand, there may be large, significant adjustments that need only be done once or twice during the analysis period. The costs of these larger repairs or replacements should be explicitly included in the analysis.

The more common method of accounting for these significant repairs and replacements is to assume that the repair or replacement occurs at the end of the component's expected useful life, discount the repair or replaccment cost to its present value at the beginning of the analysis period, then add it to the initial investment cost. Of course, the present value of the repair or replacement should not be added to the initial investment costs before the investment cost is multiplied by factors that compute properly taxes, insurance, and so on.

Another method of accounting for repair and replacement costs is to annualize the costs over the system life and include these costs with annual $O \& M$. However, the analyst must be careful when using this method because for tax purposes major repair or replacement costs should be capitalized and the cost recovered through depreciation. The method would be fine for a homeowncr, who does not depreciate itcms for tax purposes.

\section{Salvage Value}

Salvage value is the value of an investment remaining at the end of the analysis period. For example, if an investment can be resold or recycled, a positive salvage value exists, and if the investment must be dismantled or destroyed, a negative salvage value exists. In most cases, salvage value is estimated as the resale value of the investment. Another method is replacing the cost of the investment with that of equal characteristics and conditions. Still another method is to equate salvage value to the unamortized portion of the original or replacement costs.

For all economic measures, exccpt payback, salvage value is Ireated as a revenue stream at the end of the evaluation life. Salvage value is not accounted for when calculating depreciation for tax purposes using an accelerated depreciation method. However, an asset may not be depreciated below a rcasonable salvagc value (CCH 1992).

\section{Unequal Lifetimes}

Many of the measures introduced up to this point present useful, unbiased results only if the two investments being compared have equal lifetimes. Those measures most impacted by unequal lifetimes include life-cycle cost, required revenues, and internal rate of return. The inequity of comparing alternatives with different lifetimes using cost measures such as life-cycle cost arises because the costs of 
the longer-lived investment are summed over a longer period, but benefits that occur over the longer life are ignored. With measures such as internal rate of return, the inequities, which are less obvious, are a result of uncertainties as to what will happen at the end of the lifetime of the shorter-lived investment. These uncertainties include: Will it be possible to reinvest in a similar short-lived investment at that time? Will the same financing and tax depreciation be available then?

Although there is no way to fully overcome such issues, there arc four options: (1) assume multiple shortterm investments with a total analysis period equal to the life of the longer-lived option, (2) find the least common multiple of the service lives, (3) lengthen the shorter investment life (through increased repair and maintenance), or (4) shorten the longer investment life (by adding the estimated forcgone years of future return to the salvage value of the longer lifetime investment). The problem with both of the last two approaches is that there is the addition of a subjective estimate on future costs and worth (i.e., increases in repair and maintenance or replacement costs or salvage value). There is no universal rule as to which method to use or how to approach the problem. Each situation is unique and requires the analyst to make an individual decision (Short 1983). Sensitivity analysis with respect to the lifetime assumptions is recommended.

It may very well be that the lifelime of the investment is not a critical factor. In this case, a fifth alternalive is available in which the alternative investments are treated as any other investments using measures in which lifetime does not have a major impact on the comparison of alternatives such as LCOE and payback.

\section{Retrofits}

In the economic analysis of retrofits, the analyst must not only determine if it is economical to retrofit, but also when it would be most economical to retrofit. If conventional fuel prices are predicted to rise substantially in a couple of years, then it may be more economical to wait and retrofit in 2 years.

Determining the appropriate time to retrofit is difficult because the useful life of the retrofit investment ends for each alternative at a different point in time. This complexity is minimized by comparing only two alternatives at a time, with the second alternative representing investment in the retrofit 1 year later than the first alternative. The approach follows:

1. Select the first year for which the retrofit will be considered (frequently the present).

2. Compare the retrolit in this base year with no retrofit at all to ensure that retrofitting makes economic sense. If it is not economical, proceed no further until at least one point in time (the new base year) can be identified at which retrofitting is economical.

3. Compare retrofit in the year after the base year with no retrofit at all. If the next year retrofit is not economical, the base year is optimal.

4. Using the LCOE as the economic measure and the useful life of the retrofit investment, compute the LCOE of the base year retrofit.

5. Compute the LCOE of the next year retrofit with an analysis period 1 year longer beginning at the same time as the analysis period of the base year retrofit (i.e., the retrofit does not occur until the second year of the analysis period) and ending at the end of the useful life of the next year retrofit.

6. Compare these two LCOEs. If the base year LCOE is better, it is optimal. If nol, assign the next year as the base year and return to step 3 . 
Figure 5-2 provides an example of different scenarios that could occur using this six-step approach and indicates the appropriate action that should be taken. In the simple case (Case 2) in which real conventional O\&M costs (including encrgy costs) start below the rcal LCOE of the retrofit and rise above it over time, and the costs of the retrolit are unchanging in real terms, the optimal retrofit time is the beginning of the year in which the real delivered conventional O\&M cost first exceeds the real LCOE of the retrofit (see Appendix G).

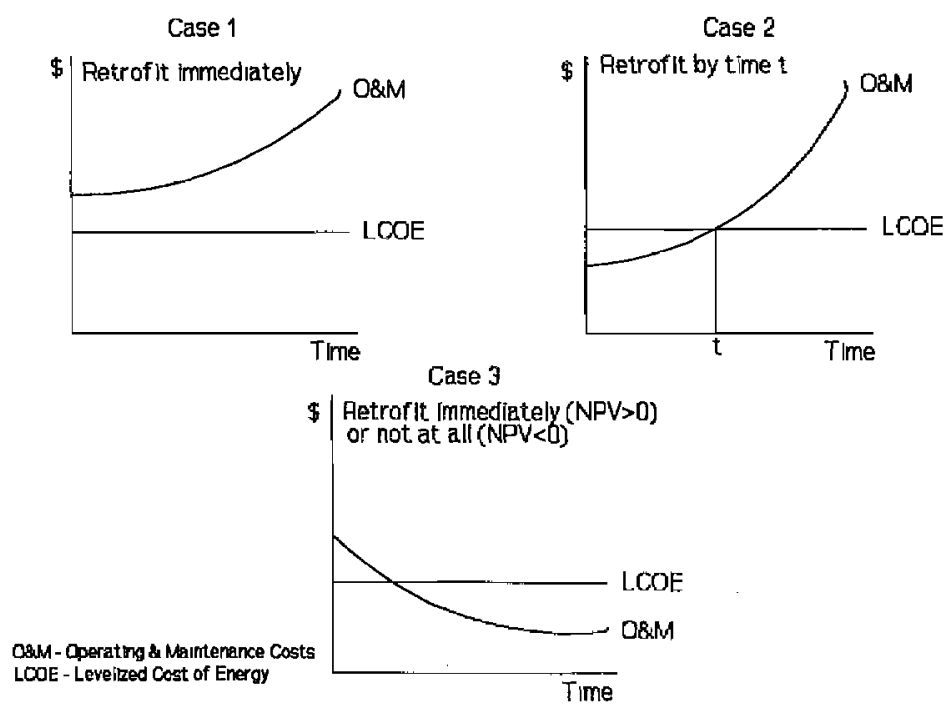

Figure 5-2. Retrofit scenarios

For analyses in which the $O \& M$ costs are nonmonotonic, the retrofit costs (operating, capital, and so forth) vary, or both, the previous approach may yield only a local optima, and additional comparisons may be necessary between retrofits separated in time by more than 1 year. Even when all costs are expected to be unchanging over time, there is some risk that they will change, altering the optimal time to retrofit. The analyst should consider such uncertainties in the analysis and its conclusions.

\section{Incorporating Electric Utility Rates in an Analysis}

Electricity rates and the implications of those rates on the investment itself are a key aspect of an economic analysis of EE technologies. For most electric utilities, the objective is to design rates that will reflect the utility's cost of service to the particular customer or customer class. These costs can be classified into capacity, energy, and customer-related cost components. Such functional classification is necessary because each of these costs for a utility system are incurred in a different manner. For example, capacily costs vary with the customer's peak demand and are associated wilh clectricity usage and the maximum capacity required to serve this load (i.e., production facilitics). Encrgy costs are those costs associated with the consumption of electricity, and thus vary largely with kilowatt-hour usage (i.e., fuel use and cost). Customer costs vary principally with the number of customers a utility serves (e.g., meters, billing).

Rates will be different for residential, commercial, and industrial customers because the cost of providing service to these different classes of customers is different. In addition, each electric utility will have different rate structures given differing costs. Most utilities usually offer rate choices to customer classes. Residential customers may have a choice between straight customer and energy charges, blocked rate structures, rates including demand charges, time-of-use structures, and others. Most commercial and industrial rate structures will be blocked structures and include demand charges. Time-of-use rates are 
usually an option for these two classes. In addition, the industrial customer may have choices of intcruptible and standby rates and may even have the option of selling the utility electricity if the customer is a cogenerator.

It is very important that the analyst consider the appropriate rates and effects that any investment may have on the customer's consumption pattern. Given an analysis associated with a well-defined specific investment (electricity usage patterns before and after the investment is made are known and the investment is made in a specific utility's service area in which the appropriate rates are known), the analyst should use the appropriate electricity rates and usage patterns of the customer. The actual change in usage patterns due to the investment may in some cases be difficult to arrive at. For example, the reduced nameplate capacity of a new, more energy-efficient appliance does not necessarily translate into an equal reduction in the investor's peak demand. In this case, it is appropriate to perform a sensitivity analysis, varying the impact of the investment on the investor's electricity usage.

Given a nonspecific or generic analysis, it may be more difficult to perform an analysis incorporating utility rate structures because rate structures vary significantly among utilities. In these nonspecific cases, the analyst may have no choice other than to use an average cents per kWh figure for the price of electricity. The Edison Electric Institute (EEI) publishes an annual report called Statistical Yearbook of the Electric Utility Industry (1991) in which average electricity prices (cents per kWh) are given for residential, commercial, and industrial customers by state and region, and for the nation. Whenever an average cents per $\mathrm{kWh}$ figure is used in an analysis, it should be noted that no distinction is being made between capacity and energy through the use of such an average rate.

Most residential rates do not include demand charges; thus, the cents per kWh figures found in the EEI yearbook will provide good approximations for use when the analysis is directed to the residential class. On the other hand, most commercial and industrial rates include demand charges, and use of the EEI cents per $\mathrm{kWh}$ figures may skew the results of the analysis. The problem associated with using these figures is that they do not account for usage pattern changes in demand. For example, a commercial cool storage investment may shift a customer's peak demand usage while maintaining the same total $\mathrm{kWh}$ usage. Therefore, using a cents per kWh figure as the proxy for the electricity bill would show no change in the customer's bill after installing the cool storage system.

If the technology being analyred leads to changes in the time of electricity use for a generic industrial or commercial customer, the implications of this usage pattern change should be investigated through a sensitivity analysis. The impact of the change should be assessed by varying both the change in size and/or timing of peak demands, as well as by varying the rate structures and rates associated with energy and demand changes. For example, the effects of replacing a commercial chiller with a more efficient unit having electrical requirements $5 \mathrm{~kW}$ lower than its predecessor should be analyzed over a range of impacts on the commercial establishment's peak load (the high end of the range being $5 \mathrm{~kW}$ ) and over a range of demand charges per $\mathrm{kW}$ representative of the utilities' rate structures in the region(s) of interest. 


\section{References}

Au, Tung and Au, Thomas P., (1983). Engineering Economics for Capital Investment Analysis, Boston: Allyn and Bacon Inc.

Blum, S., Schweizer, T., Morse, F., (1989). Guidelines for the Economic Analysis of Renewable Energy Technology Applications, Based on the Findings of the International Energy Agency Workshop on the Economics of Renewable Energy Technologies, Quebec, Canada.

Brown, Robert J., and Yanuck, Rudolph R., (1980). Life Cycle Costing: A Practical Guide for Energy Working Definitions, Managers, Atlanta: Fairmont Press Inc.

Carasso, Meir. (1995). Energy Efficiency and Renewable Energy Technology Characterizations: Working Definitions, Guidelines, and Forms. Golden, CO: National Renewable Energy Laboratory.

Charles River Associates Inc., (1986). Capital Budgeting for Utilities: The Revenue Requirements Method, EPRI rescarch project EA-4879, 1920-3-1, Palo Alto: EPRI.

Commerce Clearing House, Inc. (CCH), (1992), 1992 U.S. Master Tax Guide, 75th Anniversary Edition.

Commerce Clearing House, Inc. (CCH), (1993). December 311993 State Tax Handbook.

Edison Electric Institute (EEI), (October 1991). Statistical Yearbook of the Electric Utility Industry 1990.

Electric Power Research Institute (EPRI), (May 1987). TAG - Technical Assessment Guide, Volume 3: Fundamentals and Methods, Supply-1986, Palo Alto: Electric Power Research Institute, EPRI P-4463-SR.

Electric Power Research Institute (EPRI), (September 1989). TAG - Technical Assessment Guide, Electricity Supply-1989, Palo Alto: Electric Power Research Institute, EPRI P-6857-L.

Electric Power Research Institute (EPRI), (December 1991). TAG TM Technical Assessment Guide Electricity Supply, Palo Alto: Electric Power Research Institute, EPRI TR-100281, Volume 3: Rev. 6.

Electric Power Research Institute (EPRI), (June 1993). TAG ${ }^{T M}$ Technical Assessment Guide - Electricity Supply, Palo Alto: Electric Power Research Institute, EPRI TR-100281, Volume 3: Rev. 7.

Electric Power Research Institute (EPRI), (August 1993). Principles and Practice of Demand-Side Management, Palo Alto: Electric Power Research Institute, EPRI TR-102556.

Goldman, C., Hirst, E., and Krause, F. (May 1989). Least-Cost Planning in the Utility Sector: Progress and Challenges, Washington D.C.: U.S. Department of Energy; Berkeley, CA: Lawrence Berkeley; Oak Ridge, TN: Oak Ridge National Laboratory.

Hammersley, J. M., (1965). Monte Carlo Methods, London: Methuen.

Howard, R.A., (1977). Readings in Decision Analysis, The Foundations of Decision Analysis, Stanford Research Institute.

Howard, R.A., (1990). Influence Diagrams, Belief Nets, and Decision Analysis, From Influence to Relevance to Knowledge, New York: John Wiley and Sons. 
Internal Revenue Service (IRS), Department of the Treasury, (1993). Depreciation, publication 534.

Koomey, J., (1990). Energy Efficiency Choices in New Office Buildings: An Investigation of Market Failures and Corrective Policies, Dissertation - University of California at Bcrkeley.

Koomey, J., (July 1990). Comparative Analysis of Monetary Estimates of External Environmental Costs Associated with Combustion of Fossil Fuels, Berkeley, CA: Lawrence Berkeley Laboratory, LBL-28313.

Krause, F., Busch, I., and Koomey, J., (1992). Incorporating Global Warming Risks in Power Sector Planning, A Case Study of the New England Region: Volume II, Berkeley, CA: Lawrence Berkeley Laboratory, LBL-30797.

Leftwich, Richard H., and Eckert, Ross D., (1985). The Price System and Resource Allocation, Ninth edition, New York: Dryden Press.

Lind, Robert, C., (1982). Discounting for Time and Risk in Energy Policy, Resources for the Future, Inc., introduction of publication.

Logan, D., Neil, C., and Taylor, A., (1994). Modeling Renewable Energy Resources in Integrated Resource Planning, Golden, CO: National Renewable Energy Laboratory, NREL/TP-462-6439.

Lotus Development Company, (1991). Lotus 1-2-3 Release 3.1: Reference, Cambridge: Lotus Developmenl Company.

Office of Management and Budget (OMB), (October 1992). Circular No. A-94, Executive Office of the President, Appendix C addendum (January 1995).

Packey, Daniel, (1993). Market Penetration of New Energy Technologies, Golden, CO: National Renewable Energy Laboratory, NREL/TP-462-4860.

Palm, Thomas and Qayum, Abdul, (1985). Private and Public Investment Analysis, Cincinnati: SouthWestern Publishing Co.

Petersen, Stephen R., (1994). Energy Prices and Discount Factors for Life-Cycle Cost Analysis 1995: Annual Supplement to NIST Handbook 135 and NBS Special Publication 709, Department of Commerce, National Institute of Standards and Technology, NISTIR 85-3273-9.

Phillips, Charles F., Jr., (1988). The Regulation of Public Utilities, Public Utilities Reports, Inc., Second Edition.

Ruegg, Rosalic, (1987). Life-Cycle Costing Manual for the Federal Management Program, NBS Handbook 135 (Revised 1987) Washington, DC: U. S. Printing Oflice.

Ruegg, R. and Marshall, H., (1990). Building Economics: Theory and Practice, Van Nostrand Reinhold.

Ruegg, R. and Petersen, S., (1987). Comprehensive Guide for Least-Cost Energy Decisions, NBS Special Publication 709, Washinglon, DC: U. S. Printing Office.

Samuelson, Paul A. and Nordhaus, William D., (1985). Economics, Twelfth Edition, New York: McGrawHill Book Company. 
Shirley, L. and Sholar, J., "State and Utility Financial Incentives for Solar Applications," Solar Today, July/August 1993.

Short, Walter, (1983). Guide to Economic Assessment of Conservation and Solar Technologies: Methods and Data, Prepared for the U. S. Department of Energy Contract No. EG-77-C-01-4042, Golden: Solar Energy Research Institute.

Simpson, J., (April 1992). "Basic Concepts of Project Finance." Project Finance: The Tutorial, Infocast Inc. Conference.

Stermole, Franklin J., (1984). Economic Evaluation and Investment Decision Methods, Fifth Edition, Investment Evaluations Corporation.

Stermole, Franklin J. and Stermole, John M., (1990). Economic Evaluation and Investment Decision Methods, Seventh Edition, Investment Evaluations Corporation.

U.S. Department of Commerce, Statistical Abstract of the United States 1992, 112th Edition.

Western Area Power Administration (WAPA), (December 1993). Resource Planning Guide, Prepared for the Western Area Power Administration, Contract DE-AC65-90WA06473, Englewood; Stone \& Wcbster Management Consultants, Inc. Volumes I-IV.

Weston, J. Fred and Brigham, Eugene F., (1981). Managerial Finance, The Dryden Press, Seventh Edition. 


\section{Bibliography}

California Public Utilities Commission (CPUC) and California Energy Commission (CEC), (1987). Standard Practice Manual for Economic Analysis of Demand-Side Management Programs, San Francisco: California Public Utilities Commission.

Hausman, J., (Spring 1979). "Individual Discount Rates and the Purchase and Utilization of Energy-Using Durables." The Bell Journal of Economics.

Howe, Keith M. and Rasmussen, Eugene F., (1982). Public Utility Economics and Finance, Englewood Cliffs: Prentice-Hall Inc.

Koomey, J., Rosenfeld, A., Gadgil, A., (1989). Conservation Screening Curves to Compare Efficiency Investments to Power Plants, Berkeley, CA: Lawrence Berkcley Laboratory, LBL-27286, UC-350.

Krause, F., and Eto, J., (1988). Least-Cost Utility Planning Handbook for Public Utility Commissioners-Volume 2 The Demand Side: Conceptual and Methodological Issues, Washington: National Association of Regulatory Utility Commissioners.

Nadel, S., (1990). Lessons Leamed: A Review of Utility Experience with Conservation and Load Management Programs for Commercial and Industrial Customers, New York State Energy Research and Development Authority. 


\section{Glossary}

Many of the terms and related definitions included in this glossary were oblained from the Electric Power Research Institute's Technical Assessment Guide, Managerial Finance by Weston, and Economic Evaluation and Investment Decision Methods by Stcrmole. These sources are included in the references. Some of the terms included in this glossary arc not mentioned in the body of the manual and are included here simply as additional information. Also included, when applicable, is the acronym or symbol used for the term in the manual.

\section{Amortize}

To recover or pay back, on a regular schedule, a sum of money.

\section{Analysis Period - N}

The amount of time or the period an analysis covers.

\section{Analysis, Breakeven}

A determination of the conditions under which the economic values of two alternatives are equal.

\section{Annualization}

The conversion of a series of transactions to an equivalent annuity.

\section{Annuity}

A series of equal anmual payments occurring over a period of time.

\section{Base Year}

Year to which all cash flows are converted.

\section{Benefit/Cost Ratio - B/C}

The ratio of the sum of all discounted benefits accrued from an investment to the sum of all associated discounted costs.

\section{Book}

A general term that connotes the financial records of a company, usually related to rate making and investment matters.

\section{Book Life}

Period over which an investment amount is recovered through book depreciation. 


\section{Capacity, Rated}

The maximum capacity that a generating unit can sustain over a specified period of time.

\section{Capacity Factor}

The total energy output over a period of time in hours, divided by the product of the period hours and the rated capacity.

\section{Capital Investment}

See Investment.

\section{Capitalize}

To place an investment on the books of a company.

\section{Capitalization}

The total of all debt and equity in a company.

\section{Carrying Charges}

The revenue needed to support an investment. Equal to the sum of

$$
\begin{aligned}
& \text { Return on debt } \\
& \text { Return of equity } \\
& \text { Income taxes } \\
& \text { Book depreciation } \\
& \text { Property tax } \\
& \text { Insurance. }
\end{aligned}
$$

\section{Carrying Charge Factor (Rate)}

The amount of revenue per dollar of investment that must be collected from customers in order to pay the carrying charges on that investment. The carrying charge factor (rate) is expressed as a decimal that is multiplied by the original investment to obtain a dollar amount. The carrying charge rate can be a present value or annualized quantity, over a specified period of time (up to the book life), or an annual quantity in a specific year of life.

\section{Cash Flow - F}

Net income plus amount charged off for depreciation, depletion, amortization, and extraordinary charges to reserves.

\section{Common Stock}

A type of equity security in which the holder is a part owner in the company. This is the most speculative type of secunity normally sold by a utility and pays the highest relative return but is the last to receive a payment and has the lowest priority in the case of liquidation. There is no guarantee that the company will ever pay a return (dividend) to the common stock holder. 


\section{Constant Dollar Analysis}

An analysis made without including the effect of inflation, although real escalation is included.

\section{Consumer Surplus}

The difference between the total amount of money consumers are willing to pay for a given quantity of a commodity minus the total expenditures that are necessary to acquire that quantity of the commodity.

\section{Cost of Capital}

The return required by investors in order to attract investment capital for a utility. It is numerically equal to the sum of return of debt plus return of equity, and is the time value of money or the discount rate used in present-worth arithmetic.

\section{Cost of Debt}

The amount paid to the holders of debt securities for the use of their money. The magnitude is stated on the debt certificate (contract) and is independent of future financial conditions, including expected future inflation.

\section{Cost of Equity}

The earnings expected by an investor when purchasing cquity shares in a company. The magnitude may vary, depending on inflation and the financial condition of the company.

\section{Current Dollar Analysis}

An analysis that includes the effect of inflation and real escalation.

\section{Debt Ratio}

The ratio of debt money to total capitalization.

\section{Decision Analysis}

The evaluation of decision options and the estimation of the value of additional information or testing, using the time and risk preferences of the decision maker.

\section{Deferred Income Tax}

The portion of the total income tax liability that may be deferred to a future date.

\section{Depletion}

Recovery of an investor's economic interest in mineral (including oil and gas) reserves through federal tax deductions related to removal of the mineral over the economic life of the property. 


\section{Depreciation}

The accounting mechanism for the reduction in value of a capitalized item. The procise definition and the schedule of reduction will vary widcly, depending on the usc. Frequently associated with capital cost deductions for income tax purposes.

\section{Depreciation Period - M}

The amount of time required for the original capital investment to be fully recovered.

\section{Depreciation, Accelerated}

Any schedule of depreciation that reduces a sum of money more rapidly than would be done with straightline depreciation.

\section{Depreciation, Book}

A component of the carrying charge, it is the revenue required to repay the original investment. In the utility industry, it is usually calculated on a straight-line basis.

\section{Discount Rate}

The rate used for computing present values, which reflects the fact that the value of a cash flow depends on the time in which the flow occurs.

\section{Dollar Year}

The year in which constant dollar results of an analysis are reported.

\section{Economic Dispatch}

Commitment and operation of electric generating units or load control activities so as to meet demand with minimum total systcm operating costs.

\section{Earnings}

That portion of revenue that remains after all charges, including interest, have been satisfied.

\section{Electricity Demand}

The rate at which electric energy is delivered, expressed in units of power, such as kilowatts, at a given instant (indicated) or averaged (integrated) over a designated period of time. In the utility industry, it is common to express demand as 1 hour integrated.

\section{Embedded Cost}

The average or fully distributed cost.

\section{Energy Efficiency}

The ratio of the useful energy delivered by a system to the energy supplied to it. 


\section{Equity}

That portion of a company's total capitalization resulting from the sale of common and preferred stock and retained equity earnings.

\section{Equity Ratio}

The ratio of equity money to total capitalization. It is also equal to one minus the debt ratio.

\section{Escalation, Apparent}

The total annual rate of increasc in cost. The apparent escalation rate includes the effects of inflation and real escalation.

\section{Escalation, Real - $\Delta p$}

The annual rate of increase of an expenditure that is due to factors such as resource depletion, increased demand, and improvements in design or manufacturing (negative rate). The real escalation rate does not include inflation.

\section{Expected Value}

The mean or average value of a variable.

\section{Expense}

A cost for goods and services that normally are utilized in 1 year or less. Examples include fuel, operation, and maintenance.

\section{Financing}

The sources of funds raised from external sources in order for a firm to invest and to conduct organizational operations.

\section{Finance Period - Y}

Period of time for which an investment's financing is structured (e.g., a loan is amortized over 30 years).

\section{Fixed Charge Rate - FCR}

The factor by which the present value of capital investment is multiplied to obtain the annual cost attributable to the capital investment.

\section{Flow Through Accounting}

An accounting practice used by regulated utilities in which deferred income taxes are passed on immediately either to the rate payers through a decrcase in rates or to the stockholders through an increase in earnings (return of equity). It is the opposite of normalization accounting. 


\section{Heat Rate}

The amount of energy expressed in Btu required to produce a $\mathrm{kWh}$ of electric energy.

\section{Hurdle Rate}

The minimum acceptable rate of return on a project.

\section{Inflation - e}

The rise in price levels caused by an increase in available currency and credit without a proportionate increase in available goods and services of equal quality. Inflation does not include real escalation. Inflation is normally expressed in terms of an annual percentage change.

Integrated Resource Planning - IRP

Analytic tools used to determine whether benefits are greater than costs for various resource planning options.

\section{Internal Rate of Return - IRR}

The discount rate required to equate the net present value of a cash flow stream to zero.

\section{Internal Rate of Return, Modified - MIRR}

The discount rate required to equate the future value of all returns to the present value of all investments. MIRR accounts for reinvestment of cash flows.

\section{Investment - I}

An expenditure for which returns are expected to extend beyond 1 year.

\section{Investment Useful Lifetime - L}

The estimated useful life of a capital investment.

\section{Investment Tux Credit}

An immediate reduction in income taxes equal to a percentage of the installed cost of a new investment.

\section{Investment Year}

The year in which a capital or equipment investment is fully constructed or installed and placed into service.

\section{Levelization}

Conversion of a series of transactions to an equivalent value per unit of output. 


\section{Levelization Period - P}

The time over which a series of transactions is converted to an equivalent value per unit of output.

\section{Levelized Capacity Factor}

A constant annual capacity factor for an electric generaling unit such that the present value of the energy produced during the analysis period using constant annual capacity factors is the same as the present value of the energy produced by the individual annual capacity factors.

\section{Levelized Cost of Energy - LCOE}

The cost per unit of energy that, if held constant through the analysis period, would provide the same net present revenue value as the net present value cost of the system.

\section{Life-Cycle Cost - LCC}

The present value over the analysis period of all system resultant costs.

\section{Load Duration Curve}

A chart showing electric demand in decreasing magnitude plotted against total duration of occurrence over a specified period of time (usually a year).

\section{Load Factor}

The ratio of the actual energy consumed during a designated period to the energy that would have bcen consumed if the peak load were to exist throughout the designated period. The term is used to describe a characteristic of individual or aggregated load rather than that of generation.

\section{Load Management}

The application of measures to influence customers' use of electricity so as to modify the demand and load factor.

\section{Load Profile Curve}

A chart showing chronological electric demand plotted against time of occurrence. It illustrates the varying magnitude of the load during the period covercd.

\section{Loss of Load Probability (LOLP)}

The proportion of time that the available generation is expected to be unable to meet the system load.

\section{Marginal Cost - MC}

The cost of an additional unit. The marginal cost of capital is the cost of additional funds.

\section{Net Present Value - NPV}

The value in the base year (usually the present) of all cash flows associated with a project. 


\section{Normalization Accounting}

An accounting practice used by regulated utilities in which deferred income taxes are accumulated in a rescrve account and effectively used to purchase new investments. The rate base is reduced by the accumulated reserve. Normalization accounting is the opposite of flow through accounting.

\section{Opportunity Cost}

The rate of return on the best alternative investment available.

\section{Overnight Construction Cost - OCC}

The value of total plant investment if construction had occurred overnight and all expenditures were made instantaneously.

\section{Payback Period}

The time required for net revenues associated with an investment to return the cost of the investment.

\section{Payback Period, Simple - SPB}

The payback period computed without accounting for the time value of money.

\section{Payback Period, Discounted - DPB}

The payback period computed that accounts for the time value of money.

\section{Preferred Stock}

A type of security in which the holder is a part owner in the company. This is the second most speculative type of security and usually carrics a promise to pay a stated return, if a return is paid. No relurn on common stock can be paid until return of preferred stock has been paid. Preferred stock has the second lowest priority in the case of liquidation.

\section{Present Value - PV}

The value in the base year (usually the present) of a cash flow adjusted for the time-value differences in those cash flows bctween the time of the actual flow and the base year.

\section{Producer Surplus}

The amount of money paid to producers by consumers for a given quantity of a commodity over and above the amount the producers would have been willing to accept for the given quantity of the commodity.

\section{Rate Base}

That portion of total assets (principally investments in plant and equipment) for regulated utilities, as defined by a rate regulatory body, upon which a utility is allowed to earn a return. 


\section{Reinvestment Rate}

The rate of return at which cash flows from an investment are reinvested.

\section{Return on Debt $-\mathbf{r}_{d}$}

A component of the carrying charge, return on debt is the revenue recluired to pay for the use of debt. money. It is usually stated as a percentagc and is applied to the unrecovered capital in a particular year. Numerically, it is equal to the cost of debt money limes the debt ratio.

\section{Return on Equity - $\mathbf{r}_{\mathrm{ec}}$}

A component of the carrying charge, return on equity is the revenue required to pay for the use of equity money. It is usually stated as a percentage and is applied to the unrecovered capital in a particular ycar. Numerically, it is equal to the cost of equity money times the equity ratio.

\section{Revenue Requirement - RR}

The amount of money that must be collected from customers to compensate a utility for all expenditures associated with an investment.

\section{Risk Analysis}

Method of quantifying and evaluating uncertainty.

\section{Salvage Value}

The value of a capital asset at the end of a specified period.

\section{Savings/Investment Ratio - SIR}

The ratio of discounted net savings accrued from an investment to the discounted capital costs (plus replacement costs minus salvage value).

\section{Scenario Analysis}

Evaluation of a set of conditional relationships between variables.

\section{Sensitivity Analysis}

The evaluation of a project under a number of different assumptions on the values of one or more uncertain variables.

\section{Standard Deviation}

A statistical term that measures the variability of a set of observations from the mean of the distribution.

\section{Subjective Uncertainty}

A probabilistic distribution representing a person's beliefs about the possible values of a variable, based on that person's experience and knowledge. 


\section{Sunk Cost}

Any cost incurred by a prior decision that cannot be affected by the current course of action.

\section{Taxable Income}

That portion of revenue remaining after all deductions permitted under the Internal Revenue Code or a State Revenue Code have been taken.

\section{Tax Recovery Class}

One of several classes that determines the period of time over which the cost recovery tax deduction occurs.

\section{Tax Preferences}

Incentives designed to encourage investment as a stimulus to the overall economy. Examples are deferred income taxes and the investment tax credit.

\section{Tax Rate}

The rate applied to taxable income to determine federal and state income taxes.

\section{Total Plant Investment - TPI}

Total plant cost as modified by escalation and interest during construction.

\section{Uncertainty}

The range of possible values a variable may have in the future.

\section{Uniform Capital Recovery Factor - UCRF}

The uniform periodic payment, as a fraction of the original investment cost, that will fully repay a loan, including all interest, over the term of the loan.

\section{Weighted Average Cost of Capital}

The weighted average of the component costs of debt, preferred stock, and common equity. This is sometimes used as a proxy for discount rates in the industrial and utility sectors. 
Appendices 


\section{Appendix A: Selected Inflation Indices}

Table A-1 provides historical consumer and producer price indices as well as Gross Domestic Product (GDP) and Gross National Product (GNP) implicit price deflators. 
Table A-1. Selected Inflation Indices

\begin{tabular}{|c|c|c|c|c|c|c|c|c|c|}
\hline Year & $\begin{array}{l}\text { GDP } \\
\text { Implicit } \\
\text { Price } \\
\text { Deflator } \\
(87=100)\end{array}$ & $\begin{array}{c}\text { GNP } \\
\text { Implicit } \\
\text { Price } \\
\text { Deflator } \\
(82=100)\end{array}$ & $\begin{array}{c}\text { Consumer } \\
\text { Price } \\
\text { Indices } \\
(83-84=100)\end{array}$ & $\begin{array}{c}\text { Producer } \\
\text { Price } \\
\text { Indices } \\
(82=100)\end{array}$ & Year & $\begin{array}{l}\text { GDP } \\
\text { Implicit } \\
\text { Price } \\
\text { Deflator } \\
(87=100)\end{array}$ & $\begin{array}{c}\text { GNP } \\
\text { Implicit } \\
\text { Price } \\
\text { Deflator } \\
(82=100)\end{array}$ & $\begin{array}{c}\text { Consumer } \\
\text { Price } \\
\text { Indices } \\
(\mathbf{8 3 - 8 4 = 1 0 0 )}\end{array}$ & $\begin{array}{c}\text { Producer } \\
\text { Price } \\
\text { Indices } \\
(82=100)\end{array}$ \\
\hline 1950 & $\mathrm{n} / \mathrm{a}$ & 23.9 & 24.1 & 28.2 & 1973 & 41.3 & 49.5 & 44.4 & 45.6 \\
\hline 1951 & $n / a$ & 25.1 & 26.0 & 30.8 & 1974 & 44.9 & 54.0 & 49.3 & 52.6 \\
\hline 1952 & $\mathrm{n} / \mathrm{a}$ & 25.5 & 26.5 & 30.6 & 1975 & 49.2 & 59.3 & 53.8 & 58.2 \\
\hline 1953 & $\mathrm{n} / \mathrm{a}$ & 25.9 & 26.7 & 30.3 & 1976 & 52.3 & 63.1 & 56.9 & 60.8 \\
\hline 1954 & $n / a$ & 26.3 & 26.9 & 30.4 & 1977 & 55.9 & 67.3 & 60.6 & 64.7 \\
\hline 1955 & $\mathrm{n} / \mathrm{a}$ & 27.2 & 26.8 & 30.5 & 1978 & 60.3 & 72.2 & 65.2 & 69.8 \\
\hline 1956 & $n / a$ & 28.1 & 27.2 & 31.3 & 1979 & 65.5 & 78.6 & 72.6 & 77.6 \\
\hline 1957 & $n / a$ & 29.1 & 28.1 & 32.5 & 1980 & 71.7 & 85.7 & 82.4 & 88.0 \\
\hline 1958 & $\mathrm{n} / \mathrm{a}$ & 29.7 & 28.9 & 33.2 & 1981 & 78.9 & 94.0 & 90,9 & 96.1 \\
\hline 1959 & 25.6 & 30.4 & 29.1 & 33.1 & 1982 & 83.8 & 100.0 & 96.5 & 100.0 \\
\hline 1960 & 26.0 & 30.9 & 29.6 & 33.4 & 1983 & 87.2 & 103.9 & 99.6 & 101.6 \\
\hline 1961 & 26.3 & 31.2 & 29.9 & 33.4 & 1984 & 91.0 & 107.7 & 103.9 & 103.7 \\
\hline 1962 & 26.8 & 31.9 & 30.2 & 33.5 & 1985 & 94.4 & 110.9 & 107.6 & 104.7 \\
\hline 1963 & 27.2 & 32.4 & 30.6 & 33.4 & 1986 & 96.9 & 113.8 & 109.6 & 103.2 \\
\hline 1964 & 27.7 & 32.9 & 31.0 & 33.5 & 1987 & 100.0 & 117.4 & 113.6 & 105.4 \\
\hline 1965 & 28.4 & 33.8 & 31.5 & 34.1 & 1988 & 103.9 & 121.3 & 118.3 & 108.0 \\
\hline 1966 & 29.4 & 35.0 & 32.4 & 35.2 & 1989 & 108.5 & 126.3 & 124.0 & 113.6 \\
\hline 1967 & 30.3 & 35.9 & 33.4 & 35.6 & 1990 & 113.3 & 131.5 & 130.7 & 119.2 \\
\hline 1968 & 31.7 & 37.7 & 34.8 & 36.6 & 1991 & 117.7 & & 136.2 & 121.7 \\
\hline 1969 & 33.3 & 39.8 & 36.7 & 38.0 & 1992 & 121.1 & & 140.3 & 123.2 \\
\hline 1970 & 35.1 & 42.0 & 38.8 & 39.3 & 1993 & 124.2 & & 144.5 & 124.7 \\
\hline 1971 & 37.1 & 44.4 & 40.5 & 40.5 & & & & & \\
\hline 1972 & 38.8 & 46.5 & 41.8 & 41.8 & & & & & \\
\hline
\end{tabular}




\section{Appendix B: Escalation (De-escalation) Factors}

The inflation rate is the rate of rise in prices due to general increases in prices for goods and factors of production, whereas escalation is the rise in prices attributable to causes such as resource depletion or increased demand (EPRI September 1989).

If the inflation rate (e) does not adequately reflect the historical price changes for similar projects, an adjustment factor $(\Delta \mathrm{p})$ can be used, which helps to address this problem. The adjustment factor can be positive or negative (escalate or de-escalate the payment stream). The inclusion of inflation and escalation (de-escalation) adjustment factors within a present value calculation can be expressed as:

$$
P V=\sum_{n=0}^{N}\left\{F_{n}[(1+\Delta p)(1+e)]^{n} \div(1+d)^{n}\right\}
$$

Where:

$\begin{array}{lll}\mathrm{PV} & = & \text { present value } \\ \mathrm{N} & = & \text { evaluation period } \\ \mathrm{F}_{\mathrm{n}} & = & \text { cash flow } \mathrm{n} \text { years in the future } \\ \mathrm{d} & = & \text { annual discount rate } \\ \mathrm{e} & = & \text { annual inflation rate } \\ \Delta \mathrm{p} & = & \text { annual real escalation (de-escalation) ratc. }\end{array}$

For example, assume a discount rate of $9 \%$, an inflation rate of $6 \%$, and 4 years of unequal cash flows starting with $\$ 1,000\left(\mathrm{~F}_{\mathrm{o}}=1000\right)$ and growing at a real escalation rate of $4 \%$. In this case, the present value is $\$ 4,068.78$.

An escalation rate can be expressed either in real terms (excludes inflation) or nominal terms (includes inflation and is sometimes called the apparent escalation ratc). 


\section{Appendix C: Real Weighted Average Cost of New Capital 1976-1989}

Figure C-1 plots the real weighted average cost of new capital (WACNC[T]) to U.S. industry over time. The annual WACNC(T) values shown in the figure are national averages based on calculations using average annual rates for new debt, equity, and preferred stock. The average of the annual values, $4.81 \%$, is also shown. The actual data for the graph are provided in Table C-1. The return on debt has been adjusted for taxes.

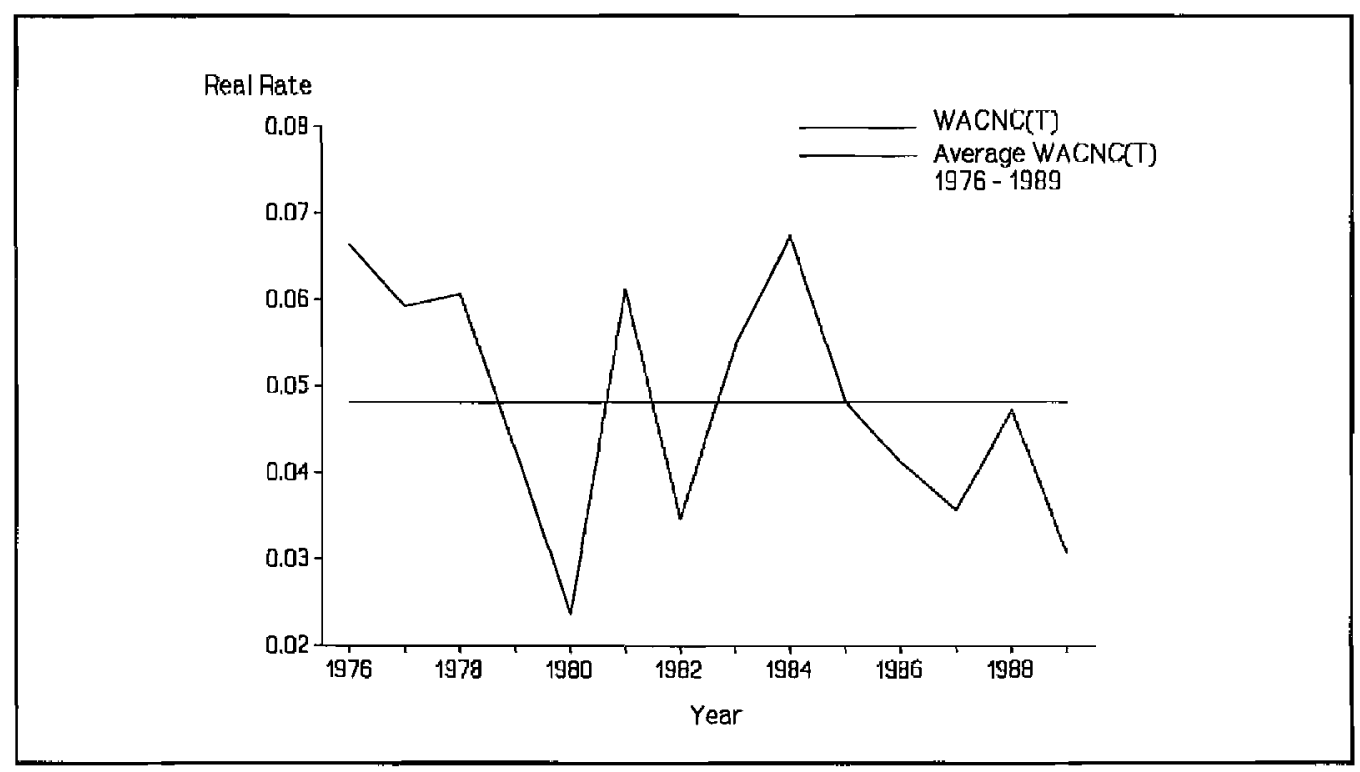

Figure C-1. Weighted average cost of new capital WACNC(T) tax adjusted return on debt

Table C-1. Annual WACNC(T) Values

\begin{tabular}{||c|c|c|c|c|c||}
\hline Year & $\begin{array}{c}\text { GNP } \\
\text { Deflator }\end{array}$ & $\begin{array}{c}\text { Real } \\
\text { WACNC(T) }\end{array}$ & Year & $\begin{array}{c}\text { GNP } \\
\text { Deflator }\end{array}$ & $\begin{array}{c}\text { Real } \\
\text { WACNC(T) }\end{array}$ \\
\hline 1976 & 0.0640 & 0.0663 & 1983 & 0.0390 & 0.0546 \\
\hline 1977 & 0.0670 & 0.0592 & 1984 & 0.0370 & 0.0674 \\
\hline 1978 & 0.0730 & 0.0606 & 1985 & 0.0300 & 0.0482 \\
\hline 1979 & 0.0890 & 0.0426 & 1986 & 0.0260 & 0.0412 \\
\hline 1980 & 0.0900 & 0.0237 & 1987 & 0.0320 & 0.0356 \\
\hline 1981 & 0.0970 & 0.0611 & 1988 & 0.0330 & 0.0472 \\
\hline 1982 & 0.0640 & 0.0347 & 1989 & 0.0410 & 0.0307 \\
\hline & & Mean & 0.0481 & \\
\hline
\end{tabular}

As shown by the graph and the standard deviation, the real cost of new capital fluctuates significantly over lime. Although not analyzed here, it is reasonable to assume that the cost to different investors (at the 
same point in time) also varies significantly, reflccting different risks and actual returns to equity shareholders.

The formula used to calculate the annual WACNC(T) is as follows:

$W A C C=r_{c c}\left[C_{c} \div\left(C_{e}+P_{s}+D\right)\right]+r_{e p}\left[P_{s} \div\left(C_{e}+P_{s}+D\right)\right]+(1-T) r_{d}\left[D \div\left(C_{e}+P_{s}+D\right)\right]$

Where:

$\begin{array}{ll}\mathbf{r}_{\mathrm{cc}} & =\text { rate of return on common equity } \\ \mathrm{C}_{\mathrm{e}} & =\text { common stock and corporate retained earnings (Weston and Brigham 1981) } \\ \mathrm{P}_{\mathrm{s}} & =\text { preferred stock } \\ \mathrm{D} & =\text { debt issues } \\ \mathbf{r}_{\mathrm{ep}} & =\text { rate of return on preferred stock } \\ \mathrm{T} & =\text { corporate tax rate } \\ \mathbf{r}_{d} & =\text { interest rate paid on debt. }\end{array}$

The data on the dollar amounts of debt and preferred and common stock are annual U.S. figures based on data from several sources. The data on the dollar amounts of preferred (P) and common stock (C) and data on dollar values of debt (D) were taken from Moody's. The rates associated with corporate debt are the average return on new bonds $\left(\mathrm{r}_{\mathrm{d}}\right)$. This was also taken from Moody's. The data on the rate of return on preferred stock $\left(\mathrm{r}_{\mathrm{ep}}\right)$ were taken from the values given for preferred stock of Moody's medium grade industrials. The return on common equity $\left(r_{\mathrm{ec}}\right)$ was calculated using the formula

$$
\mathrm{r}_{\mathrm{ec}}=\operatorname{div} / \mathrm{p}+\mathrm{g} \text {, }
$$

where data on dividends (div) and dividends divided by price (div/p) were obtained from the Economic Report of the President, as was retained earnings.

The growth rate of dividends is the 5-year averagc compound growth rate. New common equity equals the new common stock issuc plus the retained carnings for that year. The return on common equity was calculated using a year-to-year estimate of growth. The tax rates were obtained from the IRS for pertinent years and brackets. The yearly WACNC(T) figures were then converted to a common year using the GNP deflator.

The mean WACNC can also be calculated without the effect of taxes. This was performed using the same format as was used in the previous example. The resulting WACNC (unadjusted for taxes) was 7.06\%. The choice of which WACNC (after-tax or before-tax) depends on the purpose of the analysis. As was emphasized carlier, usually after-tax cash flows should be used. The actual value of the WACNC probably lies somewhere between the after-tax and before-lax figures because utilities will pay taxes, but given deductions, credits, and so forth, the effective tax rate for an investment will rarely be cqual to the percentage in the top tax bracket.

${ }^{*}$ The corporate tax rate includes both state and federal income tax rates. The effective tax rate, or combined state and federal tax rate, can be calculated as

Effective Tax Rate = State Tax Rate + Federal Tax Rate $(1-$ State Tax Rate $)$. 


\section{Appendix D: Amortization Formulas}

The example of an amortization schedule from the Financing subsection of Section 2 of this manual follows:

A business borrows $\$ 10,000$ at $10 \%$ compounded annually to be repaid in 5 years. The annual payment due to the lender can be calculated by multiplying the uniform capital recovery factor--(UCRF $=$ $\left.\left[\mathrm{d}(1+\mathrm{d})^{\mathrm{n}}\right] /\left[(1+\mathrm{d})^{\mathrm{n}}-1\right]\right)$--by the amount borrowed. In this example, UCRF equals $[0.1(1+$ $\left.\left.0.1)^{5}\right] / L(1+0.1)^{5}-1\right]=0.2638$, which when multiplied by the $\$ 10,000$ amount borrowed gives a uniform annual payment to the lender of $\$ 2,637.97$. Table $D-1$ illustrates the amortization schedule for this example.

Table D-1. Amortization Schedule Used for Example

\begin{tabular}{||c|r|r|r|r||}
\hline Year & $\begin{array}{c}\text { (1) } \\
\text { Annual } \\
\text { Payment } \\
\text { (I x UCRF) }\end{array}$ & $\begin{array}{c}\text { (2) } \\
\text { Interest } \\
\text { (d x Col.4 }\end{array}$ & $\begin{array}{c}\text { (3) } \\
\text { Repayment of } \\
\text { Principal } \\
\text { (Col.1 - Col.2) }\end{array}$ & $\begin{array}{c}\text { (4) } \\
\text { Principal Balance } \\
\text { (Col.4(n-1) - Col.3) }\end{array}$ \\
\hline 0 & & & & $\$ 10,000.00$ \\
1 & $\$ 2,637.97$ & $\$ 1,000.00$ & $1,637.97$ & $8,362.03$ \\
2 & $2,637.97$ & 836.20 & $1,801.77$ & $6,560.25$ \\
3 & $2,637.97$ & 656.03 & $1,981.95$ & $4,578.30$ \\
4 & $2,637.97$ & 457.83 & $2,180.14$ & $2,398.16$ \\
5 & $2,637.97$ & 239.82 & $2,398.16$ & 0.00 \\
\hline Totals & $\$ 13,189.87$ & $\$ 3,189.87$ & $\$ 10,000.00$ & \\
\hline
\end{tabular}

The formula for calculating the principal remaining after each period follows.

$$
R P_{m}=I \times\left\{1-\left[\left(U C R F_{Y}-i\right) /\left(U C R F_{m}-i\right)\right]\right\}
$$

Where:

$$
\begin{aligned}
\mathrm{RP}_{\mathrm{m}}= & \text { principal remaining after the } \mathrm{m}^{\text {th }} \text { payment } \\
\mathrm{I}= & \text { initial investment or amount borrowed } \\
\mathrm{UCRF}_{\mathrm{Y}}= & \text { uniform capital recovery factor }\left[\mathrm{d}(1+\mathrm{d})^{\mathrm{Y}}\right] /\left[(1+\mathrm{d})^{\mathrm{Y}}-1\right] \text {, where the discount rate is } \\
& \text { equal to the rate of interest (i) and the parameter y is equal to the term of the loan } \\
\mathrm{UCRF}_{\mathrm{m}}= & \text { uniform capital recovery factor }\left[\mathrm{d}(1+\mathrm{d})^{\mathrm{m}}\right] /\left[(1+\mathrm{d})^{\mathrm{m}}-1\right] \text {, where the discount rate is } \\
& \text { equal to the rale of interest (i) and the parameter } \mathrm{m} \text { is equal to the year for which the } \\
& \text { remaining principal is being calculated } \\
= & \text { interest rate of loan. }
\end{aligned}
$$

The formula for calculating the portion of interest contained in a specific payment is simple and can be calculated using the same formula for calculating the remaining principal. In the formula, UCRF $\mathrm{m}_{\mathrm{m}}$ is simply replaced by $\mathrm{UCRF}_{\mathrm{m}-1}$ to arrive at the principal remaining in the period prior to the one under examination. Once the remaining principal from the prior period is calculated, it can be multiplied by the interest rate (i) to arrive at the interest portion of the payment. 
The formula for this calculation follows:

$$
\mathrm{IP}_{\mathrm{m}}=\left(\mathrm{I} \times\left\{1-\left[\left(\mathrm{UCRF}_{\mathrm{Y}}-\mathrm{i}\right)\left(\left(\mathrm{UCRF} \mathrm{m}_{-1}\right)\right]\right\}\right) \times \mathrm{i}\right.
$$

Where:

$$
\begin{aligned}
& \mathrm{IP}_{\mathrm{m}} \quad=\text { interest portion of the } \mathrm{m}^{\mathrm{th}} \text { payment } \\
& \text { I }=\text { initial investment or amount borrowed } \\
& \mathrm{UCRF}_{\mathrm{Y}}=\text { uniform capital recovery factor } \\
& {\left[\mathrm{d}(1+\mathrm{d})^{\mathrm{Y}}\right] /\left[(1+\mathrm{d})^{\mathrm{Y}}-1\right] \text {, }} \\
& \text { where the discount rate is equal to the rate of interest (i), and the parameter } Y \text { is } \\
& \text { equal to the term of the loan } \\
& \mathrm{UCRF}_{\mathrm{m}-1}=\text { uniform capital recovery factor } \\
& {\left[\mathrm{d}(1+\mathrm{d})^{\mathrm{m}-1}\right] /\left[(1+\mathrm{d})^{\mathrm{m}-1}-1\right] \text {, }} \\
& \text { where the discount rate is equal to the rate of interest (i), and the parameter } m-1 \text { is } \\
& \text { equal to the year prior to the year being calculated } \\
& \mathrm{i}=\text { interest rate of loan. }
\end{aligned}
$$

The principal portion of a payment is calculated by multiplying the UCRF $F_{Y}$ by the initial investment or amount borrowed to arrive at the annual payment for repayment of the loan. Then the interest portion of the Ioan, as calculated above, for the specific period is subtracted from the annual payment, or:

$$
P P_{n}=\left(U C R F_{Y} \times I\right)-\left(1 \times\left\{1-\left[\left(U C R F_{Y}-i\right) /\left(U C R F_{m-1}-i\right)\right]\right\}\right) \times i
$$

Where:

$$
\begin{array}{ll}
\mathrm{PP}_{\mathrm{m}}= & \text { principal portion of payment } \\
\mathrm{I} & =\text { initial investment or amount borrowed } \\
\mathrm{UCRF}_{\mathrm{Y}}= & \text { uniform capital recovery factor } \\
& {\left[\mathrm{d}(1+\mathrm{d})^{\mathrm{Y}}\right] /\left[(1+\mathrm{d})^{\mathrm{Y}}-1\right],} \\
& \text { where the discount rate is equal to the rate of interest (i), and the parameter } \mathrm{Y} \text { is } \\
& \text { equal to the term of the loan } \\
\mathrm{UCRF}_{\mathrm{m}-1}= & \text { uniform capital recovery factor } \\
& {\left[\mathrm{d}(1+\mathrm{d})^{\mathrm{m}-1}\right] /\left[(1+\mathrm{d})^{\mathrm{m}-1}-1\right],} \\
& \text { where the discount rate is equal to the rate of interest }(\mathrm{i}) \text {, and the parameter } \mathrm{m}-1 \text { is } \\
& \text { equal to the year prior to the year being calculated }
\end{array}
$$




\section{Appendix E: Monthly and Continuous Discount Rates}

The examples in this manual have assumed end-of-year cash flows and annual discount rates. However, it is not uncommon for cash flows to occur during or at the beginning of the month, and it is not uncommon for discount rates and interest rates to be stated in semi-annual, monthly, or even continuous values.

For cxample, if a bank pays $8 \%$ intcrest compounded quarterly, this means that the nominal annual interest rate is $8 \%$ and the quarterly interest rate is $2 \%$. In this example, the investor would receive $2 \%$ interest on the principal at the end of each quarter. An effective annual interest rate is the interest rate that, when applied once per year to a principal sum, will give the same amount of interest equal to a nominal rate of $r \%$ per year compounded $n$ times per year. The formula for calculation of the effective interest rate is:

$$
\mathrm{r}_{\mathrm{e}}=(1+\mathrm{r} / \mathrm{n})^{\mathrm{n}}-1
$$

Where:

$$
\begin{array}{ll}
\mathrm{r}_{\mathrm{e}} & =\text { effective annual interest rate } \\
\mathrm{r} & =\text { nominal annual interest rate } \\
\mathrm{n} & =\text { number of compounding periods per year. }
\end{array}
$$

If the number of compounding periods is infinite, the formula for calculating effective interest becomes:

$$
\mathrm{r}_{\mathrm{e}}=\operatorname{limit}_{\mathrm{n} \rightarrow \infty}(1+\mathrm{r} / \mathrm{n})^{\mathrm{n}}-1=\operatorname{limit}_{\mathrm{n} \rightarrow \infty}\left(\mathrm{e}^{(\mathrm{n} / \mathrm{r}) \ln (1+\mathrm{r} / \mathrm{n})}\right)^{\mathrm{r}}-1=\mathrm{e}^{\mathrm{r}}-1
$$

For example, assuming a nominal interest rate of $12 \%$, the effective interest rate is as follows:

1. When compounded quarterly it is $(1+0.12 / 4)^{4}=12.55 \%$

2. When compounded monthly it is $(1+0.12 / 12)^{12}=12.68 \%$

3. When compounded daily it is $(1+0.12 / 365)^{365}=12.747 \%$

4. When compounded continuously it is $\left(\mathrm{e}^{0.12}-1\right)=12.749 \%$.

As one can see from this example, the more frequently interest is compounded, the greater the effective interest rate.

Although it is uncommon, analyses somctimes account for cash flows that occur at times other than the end of the year. In the Present Value subsection in Section 2, the following example was put forth. Cash flows of $\$ 1$ and $\$ 5$ are assumed to occur at the end of periods 1 and 2 and are discounted at a rate of $5 \%$. The calculated present value of the cash flows is $\$ 5.49$, as shown in Table E-1. 
Table E-1. Present Value for End-of-Period Cash Flows

\begin{tabular}{|cccc||}
\hline Period & Cash Flow & PVIF & Present Value \\
\hline 1 & $\$ 1$ & 0.9524 & $\$ 0.95$ \\
2 & $\$ 5$ & 0.9070 & $\$ 4.54$ \\
& & & $P V=\$ 5.49$ \\
\hline
\end{tabular}

If it is now assumed that these cash flows occur at the beginning of the period instead of the end of the period, the present value calculation changes as follows:

Table E-2. Present Value for Beginning-of-Period Cash Flows

\begin{tabular}{|cccc|}
\hline Period & Cash Flow & PVIF & Present Value \\
\hline 1 & $\$ 1$ & & $\$ 1.00$ \\
2 & $\$ 5$ & 0.9524 & $\$ 4.76$ \\
& & & $P V=\$ 5.76$ \\
\hline
\end{tabular}

The present value of the cash flow stream is now $\$ 5.76$. This value is greater than the value calculated when the cash flows occurred at the end of the period because $\$ 1$ was received today and $\$ 5$ was received at the beginning of period 2 instead of at the end of it. Under ordinary circumstances (i.e., cash flows occurring at the end of a period), the following is true:

$$
\sum_{n=1}^{N} 1 /(1+d)^{n}=1 / U_{C R F}
$$

where e denotes end-of-period cash flows.

In the case of beginning-of-period cash flows, the formula is transformed as follows:

$$
1 / \mathrm{UCRF}_{\mathrm{b}}=\sum_{\mathrm{n}=0}^{\mathrm{N}-1} 1 /(1+\mathrm{d})^{\mathrm{n}}=(1+\mathrm{d}) \sum_{\mathrm{n}=1}^{\mathrm{N}} 1 /(1+\mathrm{d})^{\mathrm{n}}=(1+\mathrm{d}) 1 / \mathrm{UCRF}_{\mathrm{e}}
$$

where $b$ denotes beginning-of-period cash flows. 


\section{Appendix F: Capital Requirements}

Throughout this manual the term initial investment (I), has been used in formulas and referred to in the text. The initial investment can be thought of as the total capital requirement of an investment or the dollar amount that is capitalized on the books of the investing firm. Initial investment can be calculated as follows:

$$
\mathrm{I}=\mathrm{TPI}+\mathrm{land}+\text { misc }
$$

Where:

$$
\begin{array}{ll}
\text { I } & =\text { initial investment } \\
\text { TPI } & =\text { total plant investment } \\
\text { land } & =\text { cost of land } \\
\text { misc. } & =\text { any other miscellaneous expenses. }
\end{array}
$$

TPI includes two variables: total cash expended. (TCE) and interest during construction (IDC).

$$
\mathrm{TPI}=\mathrm{TCE}+\mathrm{IDC} \text {. }
$$

Included in TCE are the following variables:

- Process Facilities Capital. Total construction cost of on-site equipment, including all direct and indirect construction costs plus applicable sales tax and freight costs.

- General Facililics Capital. Total construction cost of general facilities such as roads, office buildings, shops, laboratories, engineering and home office overhead and fees, and contingencies intended to cover the uncertainties in the cost and technical performance estimates.

- In addition, engineering and home office overhead is included, if applicable, (EPRI December 1991).

For systems or plants that can be constructed in less than a year, there is essentially no interest during construction (IDC). However, for multi-year construction plants, IDC includes all interest expenses that may have been required during the construction of the facility. For utilitics, interest expense during consiruction is commonly referred to as the Allowance for Funds Used During Construction (AFUDC). Under U.S. tax law, interest expenses incurred on debt used to finance construction must be capitalized if the investment (1) has a depreciable life of 15 years or more, (2) has an estimated production duration (useful lifetime) of 2 years or more, or (3) has an estimated production duration more than 1 year and a cost greater than $\$ 1$ million (Stermole and Stermole 1990).

TCE and IDC dala are generally provided as current dollar expenses (actual expenses incurred for specific years during construction). The TPI is then calculated by converting the current dollar cash flows to baseyear dollars, as depicted in the formulas that follow and illustrated in Figure $\mathrm{F}-\mathbf{1}$.

$$
\text { TPI }=\Sigma_{t=0}^{C}\left[f_{t} \times\left(1+d_{n}\right)^{t}\right]
$$




\section{Where:}
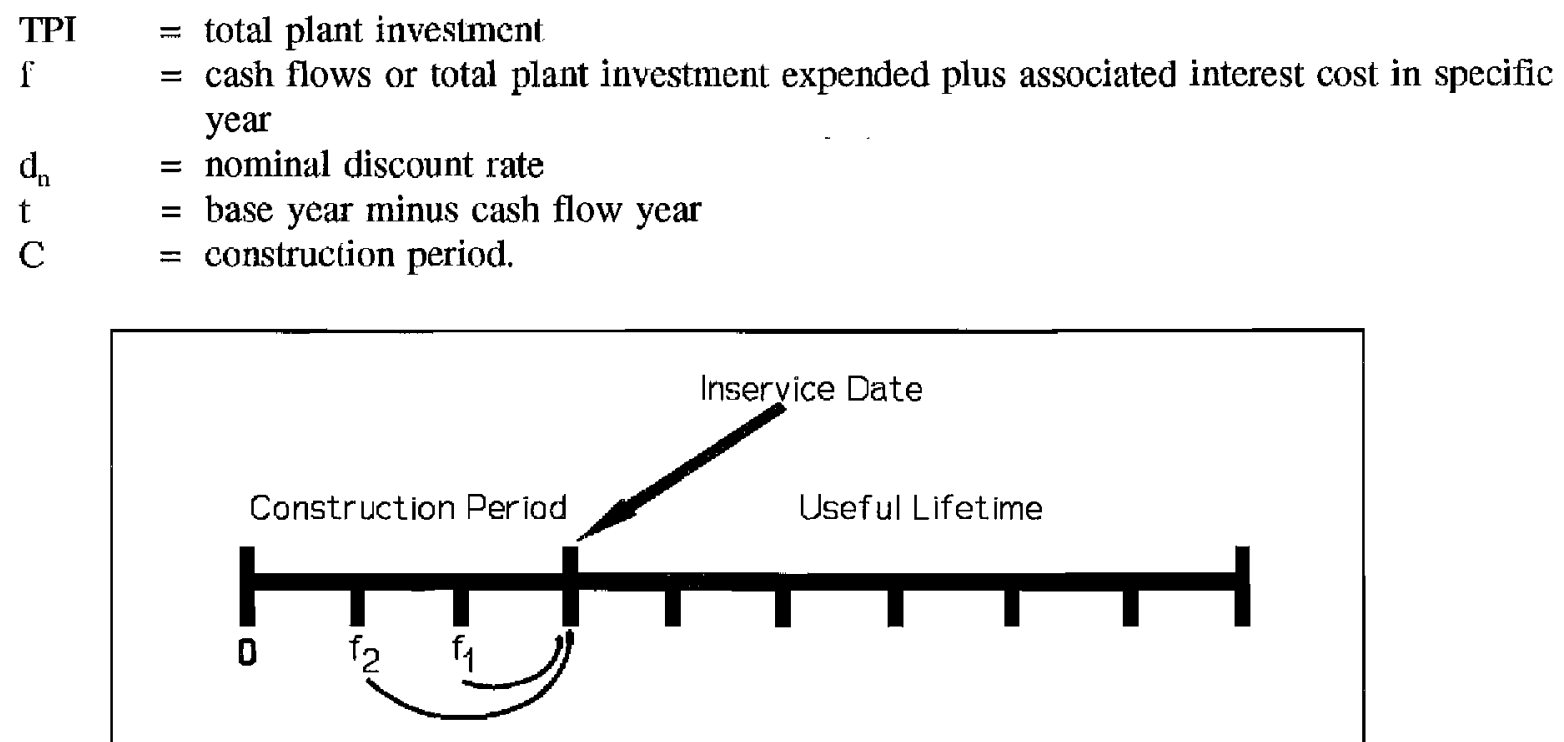

Figure F-1. Project time line

When evaluating existing plants, cash flow data are often available to calculate TPI precisely. However, for many analyses, the best data available will be an estimate of overnight construction cost (OCC). OCC represents the total plant investment if construction had occurred overnight and all expenditures were made instantaneously (no interest during construction). Because this generally does not occur in the real world, the OCC is only an approximate estimate of TPI. The process required to correct the OCC for the cxclusion of interest expense is very complex. It requires de-escalating the OCC at the inflation rate (which converts the base year payments to current year payments), then re-escalating to the base year at the discount rate (which allows for the inclusion of interest expense).

However, given the many assumptions required (i.e., determining the annual breakdown of OCC over the construction period, the length of the construction period, the inflation rate, and the discount rate), and the fact that most EE analyses are based on uncertain estimates of costs of future hypothetical plants or systems, it is recommended that the OCC be used as an estimate of the TPI in the absence of available TCE and IDC data, as follows:

$$
\mathbf{I}=\mathrm{OCC}+\text { land }+ \text { misc }
$$

The remaining parameters included in the initial investment (I) formula are land and miscellaneous. Cost incurred for the purchase of land must be included. To be morc precise, land costs should be considered separately from other investment costs because land is not deprcciable for tax purposes (i.e., land can be treated as having an infinite book and tax life). In fact, depreciation rates vary among components of a single system; this manual is not intended to provide this level of financial detail. Miscellaneous expenses to be included in the initial investment (I) value include factors such as prepaid royalties, inventory capital, preproduclion or start-up costs, and preparation of an environmental impact statement and applicable permits. 


\section{Appendix G: Retrofits}

The proof that the optimal retrofit time is the point in time at which the real variable cost of delivered conventional energy per unit of output exceeds the real levelized cost of energy (LCOE) requires several assumptions:

1. All other costs are unchanging in real terms

2. An infinite analysis period can be used.

Assuming that the retrofit is optimal now, the net present value of retrofitting at present (and every $\mathrm{N}$ years in the future when the retrofit needs to be replaced) is less than the NPV of rctrofitting next year, or

$$
\begin{gathered}
\sum_{t=0}^{\infty} \frac{T L C C}{(1+d)^{N t}} \leq O \& M+\sum_{t=0}^{\infty} \frac{T L C C /(1+d)^{N t}}{1+d} \\
\sum_{t=0}^{\infty} \frac{T L C C}{(1+d)^{N t}}[1-1 /(1+d)] \leq \frac{O \& M}{1+d} \\
\operatorname{TLCC} \frac{1}{1-1 /(1+d)^{N}}[d /(1+d)] \leq \frac{O \& M}{1+d} \\
\frac{T L C C d}{Q\left[1-1 /(1+d)^{N}\right]} \leq \frac{O \& M}{Q} \\
L C O E \leq \frac{O \& M}{Q}
\end{gathered}
$$

Where:

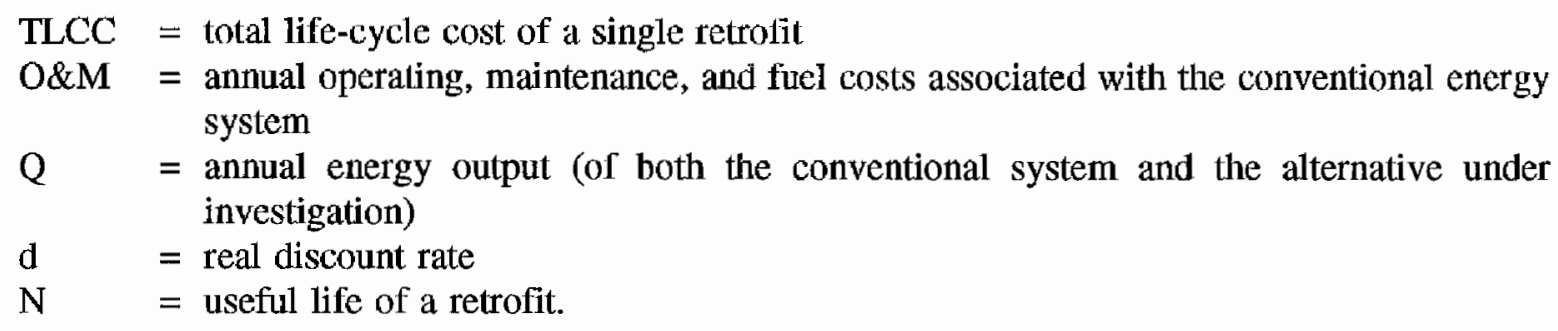




\section{Appendix H: Documentation of Evaluation Software}

The diskette at the back of this manual contains an evaluation program developed to assist analysts in tackling investment problems that are traditionally difficult to evaluate manually. This cvaluation program automales the exact equations for the first eleven economic measures in Section 4 . It is hoped that this program will improve the speed and precision with which analysts apply the methods and procedures presented within this manual.

Even though every effort has been made to assure accurate calculations, NREL does not warrant this program's accuracy. In addition, it is important to note that this program does not provide a complete demonstration of the theory and practical risks of particular financial methods. If a complex analysis is required, it is anticipated that this program will only provide a functional platform for analysts to seek further guidance.

While using this analytical tool, it is essential to consider what it can and cannot do. This program can do the following:

- Reduce hand calculation, saving time and reducing mathematical errors.

- Reduce the need to know all of the methodological nuances in order to perform sophisticated analysis.

This program cannot do the following:

- Interpret results and make decisions on that basis.

- Determine the objective of the analysis.

- Assemble all the required input information for the analysis.

This evaluation program will operate on IBM PCs with DOS operating systems. It is reasonable in size (approximately 200 kilobytes) and can run with minimum random access memory. The following files are included on the diskette:

- manual.exe, the executable program

- egavga.bgi, the Borland Graphics Interface for EGA/VGA monitors*

- trip.chr and litt.chr, the triplex and small font charactcr sets.

Each of these files must be in the same directory for successful opcration. The evaluation program can be started directly from the diskette, or for faster operation, the files can be transferred to an internal drive. To move the files from the diskette to an internal drive, first, insert the diskette into the appropriate external drive. Next, at the internal drive prompt (usually cil), create a destination directory by typing

md dirname

egavga.bgi, trip.chr, and litt.chr are registered products of Borland International, Inc. All rights rescrved. 
Then, switch to the external drive by typing

$b$ : (or $a$ : depending on hardware configuration)

Finally, at the external drive prompt type

copy**c:ldirname

To begin the program from either drive, simply type

manual

from the appropriate executable directory. 


\section{REPORT DOCUMENTATION PAGE}

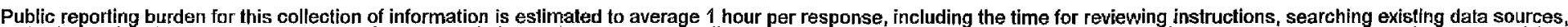

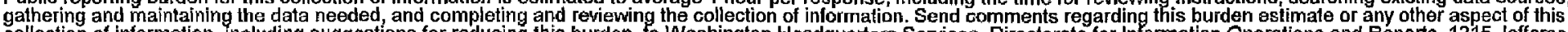

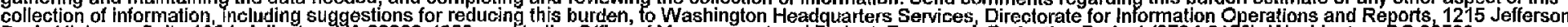
Davis Highway, Suite 1204, Arlington, VA 22202-4302, and to (he Offiee of Management and Budget, Paperwork Reduction Project (0704-0188), Washington, $0 \mathrm{C} 20503$.

\begin{tabular}{|l|l|l}
\hline 1. AGENCY USE ONLY (Leave blank) & $\begin{array}{l}\text { 2.REPORT } \\
\text { DATE. } \\
\text { March 1995 }\end{array}$ & $\begin{array}{l}\text { 3. REPORT TYPE AND DATES COVERED } \\
\text { technical report }\end{array}$ \\
\hline
\end{tabular}

4. TITLE AND SUBTITLE

A Manual for the Economic Evaluation of Energy Efficiency and Renewable Energy Technology
5. FUNDING NUMBERS AS026100

6. AUTHOR(S)

W. Short, D. Packey, and T. Holt

7. PERFORMING ORGANIZATION NAME(S) AND ADDRESS(ES)

National Renewable Energy Laboratory

1617 Cole Boulevard

Golden, Colorado 80401-3393
8. PERFORMING ORGANIZATION REPORT NUMBER

TP-462-5173
9. SPONSORING/MONITORING AGENCY NAME(S) AND ADDRESS(ES)

U.S. Department of Energy

1000 Independence Ave., SW

Washington, DC 20585

11. SUPPLEMENTARY NOTES

12a. DISTRIBUTION/AVAILABILITY STATEMENT

National Technical Information Service

U.S. Department of Commerce

5285 Port Royal Road

Springfield, VA 22161 12b. DISTRIBUTION CODE

UC 1320

13. ABSTRACT (Maximum 200 words)

This manual is a guide for analyzing the economics of energy efficiency and renewable energy (EE) technologies and projects. It is intended to help EE analysts determine the appropriate approach or type of analysis and the appropriate level of detail. It also assists EE analysts in completing consistent analyses using standard assumptions and bases, when appropriate. In addition to containing information on primary economic measures and fundamentals of finance, the manual focuses on the special considerations required in the economic evaluation of EE systems.

14. SUBJECT TERMS

economic evaluation; energy efficiency; renewable energy technologies

15. NUMBER OF PAGES

124

16. PRICE CODE

17. SECURITY CLASSIFICATION OF REPORT

unclassified
18. SECURITY CLASSIFICATION OF THIS PAGE unclassified
19. SECURITY CLASSIFICATION OF ABSTRACT unclassified
20. LIMITATION OF ABSTRACT UL

Standard Form 298 (Rev. 2-89) Prescribed by ANSI Std. Z39-18 